\title{
WestVirginiaUniversity
}

THE RESEARCH REPOSITORY @ WVU

Graduate Theses, Dissertations, and Problem Reports

2020

\section{Three Essays on Energy Markets}

\author{
Sultan Alturki \\ West Virginia University, saa0014@mix.wvu.edu
}

Follow this and additional works at: https://researchrepository.wvu.edu/etd

Part of the Finance and Financial Management Commons

\section{Recommended Citation}

Alturki, Sultan, "Three Essays on Energy Markets" (2020). Graduate Theses, Dissertations, and Problem Reports. 7647.

https://researchrepository.wvu.edu/etd/7647

This Dissertation is protected by copyright and/or related rights. It has been brought to you by the The Research Repository @ WVU with permission from the rights-holder(s). You are free to use this Dissertation in any way that is permitted by the copyright and related rights legislation that applies to your use. For other uses you must obtain permission from the rights-holder(s) directly, unless additional rights are indicated by a Creative Commons license in the record and/ or on the work itself. This Dissertation has been accepted for inclusion in WVU Graduate Theses, Dissertations, and Problem Reports collection by an authorized administrator of The Research Repository @ WVU.

For more information, please contact researchrepository@mail.wvu.edu. 


\title{
Three Essays on Energy Markets
}

\section{Sultan A. Alturki}

\author{
A dissertation submitted to \\ the John Chambers College of Business and Economics \\ at West Virginia University
}

in partial fulfillment of the requirements for the degree of

Doctor of Philosophy in Business Administration

Concentration in Finance

\author{
Alexander Kurov, Ph.D., Chair \\ Eric Olson, Ph.D. \\ Ann Marie Hibbert, Ph.D. \\ Arabinda Basistha, Ph.D. \\ Department of Finance
}

Morgantown, West Virginia

February 2020

Keywords: Oil Sentiment, Inflation Premium, Individual and Institutional Investors, Inventory Announcements, Market Efficiency, Financial Market Predictability, Oil Futures, Market Conditions, Sovereign Credit Default Swaps (CDS), Oil Shocks, Oil-Exporting Countries, G10. 


\section{ABSTRACT \\ Three Essays on Energy Markets}

\section{Sultan A. Alturki}

This dissertation includes three essays investigating topics relevant to the energy markets. The first essay employs a new dataset to measure the impact of investor sentiment regarding oil prices on the U.S. inflation premium. The empirical analysis relies on Structural Vector Autoregression (SVAR) and out-of-sample forecasts. The results indicate that a one standard deviation positive shock to overall investor sentiment regarding oil prices results in a significant increase in the U.S. inflation premium by approximately $1.2 \%$ over the subsequent 10 weeks. Compared to individual investor sentiment, institutional investor sentiment regarding oil prices has a larger impact on the U.S. inflation premium. Finally, the study finds out-of-sample evidence that the overall investor sentiment regarding oil prices has predictive power on the U.S. inflation premium.

The second essay uses sequential energy inventory announcements to shed new light on the informational efficiency of financial markets. The findings provide clear evidence of inefficiency in oil futures and stock markets. This inefficiency can be exploited by sophisticated traders. The study further examines the effect of market conditions, such as liquidity and oil attention, on the efficient incorporation of information in this setting. It also constructs a predictor that can predict inventory surprises and pre-announcement returns in-sample and out-of-sample. Finally, it develops a combination forecast that can be used as a proxy for market expectations of oil inventory announcements.

The third essay examines the impact of oil shocks on sovereign credit default swaps (CDS) for the G10 countries and major oil-exporting countries. The results show that oil demand shocks have a uniformly negative impact on CDS spreads. In contrast, oil supply shocks increase the spreads of the G10 countries, but reduce the spreads of oil-exporting countries. Using quantile regressions, the study finds that oil demand shocks affect spreads across the conditional distribution, while oil supply shocks mostly influence the upper quantiles of spread changes. Furthermore, a two-state Markov-switching modeling confirms a significant non-linearity in the impact of oil shocks 


\section{DEDICATION}

To my parents, Abdulaziz Alturki and Leyla Alturki, for their constant and unwavering support and love. 


\section{ACKNOWLEDGMENTS}

I am greatly thankful to my advisor, Professor Alexander Kurov for his support during my studies at West Virginia University. In addition, I am grateful to Dr. Eric Olson for his help. I would like to especially thank Dr. Ann Marie Hibbert and Dr. Arabinda Basistha for their support and comments. I also thank my fellow doctoral students for their constructive discussions and suggestions. 


\section{TABLE OF CONTENTS}

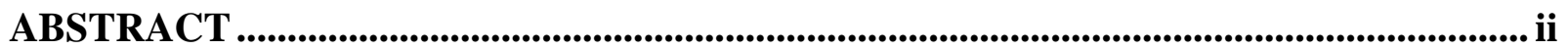

DEDICATION_...................................................................................................................

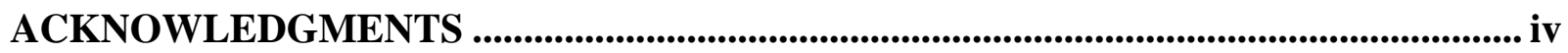

TABLE OF CONTENTS................................................................................................................. v

LIST OF TABLES ...................................................................................................................... vii

LIST OF FIGURES …….................................................................................................................. viii

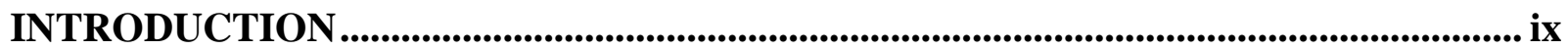

ESSAY 1. OIL SENTIMENT AND THE U.S. INFLATION PREMIUM............................. 1

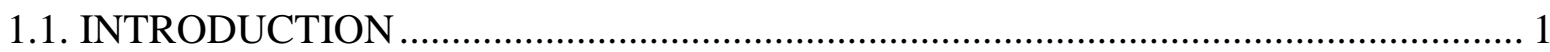

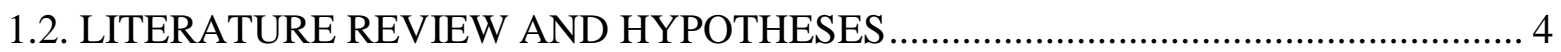

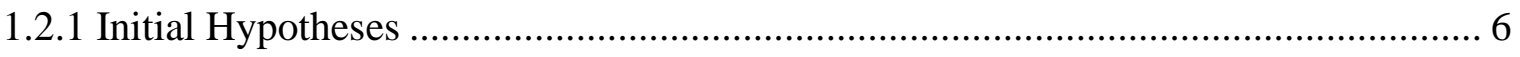

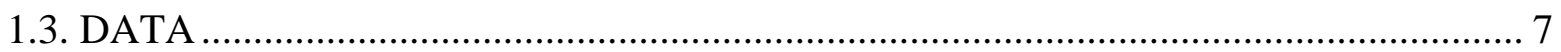

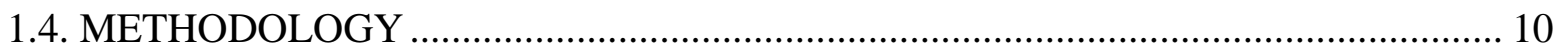

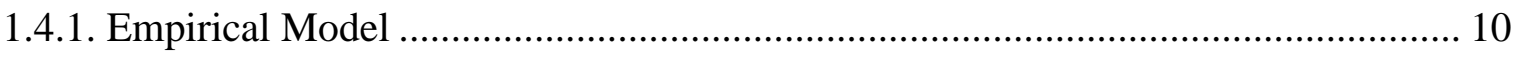

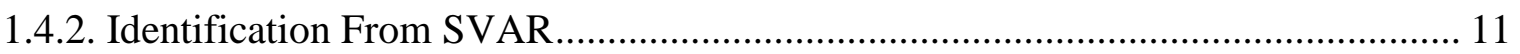

1.5. EMPIRICAL RESULTS AND DISCUSSION ……..................................................... 14

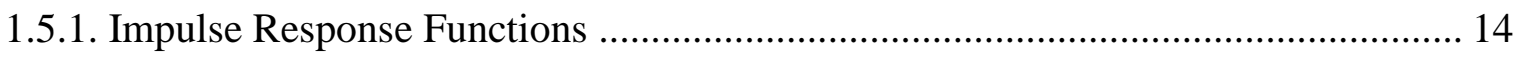

1.5.2. Structural Variance Decomposition ................................................................... 17

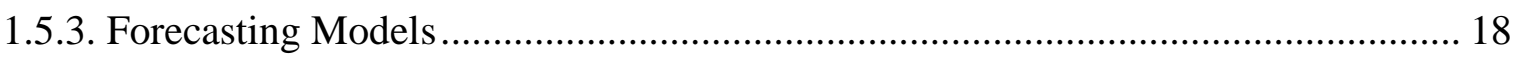

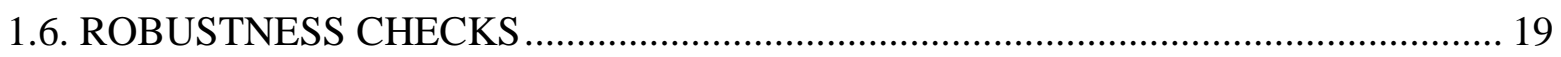

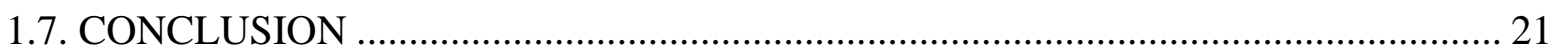

ESSAY 2. MARKET INEFFICIENCIES SURROUNDING ENERGY

ANNOUNCEMENTS............................................................................................................... 35

2.1. INTRODUCTION ……………

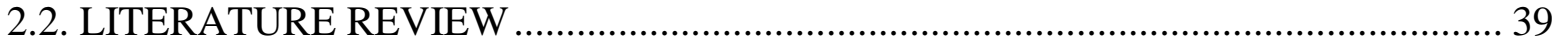

2.3. INSTITUTIONAL BACKGROUND, DATA, AND VARIABLES …………............. 42

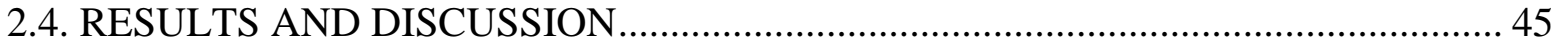

2.4.1. Predicting Returns Before the EIA Inventory Announcements.............................. 46

2.4.2. Predictability of Inventory Surprises .................................................................. 47

2.4.3. Market Conditions and Return Predictability ........................................................ 48

2.4.4. Return Predictability for Energy Stocks ............................................................. 49

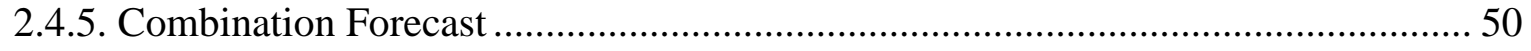

2.4.6. Economic Significance ……………………………........................................... 53 


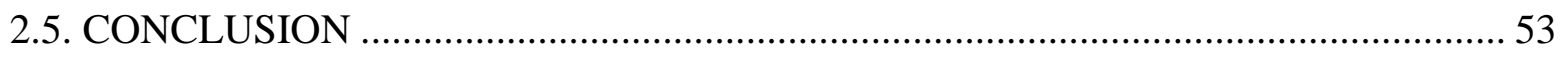

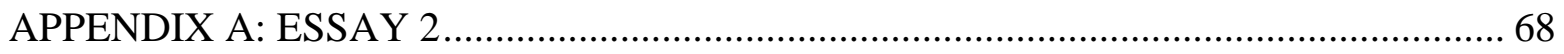

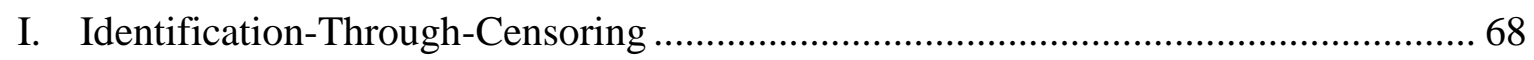

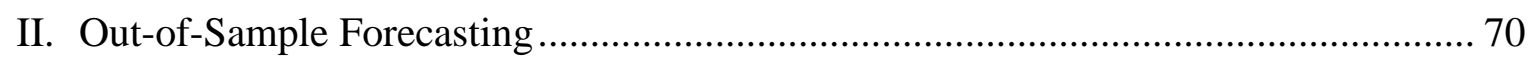

ESSAY 3. THE IMPACT OF OIL SHOCKS ON SOVEREIGN DEFAULT RISK........ 71

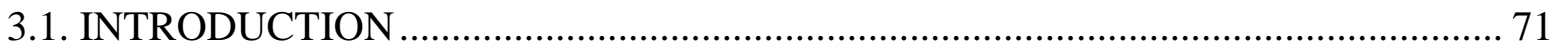

3.2. RELATED LITERATURE AND RESEARCH QUESTIONS ………………........... 75

3.2.1. Sovereign CDS Spreads: Global vs. Domestic Factors ........................................... 75

3.2.2. Oil as a Global Factor ........................................................................................ 77

3.3. DATA, VARIABLE CONSTRUCTION AND UNIVARIATE STATISTICS ............ 79

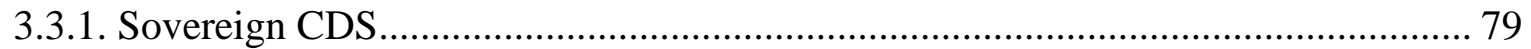

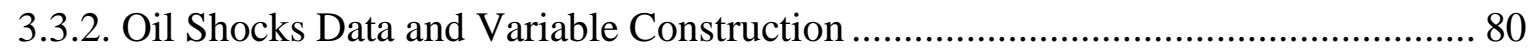

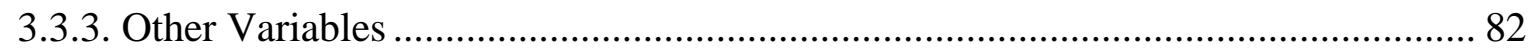

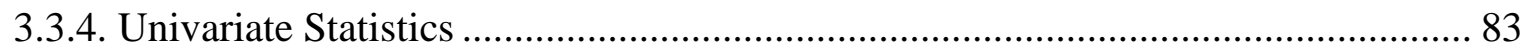

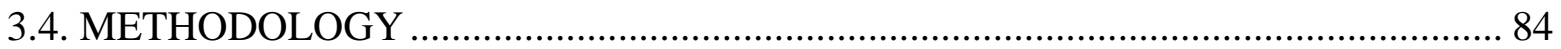

3.4.1. Main Regression Model .............................................................................. 84

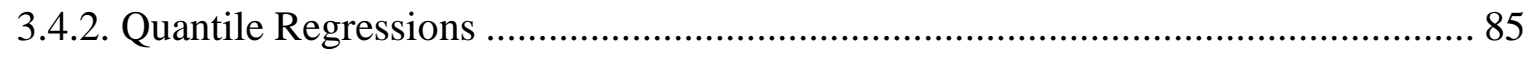

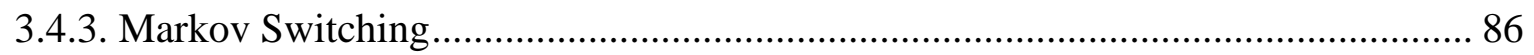

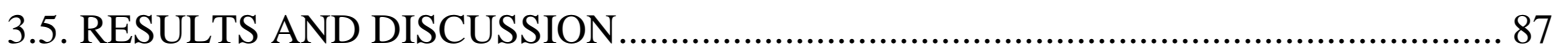

3.5.1. The Impact of Oil Shocks on Sovereign CDS Spreads........................................... 87

3.5.2. Regime Switching Model and Other Tests ......................................................... 89

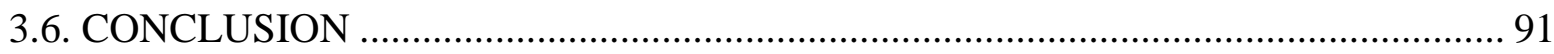

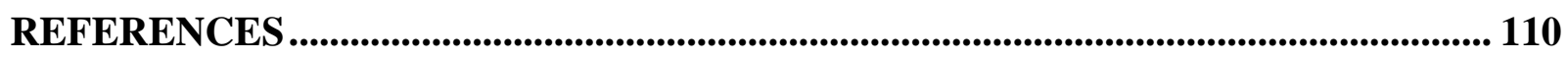




\section{LIST OF TABLES}

\section{ESSAY 1}

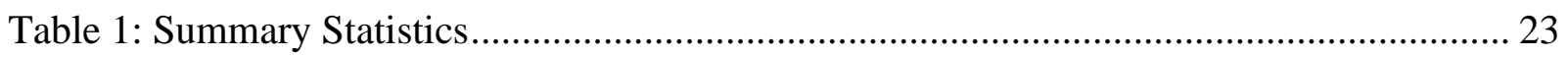

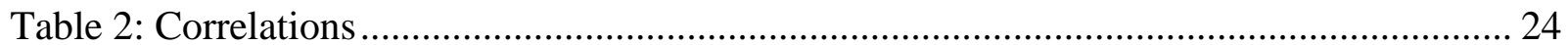

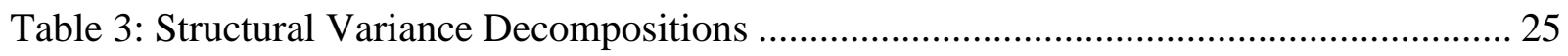

\section{ESSAY 2}

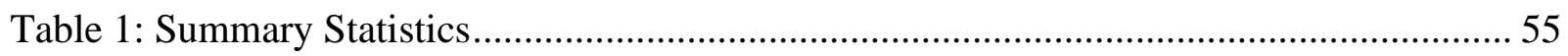

Table 2: In-sample Predictability of Pre-EIA Oil Futures Returns ........................................... 56

Table 3: Predictability of Oil Inventory Surprises ................................................................ 57

Table 4: Predictability of Pre-EIA Oil Futures Return under Different Market Conditions..... 58

Table 5: Predicting Returns of Energy Stocks ....................................................................... 59

Table 6: Response of Oil Futures Prices to Oil Inventory Announcements .............................. 60

Table 7: Predicting EIA Announcements using the Bloomberg Consensus and API Actual ... 61

Table 8: Performance of Trading Strategy based on Predictor ................................................. 62

\section{ESSAY 3}

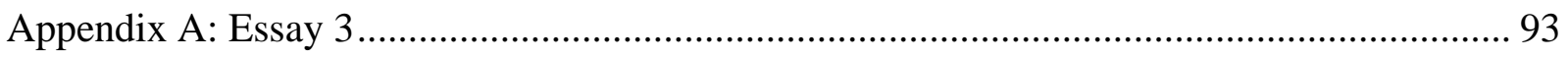

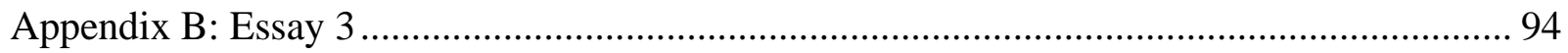

Table 1: Summary Statistics of CDS Spread Changes............................................................... 95

Table 2: Correlation Between the Main Variables...................................................................... 97

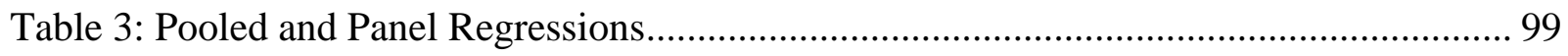

Table 4: Quantile Regression Model of Daily Spread Changes ............................................. 101

Table 5: Transition Probabilities, Expected Duration and other Indicators ............................ 102

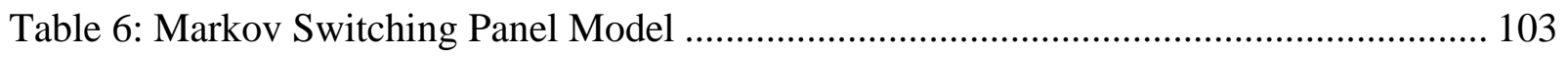

Table 7: The Effect of Global Economic Conditions on the Relation Between Soverign CDS

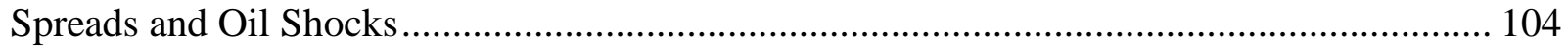

Table 8: The Effect of Countries' Oil Dependency on the Relation Between Soverign CDS

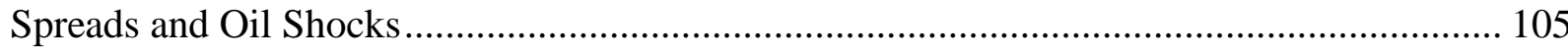




\section{LIST OF FIGURES}

\section{ESSAY 1}

Figure 1: WTI Prices and the 1-Year Breakeven Inflation Rate ......................................... 26

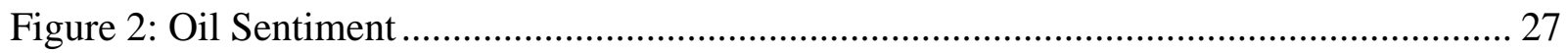

Figure 3: Real Growth Rate of Baltic Dry Index ......................................................... 27

Figure 4: The U.S. Online-Price Inflation Index......................................................... 28

Figure 5: The Accumulative Structural Impulse Responses for the U.S. 1-year BEIR with the

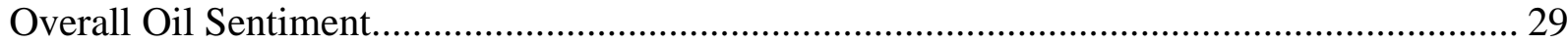

Figure 6: The Accumulative Structural Impulse Responses for the U.S. 1-year BEIR with the

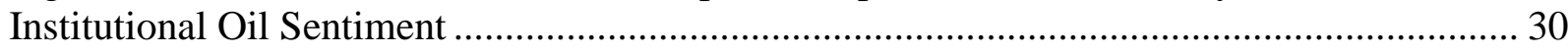

Figure 7: The Accumulative Structural Impulse Responses for the U.S. 1-year BEIR with the

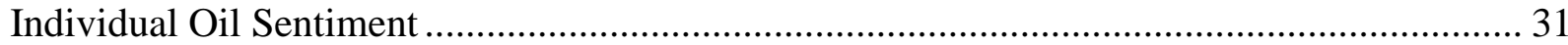

Figure 8: The Out of Sample Forecasting Models of the U.S. 1-year BEIR ........................ 32

Figure 9: The Accumulative Generalized Impulse Responses for the U.S. 1-year BEIR with the

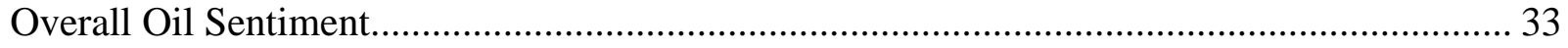

Figure 10: The Accumulative Generalized Impulse Responses for the U.S. 1-year BEIR with

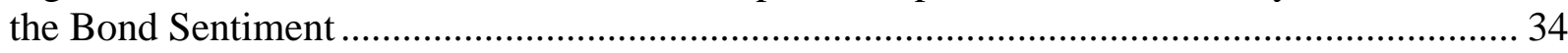

\section{ESSAY 2}

Figure 1: Weights Allocated to the API Actual in the Combination Forecast....................... 63

Figure 2: Cumulative Average Return of Oil Futures before EIA Oil Announcements .......... 64

Figure 3: Cumulative Average Return of Oil Futures before API Oil Announcements .......... 65

Figure 4: Out-of-Sample Predictability of Pre-EIA Oil Futures Returns using Post-API Oil

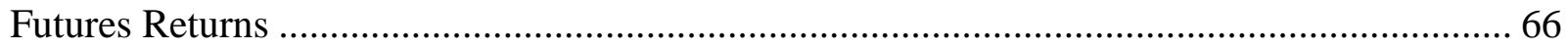

Figure 5: Out-of-Sample Predictability of Pre-EIA Oil Futures Returns using the Predictor .. 67

\section{ESSAY 3}

Figure 1: Greece Sovereign CDS Spread Level from May 2013 to December 2017 ............ 106

Figure 2: Sovereign CDS Spread Levels................................................................... 107

Figure 3: Smoothed Probabilities for the Bivariate Markov-Switching Model .................... 109 


\section{INTRODUCTION}

This dissertation presents three essays investigating topics relevant to the energy markets. The first essay examines the impact of investor sentiment regarding oil prices on the U.S. inflation premium. Based on the Structural Vector Autoregression (SVAR) analysis, a positive one standard deviation shock to the overall investor sentiment regarding oil prices results in a significant increase in the U.S. inflation premium by approximately $1.2 \%$ over the subsequent 10 weeks. Compared to individual investor sentiment, institutional investor sentiment regarding oil prices has a larger impact on the U.S. inflation premium. In this paper, we employ a new dataset to measure investor sentiment regarding oil prices. Therefore, investor sentiment regarding oil is an important factor that significantly influences the U.S. inflation premium.

The second essay sheds light on market inefficiencies using unique sequential energy inventory announcements. The main empirical results provide clear and pronounced evidence of market inefficiency in oil futures and stock markets. Additionally, market conditions, such as liquidity and oil attention, play an essential role in the efficient incorporation of information in this setting. Furthermore, the study constructs a predictor that has an in-sample and an out-of-sample predictive power over oil inventory surprises. Finally, it develops a combination forecast that could be used to accurately proxy for market expectations regarding oil inventory announcements. Hence, the results show that asset prices do not instantaneously reflect new public information; which provides profitable opportunities to several players in the financial markets.

The third essay examines the impact of oil shocks on sovereign credit default swaps (CDS) for the G10 countries and major oil-exporting countries. The study shows that oil demand shocks have a uniformly negative impact on CDS spreads. However, oil supply 
shocks increase the spreads of the CDS for the G10 countries, but reduce the spreads of the major oil-exporting countries. Moreover, using quantile regressions the study finds that oil demand shocks significantly affect spreads across the conditional distribution, while oil supply shocks mostly influence the upper quantiles. Finally, a two-state Markovswitching modeling confirms a significant non-linearity in the impact of oil shocks. 


\section{Essay 1. Oil Sentiment and the U.S. Inflation Premium*}

"Measures of short-term inflation compensation derived from yields on inflation-indexed Treasury securities increased over the inter-meeting period, due in part to sharply higher prices for oil"

FOMC Minutes, June 24-25, 2008

\subsection{Introduction}

Oil plays a vital role in industrial economies. Nine out of ten post-World War II recessions were preceded by significant increases in oil prices and oil price volatility (Hamilton, 2008). As noted in the above quote from the FOMC minutes, sharp increases in oil prices often increase the inflation compensation required by investors. Figure 1 displays the spot price of West Texas Intermediate (WTI) on the left-hand axis and the U.S. 1-year breakeven inflation rate (inflation premium) on the right-hand axis.

\section{[Insert Figure 1 Here]}

It is clear that there is a close co-movement between oil prices and the U.S. breakeven inflation rate for most of the period. We believe that the most likely mechanism through which oil price impacts the breakeven inflation rate is the Fisher equation $\left(i_{t}=r_{t}+\pi_{t}^{e}\right)$. Put simply, increases in oil prices likely increase inflation compensation, which increases interest rates. Changes in interest rates have a substantial influence on the valuation of assets. Hence, it is very important to analyze factors that impact interest rates. Given the well-established link between investor sentiment and equity markets (Baker and Wurgler, 2006; Kumar and Lee, 2006; Tetlock, 2007), our aim in this

\footnotetext{
* This essay is based on a paper coauthored with Eric Olson.
} 
paper is to examine the effect that oil sentiment has on (1) oil future return and (2) the U.S. inflation premium. We estimate a simple economic model through which oil sentiment affects both oil future return and the U.S. inflation premium.

Kilian (2009) argues that variations in oil prices are primarily affected by supply shocks, aggregate demand shocks, and the residual of the variation is classified as precautionary demand shocks. Precautionary demand arises from fears regarding shortfalls in expected supply relative to expected demand; for example, increased demand due to increased geopolitical risk in the Middle East would be an example of a precautionary demand shock. To measure oil sentiment, we use a weekly survey-based sentiment index collected by the German-based company SENTIX. To the best of our knowledge, we are the first to use the SENTIX oil sentiment indices in this context. As can be seen in Figure 2, the oil sentiment index shows substantial relevance to major events that impact the oil market, thus, the index seems to mainly reflect concerns regarding future oil supply and demand dynamics. Therefore, we believe that our oil sentiment measure captures oil precautionary demand. Other researchers use survey-based sentiment indices in a similar way to measure individuals' concerns regarding different economic and financial indicators. For instance, several papers use the Michigan Index of Consumer Sentiment to measure concerns and uncertainty regarding the growth of household spending (Carroll, Fuhrer, and Wilcox, 1994; Souleles, 2004; Akhtar et al., 2011).

\section{[Insert Figure 2 Here]}

We use the U.S. breakeven inflation rates (BEIR), the difference between the yield of the nominal bond and an inflation-linked bond with the same maturity, as a proxy for the inflation premium. BEIR is widely and extensively used by central banks, practitioners, as well as academics (Beechey, Johannsen, and Levin, 2011; Jochmann, Koop, and Potter, 2009; Garcia and 
Van Rixtel, 2007). We adopt the framework of Kilian (2009) and classifying unexpected changes in oil prices as supply shocks, aggregate demand shocks, and precautionary demand shocks. Hamilton and Baumeister (2019) critique Kilian's (2009) identification assumptions in his Structural Vector Autoregression (SVAR). Specifically, restrictions in SVAR usually force researchers to assume no contemporaneous effect between the variables. Thus, the lower the frequency of the data (i.e. annual data) the stronger the "no contemporaneous" identification appears. For example, if we were to use quarterly data, the "no contemporaneous" identification assumption would assume that a supply shock has no effect on the breakeven inflation rate within the quarter. Obviously, that would be a strong assumption that is likely not valid. One needs to balance modeling noise in very high frequency data (i.e. tick by tick data) versus identification of the structural relationships. We believe using weekly data balances the validity of the "no contemporaneous effect" identification assumption with the risk of simply modeling noise in the data. We discuss our identification assumption in depth later.

To preview our results, we find that a one standard deviation increase in oil sentiment increases the inflation premium by $1.2 \%$ over the subsequent ten weeks. This increase in the U.S. inflation premium controls for aggregate demand and supply shocks. Furthermore, the institutional investor oil sentiment has a greater impact on the U.S. inflation premium compared to the impact of individual investor oil sentiment on the U.S. inflation premium. Thus, our results support recent evidence that institutional investors may be better informed than individual investors (BenRephael, Da, and Israelsen, 2017; Roger, Edelen, Ince, and Kadlec, 2016; Sias, 2004). The rest of the paper is organized as follows. Section 1.2 reviews the literature and states our hypotheses, section 1.3 discusses the data, section 1.4 discusses our methodology, section 1.5 presents and discusses the empirical results and section 1.6 has our robustness checks. Section 1.7 contains our conclusion. 


\subsection{Literature Review and Hypotheses}

The impact of sentiment in oil markets is a relatively new area of behavioral finance. Deeney et al. (2015) analyze the role of sentiment by constructing an oil sentiment index using principal component analysis. Their findings demonstrate the importance of sentiment in explaining oil price movements. In addition, Li et al. (2016) show that sentiment Granger causes oil prices. MaslyukEscobedo, Rotaru, and Dokumentov (2016) perform a jump detection technique to identify cojumps and correlation between daily energy prices (spot and future) and sentiment indices. Their results suggest a "significant influence in crude oil and aggregate sentiment indices on jumps in energy commodity prices." Sayim, Morris, and Rahman (2013) conduct an impulse response function test which shows that a one standard deviation increase in the rational and irrational investor sentiment results in a significant positive impact on oil industry returns. Finally, Dowling, Cummins, and Lucey (2016) show the presence of psychological barriers around $\$ 10$ price levels for both WTI and Brent futures prices for the pre-credit crisis period of 1990-2006, when oil prices were traded within low ranges.

Many proxies for sentiment have been chosen in the literature to analyze its impact on financial and commodity markets. For the equity market, Baker and Wurgler (2006) construct a stock market sentiment index with six proxies "the closed-end fund discount, NYSE share turnover, the number and average first-day returns on IPOs, the equity share in new issues, and the dividend premium." Using the same proxies, Huang et al. (2014) construct the aligned investor sentiment index by implementing a partial least square (PLS), and Berger and Turtle (2015) construct a cumulative sentiment index. Other papers use a variety of proxies, such as the level of discounts on closed-end funds, the ratio of odd-lot sales to purchases, and net mutual fund redemption, buy-sell imbalance, and Wall Street Journal "Abreast of the Market" column, and net

exchange to equity funds (Neal and Wheatley, 1998; Kumar and Lee, 2006; Tetlock, 2007; Ben- 
Rephael, Kandel, and Wohl, 2012). On the other hand, sentiment in oil markets is measured using a variety of methods. Similar to the proxies used in Baker and Wurgler (2006), Deeney et al. (2015) measure sentiment in oil market by "the put-call ratio of oil options, the volume of the oil futures traded, the historical volatility of the oil price, the ratio of speculative trades to oil demand and the implied volatility of a local stock market index, namely the S\&P 500 Energy sector for WTI and the Euro Stoxx 50 for Brent." A few other research papers use Thomson Reuters news releases to capture oil market sentiment (Li et al., 2016; Maslyuk-Escobedo, Rotaru, and Dokumentov, 2016; Sayim, Morris, and Rahman, 2013).

In this paper, we use a unique survey-based index, Oil SENTIX. There have been a few other research papers that included different SENTIX indices but not the oil indices. Measuring individual and institutional sentiment around five stock markets, Schmeling (2007) "shows that in the long-horizon regressions, institutions (individuals) persistently have correct (incorrect) expectations about the markets". Further, Corredor, Ferrer, and Santamaria (2014) analyze the spot and future stock markets dynamics for the U.S. and a few European countries during different levels of investor sentiment. Menkhoff, Schmeling, and Schmidt (2012) examine whether experience and professionalism affect the degree of overconfidence among different types of investors. On the effect of weather-induced stock market sentiment, Schneider et al. (2014) "show that individual long-term sentiment about stock markets is positively impacted by barometric pressure."

Breakeven inflation rates have been used extensively as a measure of inflation compensation. This market-based inflation measure provides a higher frequency measure compared to survey-based inflation measures resulting in a more dynamic and in-depth analysis. Further, BEIR is attained from profit-maximizing agents; thus, it is a relatively accurate measure 
of the unobserved inflation expectation (Kajuth and Watzka, 2011). Jochmann, Koop, and Potter (2009) use daily breakeven inflation rates to study the relationship between the compensation of long-term and short-term inflation. Their results indicate that inflation is neither unmoored nor anchored, but it is apparently contained. Beechey et al. (2011) partially use BEIR to demonstrate that inflation in the Euro area is more anchored compared to the U.S. Christensen, Lopez, and Rudebusch (2010) decompose long-term BEIR into the inflation expectation and the inflation risk premium (IRP). Their findings indicate that the average IRP is close to zero. Lumsdaine (2009) finds that oil prices and BEIR of the U.S. comove, but the strength of the co-movement is timevarying. Jiang (2018) documents the significant impact of oil shocks on the 10-year U.S. BEIR. However, to our knowledge, none of the previous studies investigate the impact of oil investor sentiment on U.S. measures of inflation.

\subsubsection{Initial Hypotheses}

Inflation has a relatively strong correlation to oil prices for several reasons. Oil is considered as an essential component that directly or indirectly enters into the production equation for almost all industries (Cologni and Manera, 2008). Some industries are more sensitive than others are, but they are still all influenced to some extent by changes in energy markets. Inflation uncertainty increases with volatility in oil prices which in turn has a direct impact on asset pricing and investment decisions due to adjusting discount and/or required rates of return (Huizinga, 1993; Cologni and Manera, 2008). Hence, bullish sentiment regarding oil will prompt investors to require a higher inflation premium to offset the reduction in purchasing power and the increase in risk.

Hypothesis 1.1: A positive shock to the overall investor sentiment regarding oil has a significant impact on the U.S. inflation premium. 
Hypothesis 1.2: Overall investor sentiment regarding oil has predictive power over the U.S. inflation premium.

Institutional investors are considered to be informed or smart investors as they have the capability to process and to uncover asset-specific information more efficiently than individual investors (Bharath, Jayaraman, and Nagar, 2013). However, institutional investors are still prone to behavioral biases that influence their investment decisions. Roger et al. (2016) show that institutions play a causal role with assets' anomalies and strongly rejects the sophisticated institution's hypothesis. Institutions demonstrate herding behavior as they follow each other to invest in the same securities (Sias 2004). Additionally, institutional attention plays a more vital role in explaining assets' mispricing than retail attention (Ben-Rephael, Da, and Israelsen, 2017). These pieces of evidence lead us to believe that any behavioral bias by institutions may have a higher impact on inflation premium than individuals' biases.

Hypothesis 2.1: Institutional investor oil sentiment has a larger effect on the U.S. inflation premium than individual investor oil sentiment has on the U.S. inflation premium.

\subsection{Data}

Our analysis covers the period between July 18 / 2008 - August $31 / 2019$. The sample consists of 558 weekly observations. The selected time period was based on data availability. In this paper, we use a weekly survey-based sentiment index collected by the German-based company SENTIX. The data for SENTIX were accessed through Bloomberg. SENTIX has a database consisting of more than 5000 individual and institutional investors and reflects overall oil sentiment for the onemonth price outlook. As noted above, the overall oil sentiment index is broken down into individual and institutional investors' indices. Institutional investors are defined as those who register online using their firm e-mail address and go through an identity check. Individual 
investors are those who register with their individual e-mail addresses. Finally, we use bond and equity investor sentiment as part of our robustness checks to differentiate between the oil investor sentiment and overall market investor sentiment.

Participating in the survey is conducted online through the company website (www.sentix.de/index.php/en/), and a weekly reminder e-mail is sent to registered members. The participation in the survey is not mandatory but participants are rewarded by access to some exclusive data analysis as an incentive. In Oil SENTIX indices, participants are asked about their expectations of oil prices in the short-term (one month). There are four answer choices which they can select from bullish, bearish, neutral, and no opinion. In this paper, we use the short-term Headline Oil SENTIX (SNTXOIH1), which reflects the concerns and beliefs of the survey's participants regarding oil prices after one month. The survey's participants can take part in the survey weekly from Friday - Saturday, Central European Time (SENTIX, 2016). In addition, the index is constructed based on the so-called bull-bear-spread, which is used in several previous research papers such as (Brown and Cliff, 2004; Brown and Cliff, 2005). The formula is:

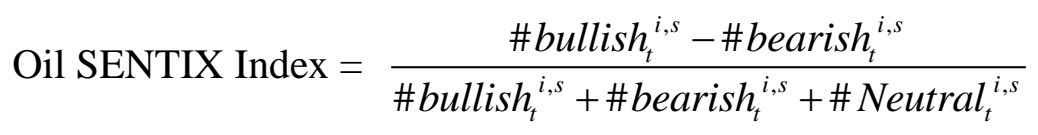

where the subscript $t$ indicates time horizon (short-term), $i$ and $s$ denote individual investors and institutional investors, respectively. Figure 2 displays the overall oil sentiment index over the 2008-2019 time period with the gray highlighted areas denoting key events (i.e. the Arab Spring, Iran Sanctions fear, etc.). As we can see, the sentiment index spikes during times of critical events.

In order to measure oil prices, we use the continuous closest to expiration Brent oil future contracts. The oil future prices are appropriately adjusted for contract rollovers. Furthermore, the weekly Brent oil futures return has been deflated using the U.S. online-inflation index (MIT's 
Billion Price Project). All the Brent oil future contracts prices are provided by Genesis Financial Technologies. As noted above, the Breakeven Inflation Rate (BEIR) is the difference between the yield of a nominal bond and an inflation-linked bond with the same maturity. This market-based inflation measure provides a higher frequency measure compared to survey-based inflation measures resulting in a more dynamic and in-depth analysis. In this paper, we choose the 1-year U.S. BEIR. ${ }^{1}$ Table 1 displays the summary statistics for all the data used in our analysis and Table 2 displays the unconditional correlations. Note in Table 1 that the mean of the 1-year U.S. inflation premium is 0.74 and has a 0.16 correlation (Table 2) with the overall investor sentiment regarding oil. However, the correlation decreases with longer horizons; for example, the U.S. the 5-year U.S. inflation premium has only 0.11 correlation with the oil sentiment measures.

\section{[Insert Tables 1 and 2 Here]}

We use the Baltic Dry Index (BDI) as a proxy for worldwide economic activity which represents the aggregate demand. It has been shown in numerous research papers that oil prices are highly correlated and significantly impact global economic activities (Brown and Yücel, 2002; Hamilton, 2009; He, Wang, and Lai, 2010). Shipping accounts for around $80 \%$ of internationally traded goods and commodities. ${ }^{2}$ Additionally, freight rates are heavily dependent on oil prices as it accounts for approximately 50\%-60\% of total operating costs (UNCTAD, 2010). Several previous studies use a similar measure to capture the global economic activities (Kilian, 2009; Kilian and Park, 2009); however, previous measures have a lower frequency (monthly), whereas the BDI is published daily which allows us to aggregate it to a weekly measure. Figure 3 displays

\footnotetext{
${ }^{1}$ We have retrieved the 2, 3,5, and 10 year U.S. breakeven inflation rate to conduct robustness checks. Furthermore, all the BEIRs data was accessed through Bloomberg terminal.

${ }^{2}$ https://www.balticexchange.com/about-us/shipping-markets
} 
the BDI index over our sample period. Furthermore, the BDI measure has been widely used in previous academic research (Bakshi, Panayotov, and Skoulakis, 2011; Apergis and Payne, 2013).

\section{[Insert Figure 3 Here]}

We use the inflation measure developed from the Billion Price Project at MIT. ${ }^{3}$ The data for this index is collected from scrapping prices from websites of large retails stores such as Walmart. This index has a high frequency (daily) compared to the traditional monthly Consumer Price Index (CPI). ${ }^{4}$ Further, it covers a substantial number of prices. In the United States, approximately a half-million prices are collected daily, whereas the U.S. Bureau of Labor Statistics collects only eighty thousand prices monthly (Cavallo and Rigobon, 2016). As such, we use it to transform our variables into real variables. Moreover, the U.S. online-price inflation index shows significant reliability as it co-moves with the U.S. CPI (see figure 4). Finally, we use the Michigan Inflation Expectation index, retrieved from Bloomberg, as part of our robustness checks.

\subsection{Methodology}

\subsubsection{Empirical Model}

As a preliminary, we conduct unit root tests to examine whether the time series contains a unit root. The null hypothesis of the ADF test $\left(H_{0}\right)$ is the series contains a unit root. In our data, all the variables were stationary with the exception of the 10-year Treasury constant maturity rate; as such, we use first differences for the 10-year Treasury. The VAR model estimated included the following four weekly endogenous variables: overall oil sentiment, the real growth rate of Baltic Dry index, Brent oil future real return, and the U.S. 1-year BEIR. We include two exogenous

\footnotetext{
${ }^{3}$ We are grateful to Prof. Alberto Cavallo and Prof. Roberto Rigobon in the Sloan School of Management at MIT and founders of the Billion Prices Project for sharing their private data.

${ }^{4}$ Due to our lack of access to the Billion Prices Project after September 2016, we use the monthly U.S. CPI to transform our variables into real variables.
} 
variables (the credit spread and the first difference of the 10-year Treasury) to control for macroeconomic conditions. The estimated reduced VAR takes the following form:

$$
Y_{t}=c_{0}+\sum_{J=1}^{k} A_{j} Y_{t-j}+\sum_{J=1}^{p} B_{j} X_{t-j}+\varepsilon_{t}
$$

where $Y_{t-j}$ is the vector of the four endogenous variables, $X_{t-j}$ is a vector of exogenous variables, and $\varepsilon_{t}$ is the vector of shocks used to estimate the structural VAR. The shocks satisfy the condition $E\left(\varepsilon_{t} \varepsilon_{t}{ }^{\prime}\right)=I$, which is, the shocks' series are uncorrelated white noise. In addition, $c_{0}$ is a vector of constants, $A_{j}$ and $B_{j}$ are coefficient matrices. The lag length was selected using the likelihood ratio tests. ${ }^{5}$ As noted above, in order to control for macroeconomic conditions and the state of the business cycle, we include the first difference of the ten-year constant maturity U.S. Treasury rate and the credit spread, defined as the difference between the Moody's BAA and AAA bonds. The weekly time series of the above variables were downloaded from the Federal Reserve Bank of St. Louis FRED database.

\subsubsection{Identification From SVAR}

In order to obtain structural impulse responses, (1) is rewritten in its moving average representation. That is:

$$
Y_{t}=B(L) v_{t}
$$

where $B(L)$ is $(4 \times 4)$ convergent matrix with $B(L)=\sum_{j=0}^{\infty} B_{j} L^{J}$ and $B_{0}=I_{4} \cdot v_{t}$ is a vector of $(4 \times$ 1) of reduced-form residuals assumed to be identically and independently distributed, $v_{t} \sim \operatorname{iid}(0$,

\footnotetext{
${ }^{5}$ The maximum number of lags allowed in a VAR model should be no more than $m p+1<T$ where $m$ is the number of endogenous variables, $\mathrm{p}$ is the number of lags, and $\mathrm{T}$ is the total number of observations (Brandt and Williams 2006) pg.26.
} 
$\Omega$ ). Further, we assume that the reduced-form residuals $\left(v_{t}\right)$ have a linear combination with the structural shocks $\left(\varepsilon_{t}\right)$ such that:

$$
v_{t}=S \varepsilon_{t}
$$

where $S$ is the $(4 \times 4)$ contemporaneous covariance matrix. Thus, we can express (1) as

$$
Y_{t}=C(L) \varepsilon_{t}
$$

which implies $B(L) S=C(L)$. In order to uniquely identify $\mathrm{S}$, we must impose additional identifying restrictions. Thus, we first order the vector of uncorrelated structural shocks as $\varepsilon_{t}=$ $\left[\varepsilon^{\text {Sent }}, \varepsilon^{\text {Baltic }}, \varepsilon^{\text {oil }}, \varepsilon^{\text {BEIR }}\right]$ where $\varepsilon^{\text {Sent. }}$ is the oil sentiment, $\varepsilon^{\text {Baltic }}$ is the real growth rate of Baltic Dry Index, $\varepsilon^{o i l}$ is Brent oil future real return, and $\varepsilon^{B E I R}$ is the U.S. 1-year BEIR.

We follow the literature in imposing our restrictions and use non-recursive identifying restrictions (Sims 1986; Blanchard and Watson, 1986; Bernanke, 1986). Under the non-recursive approach, variables could have a contemporaneous effect regardless of their ordering in the VAR. For example, oil futures return could have an impact on overall oil sentiment and vice-versa regardless of the order in which they entered the VAR system (Kim and Roubini, 2000). On the other hand, for a variable to have an impact on other variables, under the recursive approach, this variable has to enter first in the VAR system, which is not appealing in our case.

The number of restrictions has to be $(\mathrm{n} \times(\mathrm{n}-1)) / 2$ in order to achieve identification, where $\mathrm{n}$ is the number of variables (Kim and Roubini, 2000). Since we have four variables, the needed number of restrictions is six. To identify the restrictions, we use economic and finance theory and impose the following restrictions:

$$
\left[\begin{array}{c}
\text { Sent_one }_{t} \\
\text { Baltic_real_return } t \\
\text { Oil_real_return }_{t} \\
\text { BEIR }
\end{array}\right]=B(L)\left[\begin{array}{cccc}
S_{11} & S_{12} & S_{13} & 0 \\
S_{22} & S_{22} & 0 & 0 \\
S_{31} & S_{32} & S_{33} & 0 \\
S_{41} & S_{42} & S_{43} & S_{44}
\end{array}\right]\left[\begin{array}{c}
\varepsilon_{t}^{\text {Sent }} \\
\varepsilon_{t}^{\text {Blatic }} \\
\varepsilon_{t}^{\text {Oil }} \\
\varepsilon_{t}^{\text {BEIR }}
\end{array}\right]
$$


Thus, we assume:

1- It is assumed that the U.S. BEIR shock does not have a contemporaneous effect on the overall oil sentiment, the real growth rate of Baltic Dry Index and oil futures real return, which are the three zeros in column 4.

2- It is also assumed that oil futures real return shock does not have a contemporaneous effect on the real growth rate of the Baltic Dry Index, which is the zero in column 3.

Given that the matrix in (5) is two restrictions short, we impose the following long-run restrictions. A shock to oil sentiment (overall oil sentiment) has no long-run effect on itself and on the real growth rate of the Baltic Dry Index. The restrictions can be imposed by setting the values of the infinite number of relevant lag coefficients in equations (3) and (4), $\sum_{j}^{\infty} C_{11}$ and $\sum_{j}^{\infty} C_{21}$ equal to zero (Olivier Jean Blanchard and Quah 1989; Bjørnland and Leitemo 2009). The longrun restrictions of $\sum_{j}^{\infty} C_{11}$ and $\sum_{j}^{\infty} C_{21}$ imply the following linear restrictions:

$$
\begin{aligned}
& B_{11}(1) S_{11}+B_{12}(1) S_{21}+B_{13}(1) S_{31}+B_{14}(1) S_{41}=0 \\
& B_{21}(1) S_{11}+B_{22}(1) S_{21}+B_{23}(1) S_{31}+B_{24}(1) S_{41}=0
\end{aligned}
$$

The restrictions on the fourth column imply that the overall investor sentiment regarding oil, the real growth rate of Baltic Dry Index and oil futures real return do not contemporaneously respond to a shock in the U.S. 1-year BEIR. These restrictions are similar to the restrictions imposed by Kilian (2009) and Kilian and Park (2009). As mentioned before, the literature has shown that oil has an impact on inflation, whereas, the impact of inflation on oil has very weak evidence in the literature. Moreover, the restrictions in our model are moderated and more reasonable as we are using weekly frequency data. Furthermore, the restriction on the third column implies that the real growth rate of the Baltic Dry Index, a proxy for aggregate demand shock, does not contemporaneously respond to oil futures real return. This restriction is consistent with the 
literature, which asserts that the response of the aggregate demand shock, which reflects the global real economic activity, is sluggish to changes in real oil price/return (Kilian, 2009).

The restriction on the first column implies that a shock to investor sentiment regarding oil has no long-term effect on itself and on the real growth rate of the Baltic Dry Index, a proxy for aggregate demand shock. Oil sentiment as it reflects fears and uncertainty regarding the oil market does not have a long-lasting impact on aggregate demand. Aggregate demand is mostly driven by strategic planning, so it is expected to dissipate the effect of fears regarding the status of the oil market in the long run. ${ }^{6}$ Furthermore, we assume that the overall oil sentiment to have no long-run impact on itself for a couple of reasons. Fears and uncertainty regarding the oil market most likely to be mitigated in the long run as events unfold, and investors acquire more relevant information. For instance, a shocking geopolitical event may immediately increase fears and uncertainty regarding the oil market, but this fear is expected to evaporate as participants of the oil market actively acquire more information.

\subsection{Empirical Results and Discussion}

\subsubsection{Impulse Response Functions}

Figures 5 - 7 present the cumulative impulse response functions, where column 1 shows the response to shocks in the oil sentiment, column 2 shows the responses to shocks in the real rate of Dry Baltic (aggregate demand shock), column 3 shows the response to the real return of oil futures (supply shock), and column 4 shows the responses to shocks in the U.S. BEIR (inflation premium).

\footnotetext{
${ }^{6}$ Several real world examples support this restriction. For example, the recent attack in the Saudi oil company (Aramco) in September 2019, and many others.
} 
The accumulated impulse response functions (IRF) are plotted in Figure 5 for all the four endogenous variables over the ten-week horizon. Note that the results in column 1 are consistent with results one would expect from increased fears of possible negative aggregate supply shocks. ${ }^{7}$ In column 1 row 2, a positive one standard deviation shock to the overall oil sentiment results in a negative contemporaneous effect on changes in the real Baltic index (aggregate demand). Due to the relatively fixed amount of global supply in the short term, we believe an increase in oil precautionary demand, which is mainly captured by oil sentiment, would result in a decrease in the aggregate demand (Peersman and Robays, 2012; Jo, 2014). In addition, a positive shock to sentiment increases Brent oil future real return (column 1, row 3) by about 3\% in the first week, and a significant cumulative return of $2.91 \%$ over the next ten weeks. ${ }^{8}$ Furthermore, a shock to the real growth rate of the Baltic Dry index in column 2 results in a significant Brent oil future real return of about $1.02 \%$ in the first week, and a significant cumulative return of $2.46 \%$ over the next ten weeks. However, note in the second column that a shock to the Baltic Dry index (aggregate demand) does not have any meaningful effect on oil sentiment whereas a shock to the futures price of oil has a positive and statistically significant effect on oil sentiment (column 3 row 1).

As noted above, the breakeven inflation rate (BEIR) captures the premium required by investors to bear the burden of both expected inflation and inflation risk. Thus, we expect investors to require a higher inflation premium if they feel the future price of oil will increase. The impulse responses in column 1 of Figure 5 show that a positive one standard deviation shock to the overall oil sentiment results in a significant increase in the U.S. 1-year inflation premium of about $0.05 \%$

\footnotetext{
${ }^{7}$ Able, Bernanke, and Croushore (2010) use increases in oil prices during the 1970s as examples of negative aggregate supply shocks.

${ }^{8}$ The results are robust and significant when we use oil spot and future prices instead of return.
} 
in the first week, and a significant cumulative increase of $1.22 \%$ over the next ten weeks. Furthermore, column 2 of Figure 5 shows a shock to the real growth rate of the Baltic Dry index results in a significant increase on the U.S. 1-year inflation premium of about $0.04 \%$ in the first week and a significant cumulative increase of $0.23 \%$ over the next 5 weeks, and a cumulative increase of $0.43 \%$ over the next ten weeks. The oil demand shock seems to have a lower and shortterm significant impact on the inflation premium compared to the other shocks. This indicates that investors consider increases in oil prices driven by the demand side as good news and a sign of a strong economy. Furthermore, evidence shows that the U.S. economy demonstrates resilience to oil price increases driven by the demand side (Kilian, 2009). Finally, column 3 of Figure 5 demonstrates the cumulative 10-week response of the U.S. 1-year inflation premium to the oil future real return (supply shock) is approximately equal to $1.08 \%$. These results are highly significant given that the mean of the U.S. 1-year inflation premium is $0.74 \%$.

\section{[Insert Figure 5 Here]}

Overall, our results indicate that the oil sentiment measure is capturing concerns about potential disruptions in the oil market that are most likely driven by geopolitical and economic concerns given our sample period.

Furthermore, the overall oil sentiment measure is decomposed into institutional and individual oil sentiment indices and re-estimate the SVAR (see Figures 6 and 7). Our results in column 1 of Figures 6 and 7 show that institutional investor oil sentiment has a greater impact on the U.S. inflation premium (1-year BEIR) compared to the impact of individual investor oil sentiment on the U.S. inflation premium. Column 1 of Figure 6 illustrates that a shock to the institutional investor oil sentiment results in a significant cumulative increase of $1.43 \%$ in the U.S. inflation premium over the next 10 weeks, while column 1 of Figure 7 shows that a shock to the 
individual investor oil sentiment results in a significant cumulative increase of $1.15 \%$ in the U.S. inflation premium over the next 10 weeks. While the point estimates certainly appear different, given the size of the standard errors, we are not able to definitively argue that the impulse responses are statistically different from each other. Again, note also that the results in Figures 6 and 7 are consistent with the oil sentiment indices capturing concerns about potential macroeconomic supply shocks.

\section{[Insert Figures 6 and 7 Here]}

\subsubsection{Structural Variance Decomposition}

In order to better understand the dynamics of the structural VAR, we also estimate the structural variance decomposition. Specifically, we would like to address the question regarding the relative importance of each random shock in explaining the fluctuation in the U.S. inflation premium. Hence, we compute the forecast error variance decomposition from the estimated structural VAR model. This estimation allows allocating the percentage of the forecast error variance to the individual shocks. The total percentage of the variance of the error should add up to $100 \%$ at a given forecast horizon.

Table 3 displays the results of the structural variance decompositions at two different horizons: 5 weeks and 10 weeks. The column variables explain the amount of variance of the row variable. The BEIR rows in each of the two panels are italicized. Note that the oil sentiment index explains almost $11.60 \%$ of the variation of the BEIR over five weeks, and almost $17 \%$ over the subsequent 10 weeks. The real returns of oil explain $9.21 \%$ of the BEIR variation over five weeks, and $13.10 \%$ over a ten-week time period. Also, note that the oil sentiment index explains nearly half of the variance of the oil returns over both time horizons. Again, these results are consistent with the story that oil sentiment is capturing investor concerns about potential supply disruptions. 
[Insert Table 3 Here]

\subsubsection{Forecasting Models}

Finally, we also develop several forecasting models to examine the out-of-sample predictability of the oil sentiment on the inflation premium, measured by the U.S. 1-year BEIR. Welch and Goyal (2008) posit that significant in-sample predictive power doesn't ensure significant out-of-sample predictive ability. We follow Welch and Goyal (2008) to develop our benchmark model as a no predictability model which is the constant expected U.S. 1-year BEIR model:

$$
B E I R_{t}=\beta_{0}+\varepsilon_{t}
$$

Afterward, we compare our baseline model against four competing predictive regression models:

$$
\begin{aligned}
& B E I R_{t}=\alpha_{0}+\alpha_{1} \text { BEIR }_{t-1}+\varepsilon_{t} \\
& B{ } I R_{t}=\alpha_{0}+\beta \text { Sent }_{t-1}+\varepsilon_{t} \\
& \text { BEIR }_{t}=\alpha_{0}+\beta \text { Oil }_{t-1}+\varepsilon_{t} \\
& \text { BEIR }_{t}=\alpha_{0}+\beta \text { Baltic }_{t-1}+\varepsilon_{t}
\end{aligned}
$$

To compare our baseline with other competing predictive models, we compute the cumulative squared prediction errors for each regression. Subsequently, we construct our lines by computing the cumulative squared prediction errors of the NULL minus the cumulative squared prediction errors of the ALTERNATIVE. Hence, an increase in a line indicates better performance of the ALTERNATIVE model and a decrease in the line indicates better performance of the NULL. Thus, we follow the literature in which the OOS forecast starts after 20 weeks from the beginning of the data. 
In Figure 8, we find that the overall investor sentiment regarding oil can predict the U.S. inflation premium, measured by the 1-year U.S. BEIR. Furthermore, the aggregate demand, measured by the real growth rate of the Baltic Dry Index has also significant predictability over the inflation premium. However, the real return of oil does not seem to predict the inflation premium. We believe this is consistent with the findings of Kilian (2009) in which the supply shock of oil has a minimal impact on the macroeconomic aggregates.

\section{[Insert Figure 8 Here]}

\subsection{Robustness Checks}

We conduct several alternative tests to gauge the robustness of our results. First, we estimate the generalized impulse response function (IRF) and the generalized historical decomposition (HD) (see Figure 9). ${ }^{9}$ The main objective of estimating the generalized impulse response is to demonstrate the results of the same model without imposing any restrictions. All the results are consistent with the SVAR results. Columns 1 and 3 of Figure 9, show that a positive one standard deviation shock to the overall oil sentiment and the real return of oil futures result in a significant cumulative increase in U.S. 1-year inflation premium by approximately $1.25 \%$ and $1.70 \%$ respectively. However, column 2 of Figure 9 demonstrates that a shock to the real growth rate of Baltic Dry Index results in an insignificant cumulative increase in the U.S. 1-year BEIR by $0.14 \%$. This is consistent with our SVAR results that investors consider increases in oil prices driven by the demand side as good news and a sign of a strong economy.

\section{[Insert Figure 9 Here]}

Second, we substitute the breakeven inflation rate with an actual measure of the U.S. inflation, which is the online-price inflation index. This index is developed out of the Billion Price

\footnotetext{
${ }^{9}$ For the sake of brevity, historical decomposition results and graphs can be provided upon request.
} 
Project at MIT. The index was constructed by scraping prices from websites of giant stores such as Walmart. We include an actual measure of inflation to validate that sentiment regarding oil has an evident and significant impact on an actual measure of inflation. Subsequently, this impact should be reflected in inflation premiums measured by BEIR. The impulse responses show that a positive one standard deviation shock to the overall oil sentiment, and the real return of oil futures result in a significant cumulative increase on the online-price inflation index by $0.10 \%, 0.15 \%$, respectively. Again, we conclude that the results are consistent with our evidence on the U.S. inflation premium..$^{10}$

Additionally, we address the concern that the oil sentiment measure is just a reflection of market sentiment or inflation expectation. We use a U.S. bond market sentiment to evaluate the impact on the U.S. 1-year inflation premium. The main reason for using a bond market sentiment is that the inflation premium measure, BEIR, calculated as the difference between the nominal bond yield and the real bond yield. Hence, a bond sentiment measure is more relevant than the sentiment for other markets. ${ }^{11}$ We use the overall SENTIX U.S. bond sentiment index to conduct our analysis. This index is constructed exactly the same as the overall oil sentiment which allows us to compare the two. The results show that a shock to the overall bond sentiment has an insignificant impact on both the real return of oil futures and the U.S. inflation premiums (U.S. 1year BEIR) (see Figure 10). Another concern is that oil sentiment is just a reflection of inflation expectations. Thus, we repeat our main analysis by adding the Michigan Inflation Expectation index as a control variable. Our results are robust and remain almost the same. ${ }^{12}$ This contributes

\footnotetext{
${ }^{10}$ The results are based on the following sample period July 2008 - September 2016 as we don't have access to the data before and after this period. For the sake of brevity, results and graphs can be provided upon request of the authors.

${ }^{11}$ We conduct an additional robustness check using Sentix U.S. equity market sentiment. The results are very similar to those for the bond sentiment showing insignificant impact of equity market sentiment on the U.S. BEIR. The IRf graphs can be provided upon request by the authors.

${ }^{12}$ Historical decomposition results and graphs are omitted to save space.
} 
to the evidence that the oil sentiment is mostly driven by the oil market rather than the general financial market.

\section{[Insert Figure 10 Here]}

We also conduct our analysis with several U.S. BEIRs maturities to further examine the impact on the short-term and long-term. We conduct the same analysis on the 2, 3,5 7, and 10 year U.S. breakeven inflation rate. Our results are robust among all of the short term time horizons. ${ }^{13}$ The short-term U.S. BEIR (2, 3 and 5 year) show a significant impact of the overall oil sentiment on the inflation premium.

\subsection{Conclusion}

To our knowledge, this is the first paper that examines the impact of oil sentiment on the U.S. inflation premium, measured by the breakeven inflation rate (BEIR). Our main findings demonstrate a significant influence of investor sentiment regarding oil prices on the U.S. inflation premium. A positive one standard deviation shock to investor sentiment regarding oil prices results in a significant cumulative increase of $1.2 \%$ for the U.S. inflation premium over the following ten weeks. Furthermore, the institutional investor oil sentiment has a greater impact on the U.S. inflation premium compared to the impact of individual investor oil sentiment on the U.S. inflation premium, although we cannot determine whether the two are statistically different from each other. These results are highly significant given that the mean of the U.S. inflation premium is $0.74 \%$. Additionally, we find out-of-sample evidence that overall investor sentiment regarding oil along with the other oil-related measures to have predictability power over the U.S. inflation premium. Our results could potentially benefit policymakers, managers of firms, and investors, among others. Monetary policymakers should take investor sentiment regarding oil as a proxy to

\footnotetext{
${ }^{13}$ For the sake of brevity, results and graphs can be provided upon request by the authors.
} 
determine investors' beliefs about potential disruptions in oil markets. In addition, firms may need to estimate investor oil sentiment to gauge investors' risk appetite as it directly impacts their cost of capital. Finally, investors and fund managers could refine their investment strategies by incorporating investor sentiment regarding oil prices. 
Table 1: Summary Statistics

The table includes the variables used in the analysis. These variables are overall oil sentiment, individual oil sentiment, institutional oil sentiment, the real rate of Baltic Dry index, real return of $t$ oil futures, 5-year U.S. BEIR, 1-year U.S. BEIR, and bond investor sentiment. All variables are in weekly intervals. And the sample period is between July 18, 2008 - August 31, 2019.

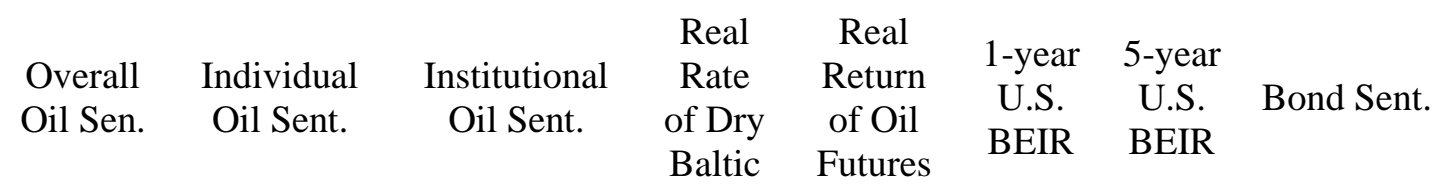

\begin{tabular}{lcccccccc}
\cline { 2 - 7 } Mean & 0.02 & 0.01 & 0.03 & 0.00 & -0.26 & 0.74 & 1.65 & -0.06 \\
Median & 0.01 & 0.01 & 0.02 & 0.00 & 0.15 & 0.94 & 1.77 & -0.06 \\
Maximum & 0.56 & 0.57 & 0.54 & 0.53 & 19.93 & 4.50 & 2.47 & 0.30 \\
Minimum & -0.44 & -0.47 & -0.43 & -0.35 & -29.77 & -6.17 & -0.78 & -0.49 \\
Std. Dev. & 0.18 & 0.18 & 0.16 & 0.10 & 4.55 & 1.36 & 0.50 & 0.14 \\
Skewness & 0.11 & 0.12 & 0.05 & 0.36 & -0.74 & -1.84 & -2.24 & -0.06 \\
Kurtosis & 2.87 & 2.86 & 2.91 & 4.89 & 7.60 & 9.22 & 9.87 & 2.60 \\
& & & & & & & & \\
Observations & 558 & 558 & 558 & 558 & 558 & 558 & 558 & 558 \\
\hline
\end{tabular}




\section{Table 2: Correlations}

The table reports the correlations of the variables used in the study. The variables are overall oil sentiment, individual oil sentiment, institutional oil sentiment, the real rate of Baltic Dry index, real return of t oil futures, 5-year U.S. BEIR, 1-year U.S. BEIR, bond investor sentiment, U.S. online inflation index. Our sample covers the period between July 18, 2008 - August 31, 2019.

\begin{tabular}{|c|c|c|c|c|c|c|c|c|}
\hline & $\begin{array}{l}\text { Overall Oil } \\
\text { Sen. }\end{array}$ & $\begin{array}{l}\text { Individual } \\
\text { Oil Sent. }\end{array}$ & $\begin{array}{c}\text { Institutional } \\
\text { Oil Sent. }\end{array}$ & $\begin{array}{c}\text { Real } \\
\text { Rate of } \\
\text { Dry } \\
\text { Baltic } \\
\end{array}$ & $\begin{array}{c}\text { Real } \\
\text { Return of } \\
\text { Oil } \\
\text { Futures } \\
\end{array}$ & $\begin{array}{l}\text { 1-year } \\
\text { U.S. } \\
\text { BEIR }\end{array}$ & $\begin{array}{l}\text { 5-year } \\
\text { U.S. } \\
\text { BEIR }\end{array}$ & $\begin{array}{l}\text { Bond } \\
\text { Sent. }\end{array}$ \\
\hline $\begin{array}{l}\text { Individual Oil } \\
\text { Sent. }\end{array}$ & 0.99 & 1.00 & & & & & & \\
\hline $\begin{array}{l}\text { Institutional Oil } \\
\text { Sent. }\end{array}$ & 0.95 & 0.92 & 1.00 & & & & & \\
\hline $\begin{array}{l}\text { Real Rate of } \\
\text { Dry Baltic }\end{array}$ & 0.08 & 0.08 & 0.06 & 1.00 & & & & \\
\hline $\begin{array}{l}\text { Real Return of } \\
\text { Oil Futures }\end{array}$ & 0.56 & 0.55 & 0.56 & 0.10 & 1.00 & & & \\
\hline $\begin{array}{l}\text { 1-year U.S. } \\
\text { BEIR }\end{array}$ & 0.16 & 0.18 & 0.06 & 0.06 & 0.15 & 1.00 & & \\
\hline $\begin{array}{l}\text { 5-year U.S. } \\
\text { BEIR }\end{array}$ & 0.11 & 0.13 & 0.03 & 0.05 & 0.16 & 0.81 & 1.00 & \\
\hline Bond Sent. & -0.29 & -0.28 & -0.30 & -0.04 & -0.24 & -0.18 & -0.18 & 1.00 \\
\hline
\end{tabular}




\section{Table 3: Structural Variance Decompositions}

This table presents the Structural Variance Decompositions at the 5-week and 10-week horizons. we compute the forecast error variance decomposition from the following estimated structural VAR model $Y_{t}=c_{0}+\sum_{J=1}^{k} A_{j} Y_{t-j}+\sum_{J=1}^{p} B_{j} X_{t-j}+\varepsilon_{t}$ where $Y_{t}$ is the vector of the four weekly endogenous variables overall oil sentiment, real rate of the Baltic Dry Index, Brent oil future real return, and the U.S. 1-year BEIR, $X_{t}$ is a vector of exogenous variables, and $\varepsilon_{t}$ is the vector of shocks used to estimate the structural VAR. Our sample covers the period between July 18, 2008 - August 31, 2019.

\begin{tabular}{lcccc}
\hline & & \multicolumn{2}{c}{5 Weeks } & \\
& Oil Sentiment & Baltic Dry Index & Real Futures Return & BEIR \\
\hline Oil Sentiment & 1.68 & 0.36 & 97.21 & 0.74 \\
Baltic Dry & 5.95 & 92.82 & 0.99 & 0.24 \\
$\begin{array}{l}\text { Index } \\
\text { Real Futures }\end{array}$ & 51.82 & 6.24 & 38.27 & 3.67 \\
Return & 11.57 & 1.92 & 9.21 & 77.30 \\
BEIR & & 10 Weeks & & \\
& Oil Sentiment & Baltic Dry Index & Real Futures Return & BEIR \\
& 1.70 & 0.54 & 96.81 & 0.95 \\
Oil Sentiment & 7.60 & 89.06 & 2.64 & 0.68 \\
Baltic Dry & & 7.15 & 37.88 & 4.35 \\
Index & 50.62 & 2.19 & 13.10 & 67.75 \\
Real Futures & 16.95 & & & \\
Return & & & & \\
BEIR & & & & \\
\hline
\end{tabular}


Figure 1: WTI Prices and the 1-Year Breakeven Inflation Rate

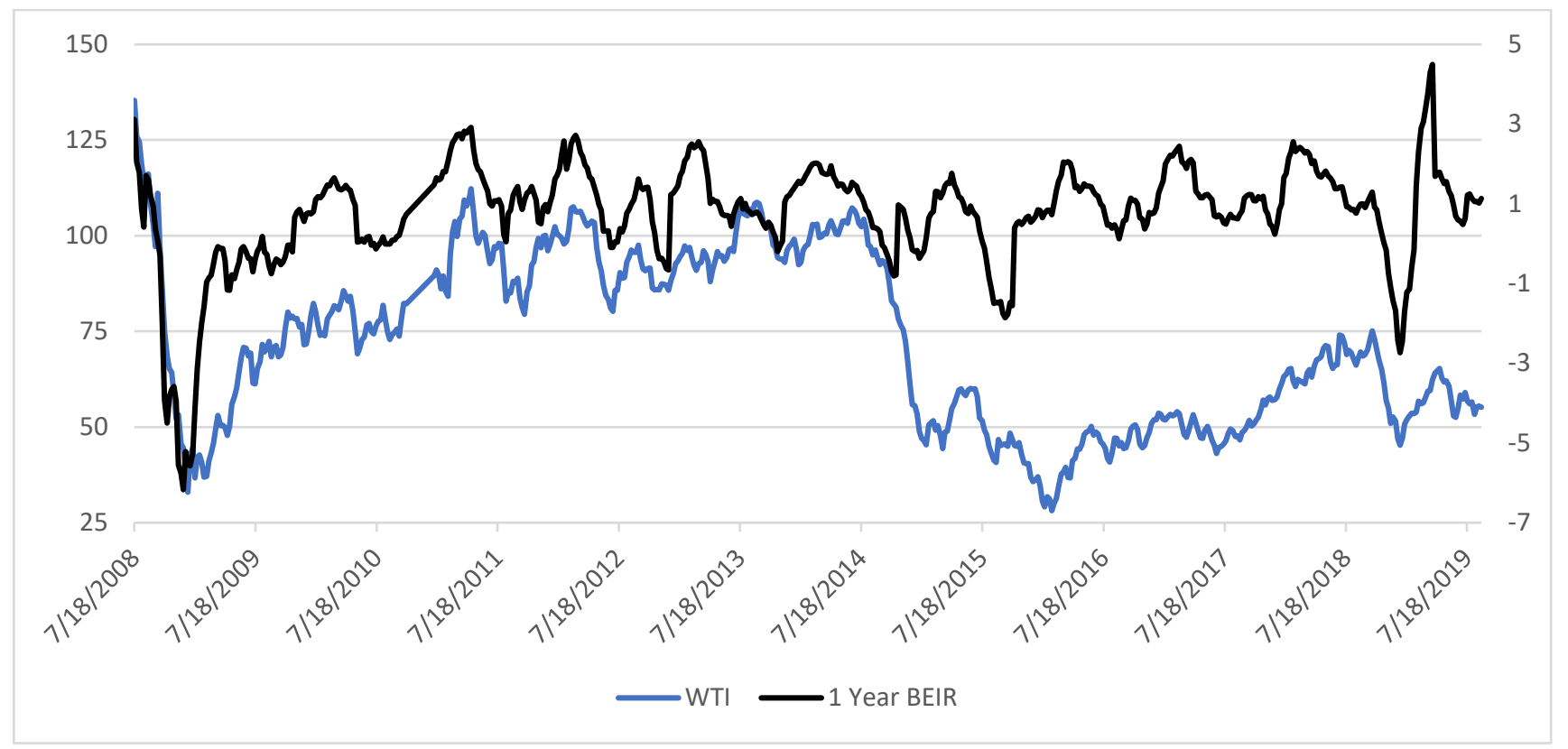




\section{Figure 2: Oil Sentiment}

This figure shows the overall oil sentiment for the period between July 18, 2008 - August 31, 2019.

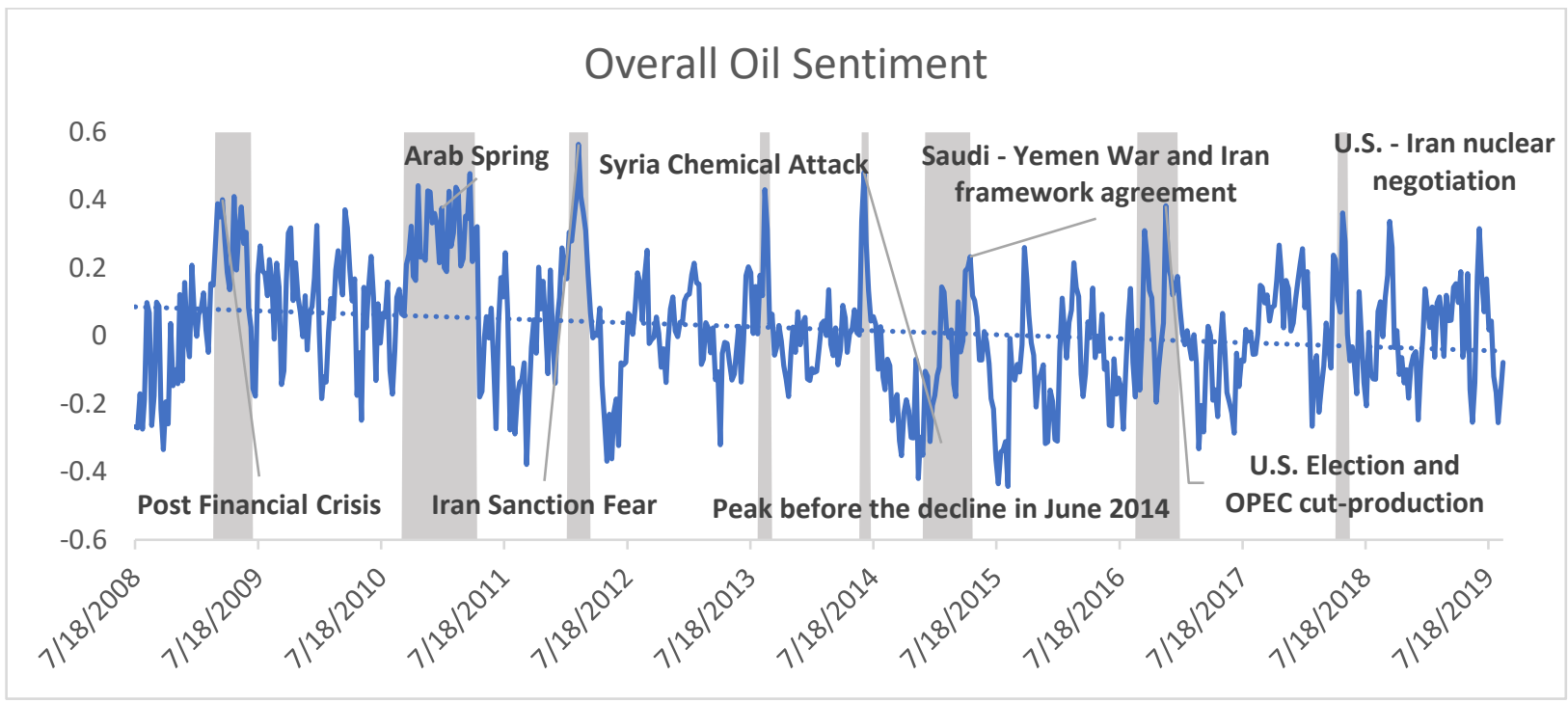

Figure 3: Real Growth Rate of Baltic Dry Index

This figure real growth rate of the Baltic Dry Index (BDI) for the period between July 18, 2008 - August 31, 2019.

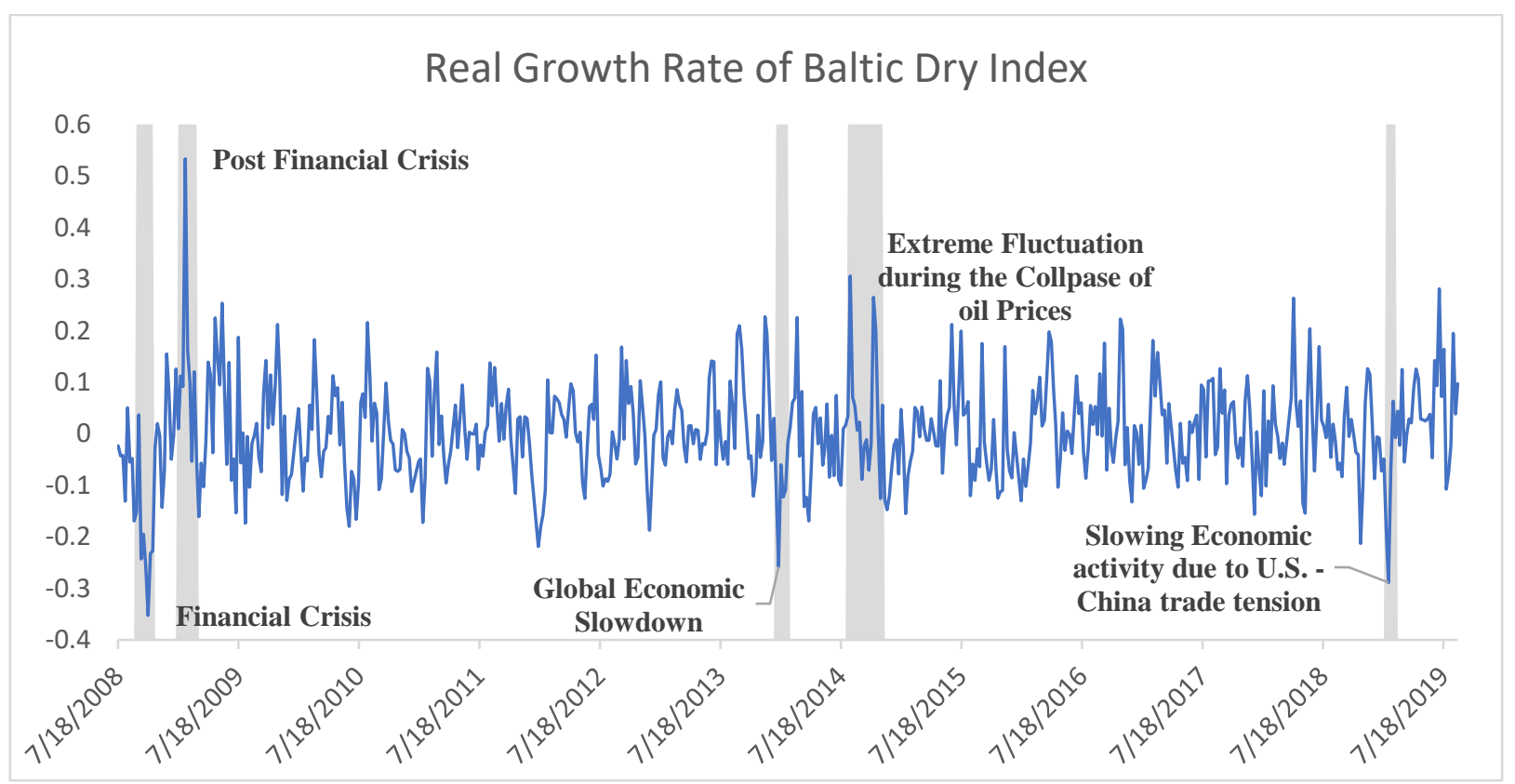




\section{Figure 4: The U.S. Online-Price Inflation Index}

The figures show the online-price inflation index (PriceStats) along the U.S. CPI (BLS), both at monthly frequency. ${ }^{14}$

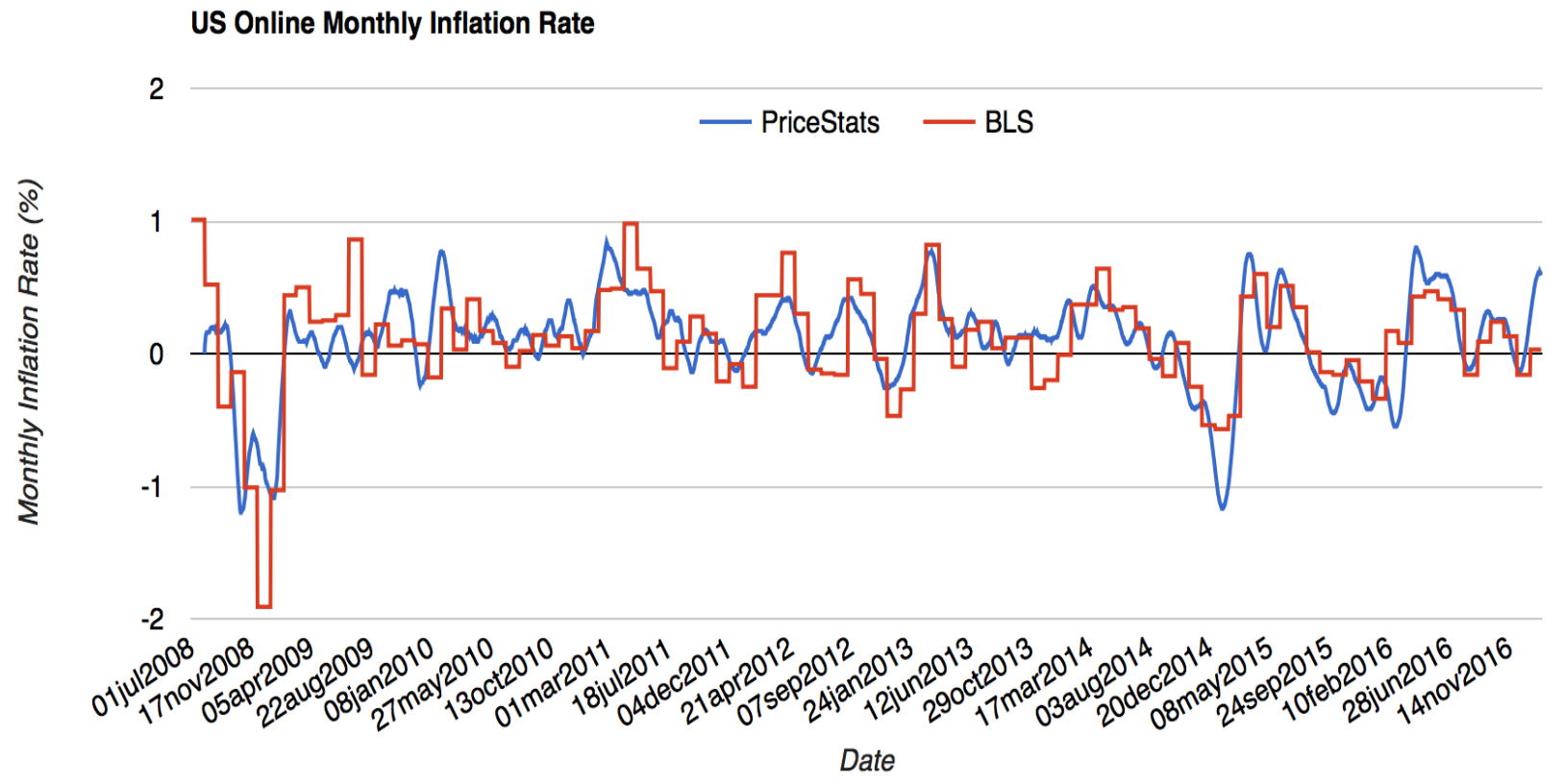

US Online Price Index

115

$$
\text { — PriceStats — BLS }
$$
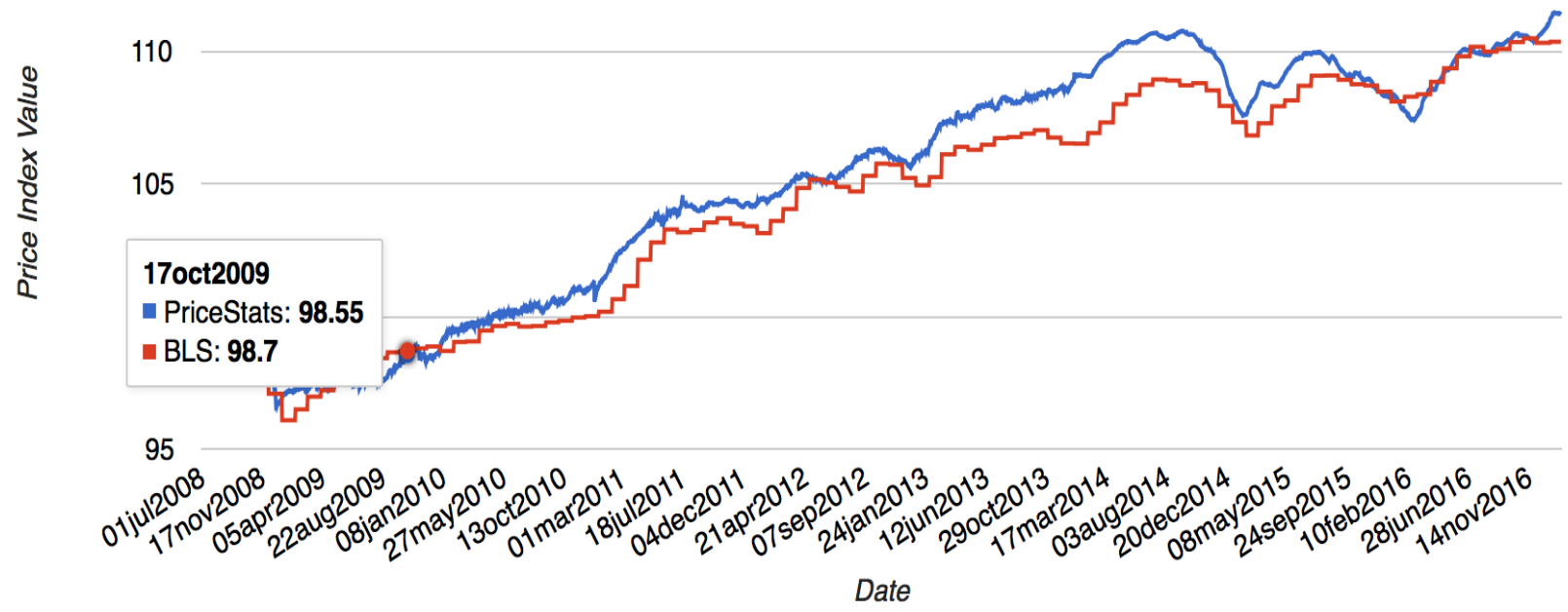

${ }^{14}$ Source: The Billion Prices Project website (http://www.thebillionpricesproject.com/usa/). The graphs were accessed on Aug/2017. 


\section{Figure 5: The Accumulative Structural Impulse Responses for the U.S. 1-year BEIR with the Overall Oil Sentiment}

This figure shows accumulative structural impulse response functions (IRF) from the following VAR: $Y_{t}=c_{0}+\sum_{J=1}^{k} A_{j} Y_{t-j}+\sum_{J=1}^{p} B_{j} X_{t-j}+\varepsilon_{t}$ where $Y_{t}$ is the vector of the four weekly endogenous variables overall oil sentiment, real rate of the Baltic Dry Index, Brent oil future real return, and the U.S. 1-year BEIR, $X_{t}$ is a vector of exogenous variables, and $\varepsilon_{t}$ is the vector of shocks used to estimate the structural VAR. Our sample covers the period between July 18, 2008 - August 31, 2019. Time on the horizontal axis is in weeks.

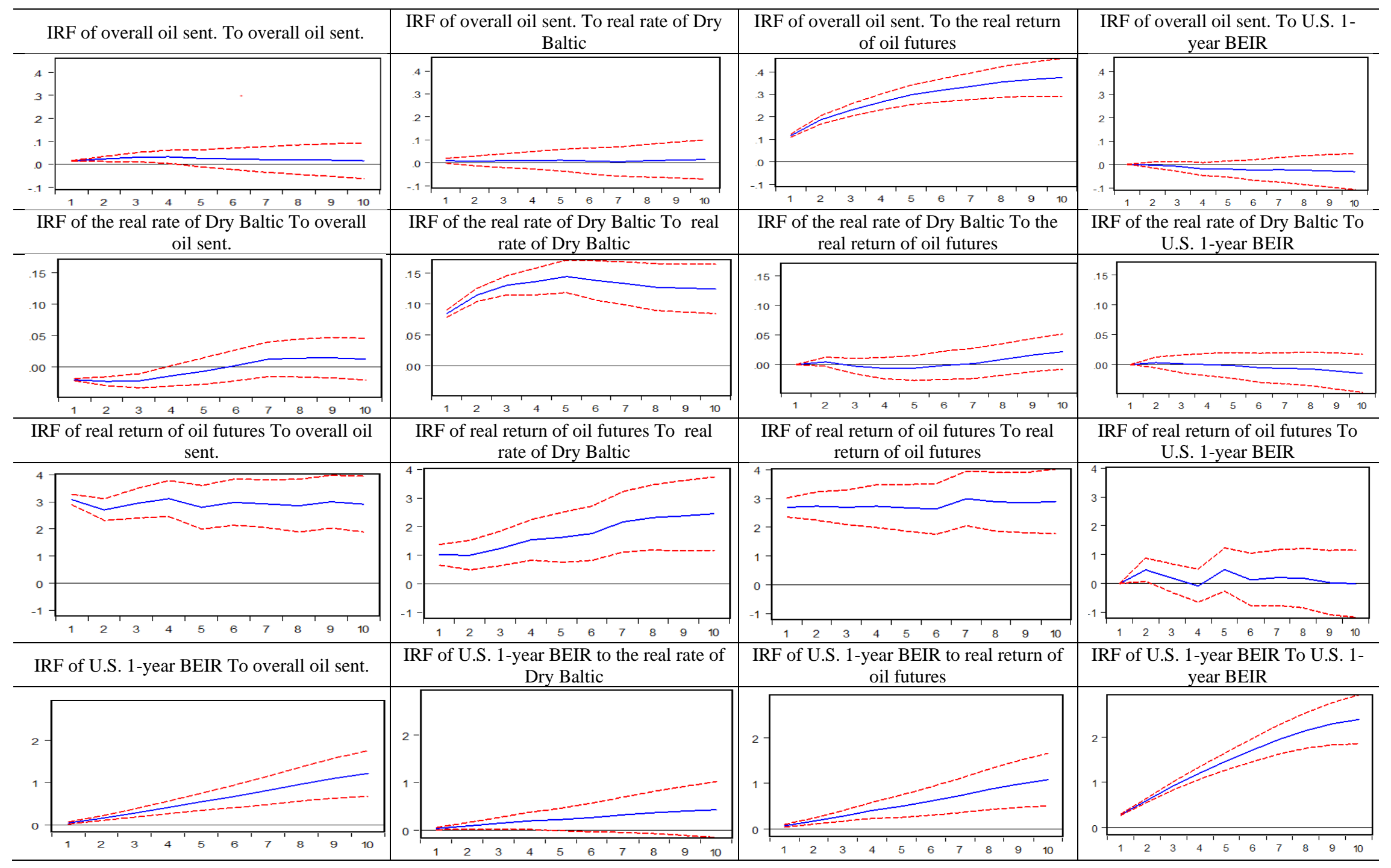




\section{Figure 6: The Accumulative Structural Impulse Responses for the U.S. 1-year BEIR with the Institutional Oil Sentiment}

This figure shows accumulative structural impulse response functions (IRF) from the following VAR: $Y_{t}=c_{0}+\sum_{J=1}^{k} A_{j} Y_{t-j}+\sum_{J=1}^{p} B_{j} X_{t-j}+\varepsilon_{t}$ where $Y_{t}$ is the vector of the four weekly endogenous variables institutional oil sentiment, real rate of the Baltic Dry Index, Brent oil future return, and the U.S. 1-year BEIR, $X_{t}$ is a vector of exogenous variables, and $\varepsilon_{t}$ is the vector of shocks used to estimate the structural VAR. Our sample covers the period between July 18, 2008 - August 31, 2019. Time on the horizontal axis is in weeks.

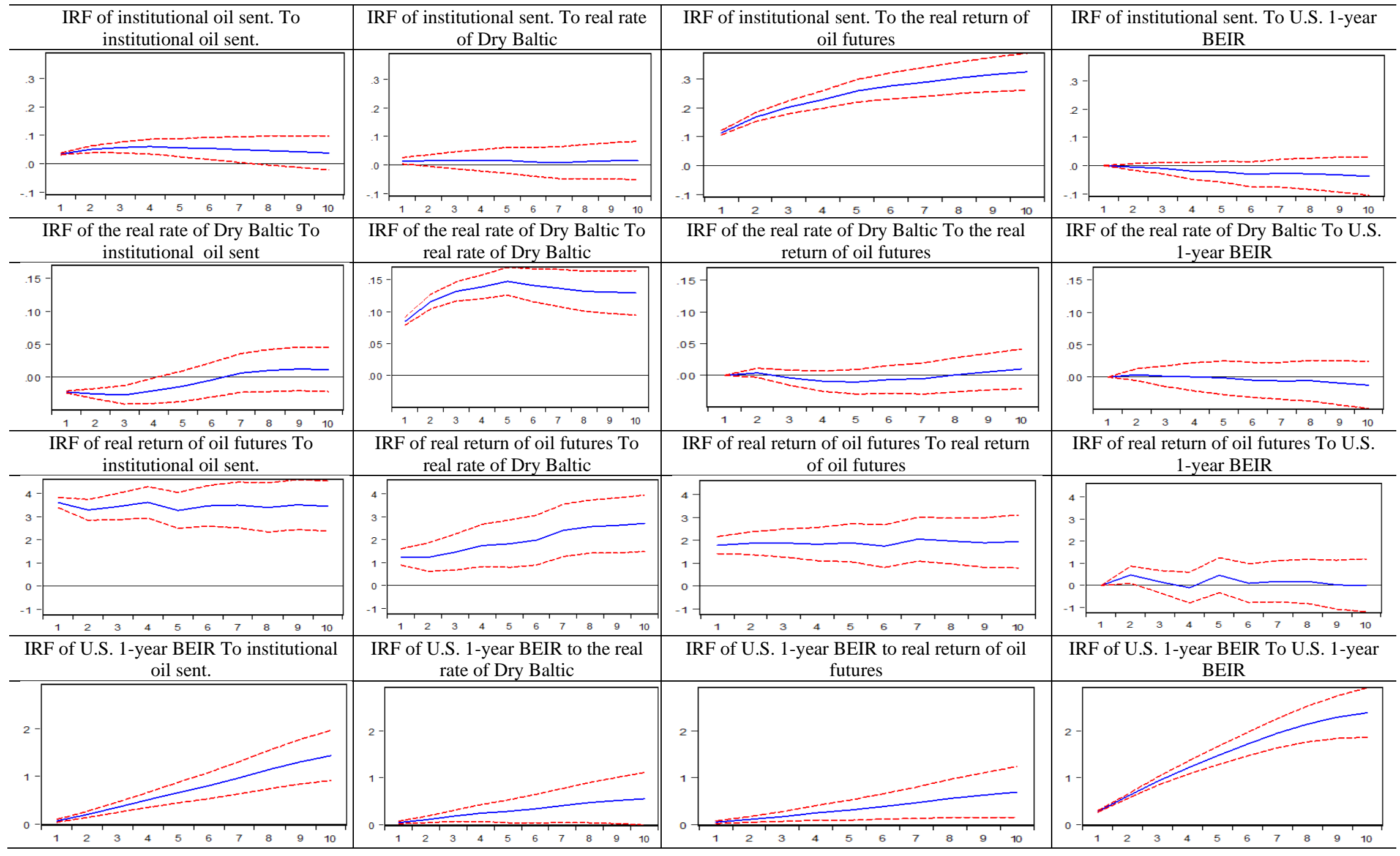




\section{Figure 7: The Accumulative Structural Impulse Responses for the U.S. 1-year BEIR with the Individual Oil Sentiment}

This figure shows accumulative structural impulse response functions (IRF) from the following VAR: $Y_{t}=c_{0}+\sum_{J=1}^{k} A_{j} Y_{t-j}+\sum_{J=1}^{p} B_{j} X_{t-j}+\varepsilon_{t}$ where $Y_{t}$ is the vector of the four weekly endogenous variables overall oil sentiment, real rate of Baltic Dthe ry Index, Brent oil future return, and the U.S. 5-year BEIR, $X_{t}$ is a vector of exogenous variables, and $\varepsilon_{t}$ is the vector of shocks used to estimate the structural VAR. Our sample covers the period between July 18, 2008 - August 31, 2019. Time on the horizontal axis is in weeks.

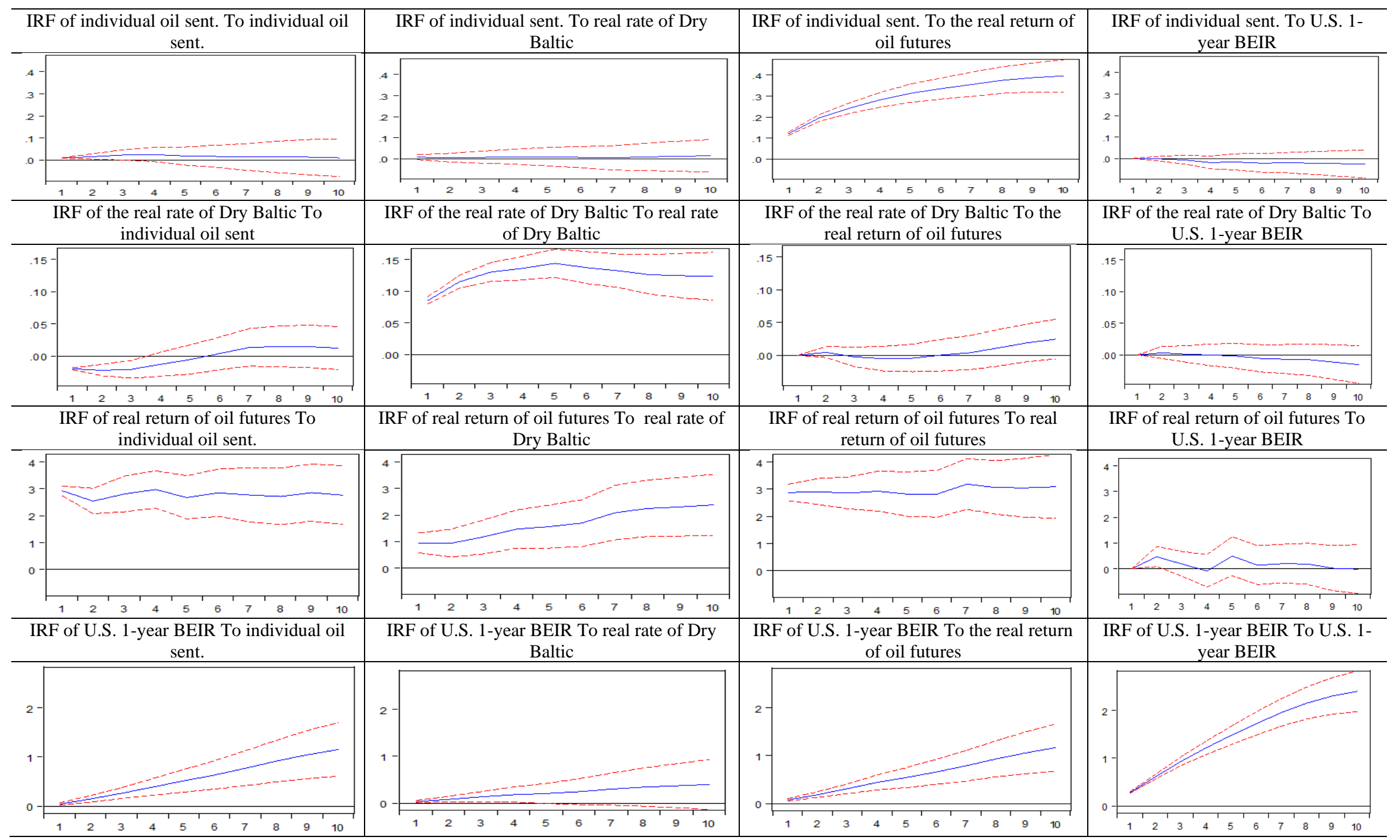




\section{Figure 8: The Out of Sample Forecasting Models of the U.S. 1-year BEIR}

These figures plot the IS and OOS performance of weekly predictive regressions. Particularly, these are the cumulative squared predictions errors of the NULL minus the cumulative squared prediction errors of the ALTERNATIVE. ALTERNATIVE is a model that relies on predictive variables noted above each graph. The NULL is a no predictability baseline model which is the constant expected U.S. 1-year BEIR $\left(B^{B E I R} t=\beta_{0}+\varepsilon_{t}\right)$. An increase in a line indicates better performance of the ALTERNATIVE model; a decrease in a line indicates better performance of the NULL. The sample period covers the period July 18, 2008 - August 31, 2019.

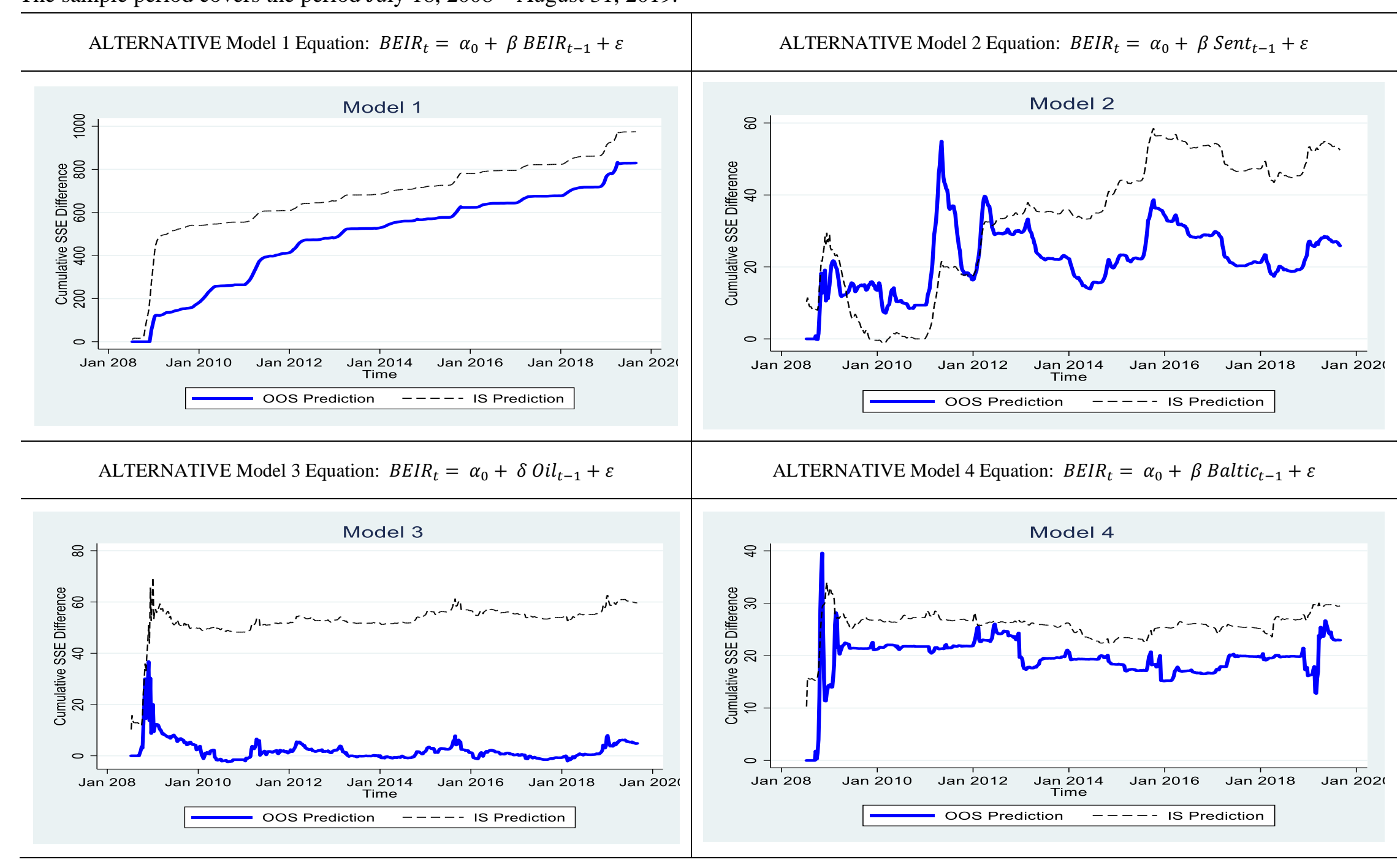




\section{Figure 9: The Accumulative Generalized Impulse Responses for the U.S. 1-year BEIR with the Overall Oil Sentiment}

This figure shows accumulative generalized impulse response functions (IRF) from the following VAR: $Y_{t}=c_{0}+\sum_{J=1}^{k} A_{j} Y_{t-j}+\sum_{J=1}^{p} B_{j} X_{t-j}+$ $\varepsilon_{t}$ where $Y_{t}$ is the vector of the four weekly endogenous variables overall oil sentiment, real rate of the Baltic Dry Index, Brent oil future return, and the U.S. 5-year BEIR, $X_{t}$ is a vector of exogenous variables, and $\varepsilon_{t}$ is the vector of shocks used to estimate the structural VAR. Our sample covers the period between July 18, 2008 - August 31, 2019. Time on the horizontal axis is in weeks.

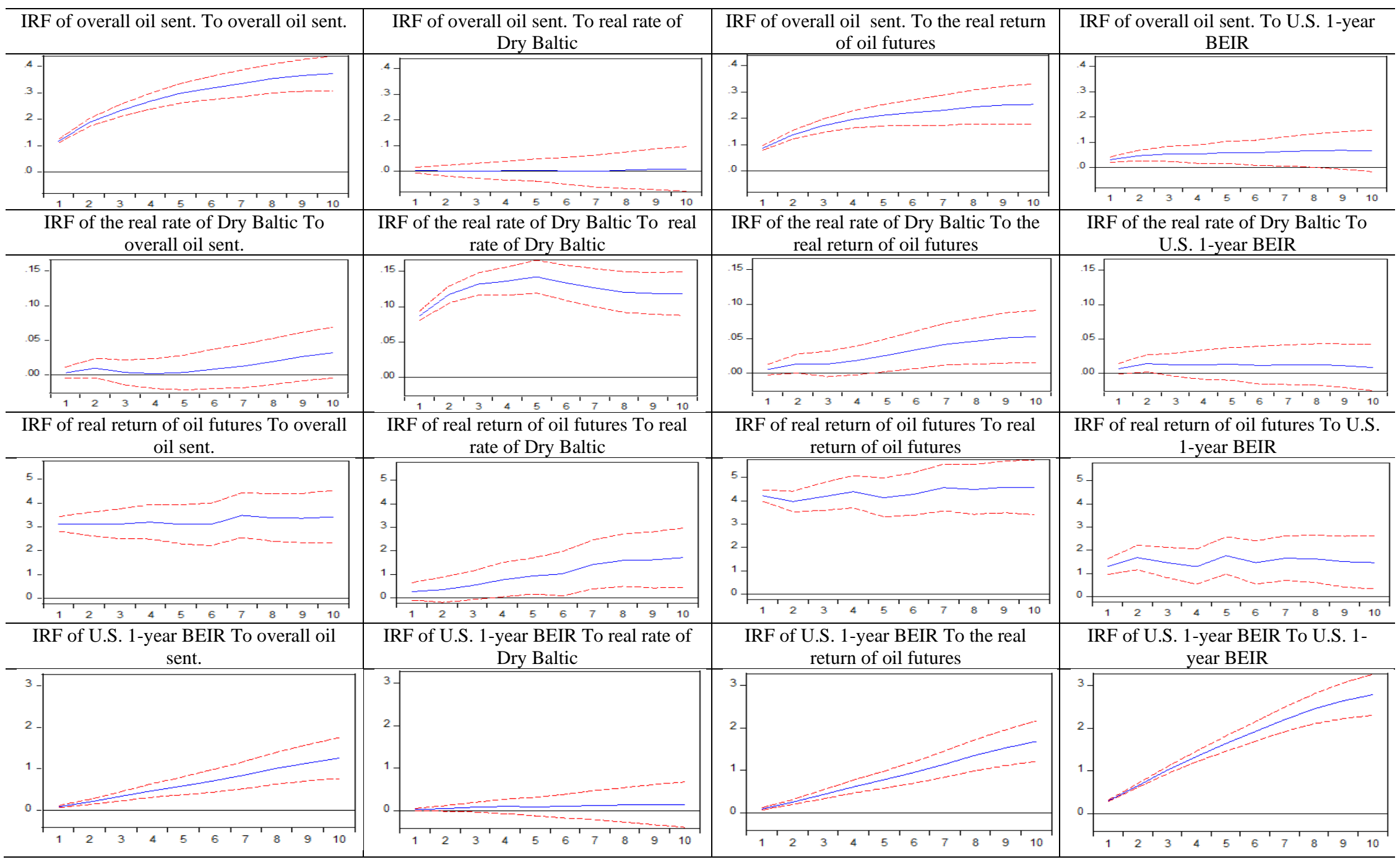




\section{Figure 10: The Accumulative Generalized Impulse Responses for the U.S. 1-year BEIR with the Bond Sentiment}

This figure shows accumulative generalized impulse response functions (IRF) from the following VAR: VAR: $Y_{t}=c_{0}+\sum_{J=1}^{k} A_{j} Y_{t-j}+$ $\sum_{J=1}^{p} B_{j} X_{t-j}+\varepsilon_{t}$ where $Y_{t}$ is the vector of the four weekly endogenous variables bond sentiment, real rate of Baltic Dry Index, Brent oil future real return, and the U.S. 1-year BEIR, $X_{t}$ is a vector of exogenous variables, and $\varepsilon_{t}$ is the vector of shocks used to estimate the structural VAR. Our sample covers the period between July 18, 2008 - August 31, 2019. Time on the horizontal axis is in weeks.

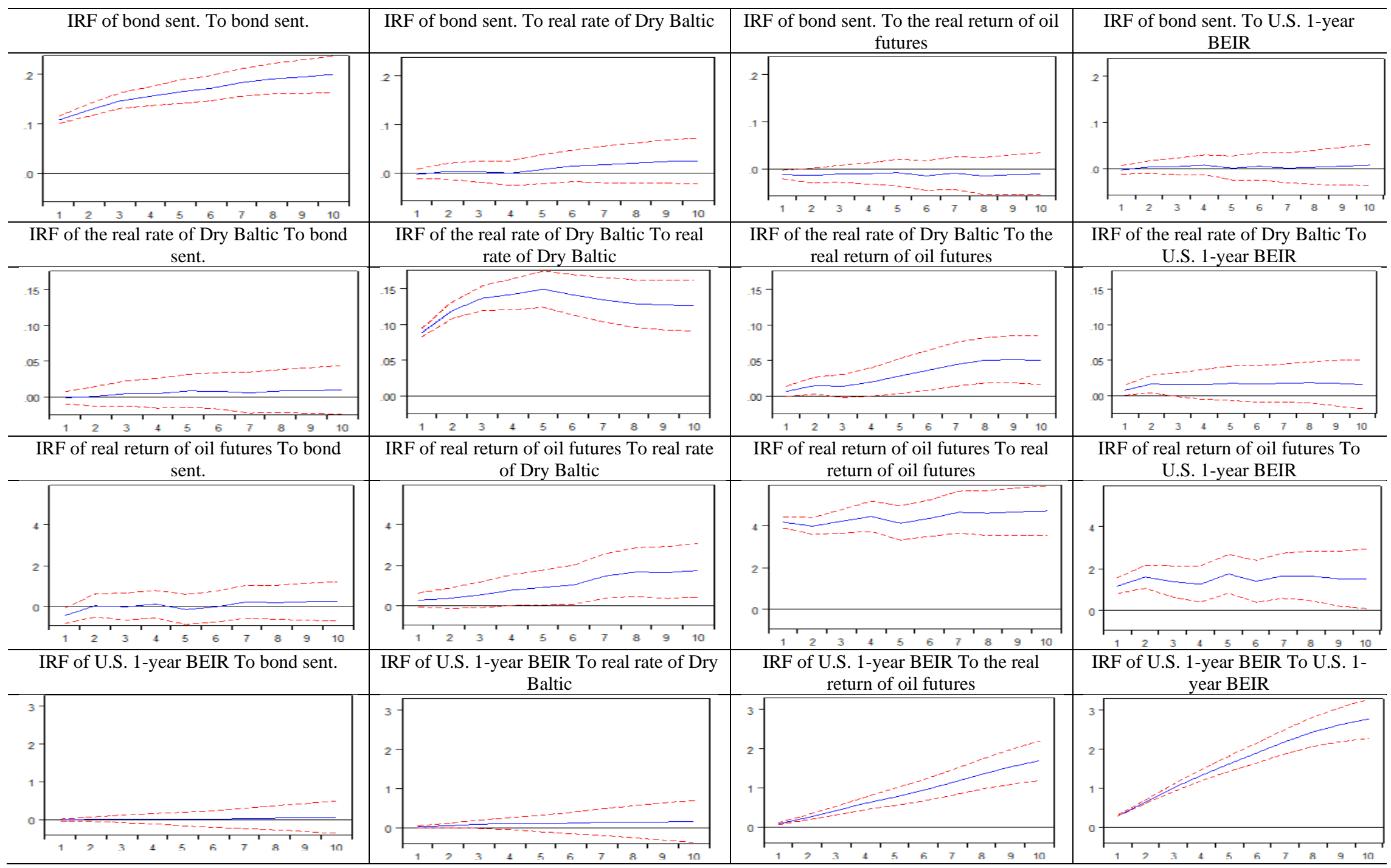




\section{Essay 2. Market Inefficiencies Surrounding Energy Announcements*}

\subsection{Introduction}

Oil inventory announcements move energy markets. These announcements provide essential signals regarding the supply and demand of oil. Two of the primary energy announcements, made by the American Petroleum Institute (API) and the U.S. Energy Information Administration (EIA), occur weekly. These two public announcements provide very similar fundamental information, and they are closely followed by traders in financial markets. According to the efficient market hypothesis, fundamental public information should be immediately impounded into asset prices. The immediate price adjustment prevents traders from exploiting public information to make profitable trades (French and Roll, 1986).

There is no consensus regarding the efficiency of oil futures markets. While some studies have found that oil futures are highly efficient (Tabak and Cajueiro, 2007; Wang and Yang, 2010; Kristoufek and Vosvrda, 2014; Kristoufek, 2018), others have found oil prices to be less efficient (Shambora and Rossiter, 2007; Alvarez-Ramirez, Alvarez, and Solis, 2010). Several studies find evidence of informed trading before energy inventory announcements. Gu and Kurov (2018) show that trading prior to the EIA weekly natural gas announcements is driven by informed traders who rely on superior forecasting skills. Rousse and Sévi (2019) suggest that information leakage is a potential cause of the observed trading pattern prior to the weekly oil inventory announcements

\footnotetext{
* This essay is based on a paper coauthored with Alexander Kurov.
} 
released by the EIA.

The API oil inventory announcements are followed 18 hours later by the oil inventory announcements from the EIA. We use the unique sequential nature of these events to analyze the efficiency of oil futures markets and to explain the evidence of informed trading before the EIA oil announcements. We utilize the same setting to contribute to the literature on stock market efficiency. In addition, we construct a simple predictor that can be used to predict inventory surprises and pre-announcement returns. We ask the following relevant questions: (1) How do market conditions influence market efficiency around energy announcements? (2) Can we utilize public news about energy to predict inventory surprises and asset prices? (3) Can we construct an improved forecast of energy announcements?

We find that the oil futures return after the API announcements significantly predicts the return before the EIA announcements. This finding provides strong evidence that oil futures do not immediately incorporate all of the public information released by the API. Thus, our results indicate that the price drift before the EIA oil announcements documented by Rousse and Sévi (2019) can be explained by delayed adjustment to public information.

Market conditions, such as liquidity and oil attention, can influence market efficiency. Chordia, Roll, and Subrahmanyam (2008), examine the role of liquidity in market efficiency. They find that the predictability of returns from past order flows decreases when liquidity is high. Akbas, Armstrong, Sorescu, and Subrahmanyam (2016) find that financial markets become more efficient when investors put more capital in mutual funds that trade on market anomalies. Furthermore, higher trading activity of algorithmic and high-frequency traders facilitates liquidity and price discovery (Hasbrouck and Saar 2013; Brogaard, Hendershott, and Riordan 2014). Therefore, high liquidity should facilitate the efficient incorporation of information in oil futures prices. Consistent 
with this expectation, we find that the oil futures returns after the API oil announcements significantly predict the pre-EIA announcement returns only during periods of low liquidity.

Additionally, attention is a limited cognitive resource that investors need to allocate to information they believe is important (Kahneman, 1973). Thus, public information should be efficiently incorporated into prices when investors pay attention to it. Barber and Odean (2008)show that investors tend to buy stocks that they pay more attention to. Han, Lv, and Yin (2017) find that oil-related SVI forecasts daily and weekly oil prices in both in-sample and out-ofsample tests. We construct an oil-related Internet search activity measure similar to the one described in Han, Lv, and Yin (2017). Our findings indicate that the predictive ability of the postAPI announcement oil futures return for the pre-EIA announcement return is confined to periods of low attention to oil.

Furthermore, we contribute to the debate regarding whether changes in oil prices can predict stock returns. Huang et al. (1996) find that oil futures are not correlated with or linked to the stock market, except stocks of oil companies. However, others have found that oil has a significant impact on stock markets depending on the type of oil shock (Chiang, Hughen, and Sagi, 2015; Kilian and Park, 2009; Ready, 2018), the specific sectors of the stock markets (Fan and Jahan-Parvar, 2012), and whether the market is international or domestic (Hu and Xiong, 2013). We find that the opening prices of oil companies do not fully incorporate oil inventory information released after trading hours. The post-API announcement oil futures return is a significant predictor of the returns of oil companies on the following day.

Previous results suggest the importance of the information released by the API in shaping the market expectations for the EIA oil announcements the following day. Most of the literature evaluates the impact of EIA announcements by considering one proxy for market expectation; for 
example, Bloomberg median consensus, as described in Halova, Kurov, and Kucher (2014) and Wolfe and Rosenman (2014), Reuters forecast as described in Bu (2014), or the API actual as described in Armstrong, Cardella, and Sabah (2017). We construct a predictor based on the difference between the API actual and the Bloomberg consensus forecast. The predictor has significant explanatory power over the pre-EIA announcement return. In addition, a simple trading strategy based on the predictor would generate an annualized Sharpe ratio of 0.67 in the full sample, and an annualized Sharpe ratio of 2.1 when the predictor has large values.

Finally, we employ the relative importance method to construct a combination forecast of the EIA oil announcements by objectively allocating weights to the Bloomberg median consensus and API actual (Grömping, 2006; Johnson and Lebreton, 2004; Thomas, Zhu, Zumbo, and Dutta, 2017). Using our combination forecast as a proxy for market expectations increases the $R^{2}$ in the regression of oil futures returns on inventory surprises by approximately $130 \%$ compared to the Bloomberg consensus forecast, and by approximately 17\% compared to the API actual. Hence, using the combination forecast to compute oil inventory surprises reduces measurement errors that could stem from the use of a single stale proxy for market expectations. We show that using the combination forecast to compute inventory surprises provides more accurate estimates that are closer to those generated by employing the Identification Through Censoring (ITC) technique proposed by Rigobon and Sack (2008). The ITC technique is employed to adjust for the bias caused by measurement error in announcement surprises.

Our study contributes to the literature in several important ways. First, we provide clear evidence of market inefficiency in the oil futures market using a unique setting of sequential energy announcements. We examine how different market conditions influence this inefficiency. Second, we show that a similar inefficiency is also present in the stock market. Specifically, opening prices 
of energy stocks do not fully incorporate public information released after the market close the day before. Third, we show that mere public information can be used to predict inventory surprises and oil futures returns before the EIA announcements. This alleviates the concerns about possible preannouncement information leakage. Finally, we construct a combination forecast of the EIA oil announcements that is more accurate than other commonly used measures of market expectations. A similar approach may be useful in creating forecasts of other public announcements.

\subsection{Literature Review}

As mentioned above, the literature has not reached a consensus regarding the efficiency of the oil markets. Shambora and Rossiter (2007) employ an artificial neural network to uncover hidden trading patterns in the oil futures and show the possibility of superior return using the network. Alvarez-Ramirez, Alvarez, and Solis (2010) use detrended fluctuation analysis (DFA) to analyze the efficiency of the daily spot price of WTI crude oil. They find that crude oil exhibits some deviations from efficiency; however, their results seem to depend on the state of the economy. On the other hand, Wang and Liu (2010) find that the behavior of WTI at different measurement frequencies is consistent with informational efficiency. These results are consistent with the findings of Alvarez-Ramirez, Alvarez, and Rodriguez (2008). Wang and Yang (2010) use intraday data for crude oil, heating oil, gasoline, and natural gas futures and test the efficiency of these markets using several nonlinear models. They find that the crude oil and gasoline futures markets are efficient, but heating oil and natural gas futures show weak-form efficiency only during the bull market. Kristoufek and Vosvrda (2014) investigate the market efficiency in 25 commodity futures. They find WTI crude oil, heating oil, and coffee to be the most efficient compared to the other commodities. Kristoufek (2018) replicated the earlier study by Tabak and Cajueiro (2007) with extended data up to June 2017. The results show that the efficiency fluctuates over time for 
both WTI and Brent crude oil but the oil market has been more efficient recently compared to the 1990s. Furthermore, WTI oil shows stronger evidence of efficiency compared to Brent oil.

The literature is very sparse in regards to trading around energy announcements. Rousse and Sévi (2019) investigate informed trading around the EIA oil inventory announcements. They find some "suspicious trading" patterns before the announcements as there are significant order imbalances on the days of oil inventory surprises. They suggest that "the inventory level released by the DOE each Wednesday is known by some market participants who can benefit from their insider position to make money with the news." Our paper differs from theirs in several aspects. First, our findings point towards sophisticated trading that is driven by mere public information which includes the API announcement in the day before. Second, we investigate sophisticated trading around both EIA and API announcements. Our findings indicate that the significant preannouncement drift exists only before the EIA release. This provides evidence that some traders have superior skills for digesting and processing public information.

In a related paper, Gu and Kurov (2018) find evidence of informed trading, a drift in the right direction, before the Weekly Natural Gas Storage Report. The difference between forecasts of analysts with superior historical forecasting ability and the Bloomberg consensus forecast predicts inventory surprises and the pre-announcement returns of natural gas futures. Our paper differs from Gu and Kurov's (2018) study in several ways. First, we show that the oil futures return following the API inventory announcements is a significant predictor of the pre-EIA announcement returns. This is a clear violation of the weak-form market efficiency. Second, we examine market conditions that influence the return predictability around the release of the Weekly Petroleum Status Report. Third, in addition to looking at the efficiency of the oil futures market we show evidence of inefficiency in stocks of oil companies. 
The literature on the impact of macroeconomic news on asset prices is extensive. ${ }^{15}$ However, the literature regarding energy announcements is limited. Miao et al. (2018) show that oil inventory announcements shocks have a significant impact on oil futures and options prices. Wolfe and Rosenman (2014) study the bidirectional causality of oil and gas inventory announcements shocks. They analyze how these shocks are transmitted from one market to the other. They find that the impact of gas inventory announcements on oil futures volatility is stronger than the effect of oil announcements on gas futures volatility. Both Miao et al. (2018) and Wolfe and Rosenman (2014) use the Bloomberg median consensus to proxy for the market expectation of the announcements. Bu (2014) uses the Reuters survey to proxy for the market expectations and finds that the oil inventory shocks move oil futures prices but have limited influence on volatility. Ye and Karali (2016) analyze the impact of both the EIA and API inventory announcements on crude oil futures returns and volatility. The EIA announcements shocks are measured relative to the API actual, whereas the API shocks measured relative to the Thomson Reuters survey. Their results show that both the EIA and API inventory shocks have a significant effect on returns and volatility. However, the effect of the API inventory shocks is smaller and shorter-lived compared to the effect of the EIA inventory news.

Armstrong, Cardella, and Sabah (2017) study the impact of the EIA oil inventory surprises on crude oil futures liquidity. They find that these shocks resolve uncertainty and increase liquidity. Chang, Daouk, and Wang (2009) investigate the impact of analyst forecast accuracy on the oil markets. They find that investors are able to identify good analysts and respond to their forecasts. Ederington et al. (2019) analyze the properties of analyst forecasts of oil and natural gas inventories. They find that the reaction of the daily price of oil and natural gas futures to the EIA

\footnotetext{
${ }^{15}$ Examples of studies in this area include Andersen et al., (2003), Andersen, Bollerslev, Diebold, and Vega (2007), Baum, Kurov, and Halova (2015), Rigobon and Sack (2004), Scholtus, van Dijk, and Frijns (2014).
} 
announcements is influenced by the level of forecast dispersion. Additionally, they find that inventory forecasts for natural gas are more accurate compared to those for oil.

Halova, Kurov, and Kucher (2014) employ the identification through censoring technique to correct for biases in the estimates of the responses of energy futures markets to inventory news. They find that the bias in the OLS estimates is quite large. Linn and Zhu (2004) analyze the impact of the weekly gas inventory announcements on the volatility of the natural gas futures. They find that the announcements cause a significant increase in volatility in the 30-minute interval after the release. Other studies examine the impact of OPEC announcements (Karali and Ramirez, 2014; Kutan and Demirer, 2010; Schmidbauer and Rösch, 2012; Spencer and Bredin, 2019).

To measure inventory news, it is important to choose an appropriate proxy for market expectations. We employ the relative importance method to construct a combination forecast which could accurately represent the market expectations. This methodology has been employed in different contexts to assess the relative importance of multiple variables (Grömping, 2006; Johnson and Lebreton, 2004; Thomas et al., 2017). To the best of our knowledge, the only prior study that uses combination forecasts to compute inventory surprises is Anatolyev, Seleznev, and Selezneva (2018). Our approach differs from theirs in that we do not impose any assumptions in allocating the weights. Furthermore, our approach is easily generalized to incorporate more than two forecasts. This approach to measuring market expectations can be used in other contexts such as macroeconomic and corporate announcements.

\subsection{Institutional Background, Data, and Variables}

Our empirical analysis centers around two major weekly oil announcements. These two announcements provide a unique setting because they contain similar information and are released on consecutive days. One of these announcements is released by the EIA. Oil companies and 
refineries are required to participate in the weekly EIA survey and provide accurate information about their oil inventory by the end of each Friday. ${ }^{16}$ The EIA compiles this information and prepares the Weekly Petroleum Status Report. The report is usually released on Wednesdays at 10:30 am ET. Market participants and policymakers closely follow these releases and use them to analyze changes in the oil supply and demand.

The American Petroleum Institute (API) was established by Congress and the domestic oil and gas industry in 1919. The institute has around 625 corporate members, and it is considered one of the largest associations in the oil and gas industry. ${ }^{17}$ The API releases its oil inventory report at 4:30 pm ET every Tuesday. These releases are reported by the traditional news media, social media and other media platforms (Armstrong, Cardella, and Sabah 2017). As mentioned above, prior research finds that the API oil inventory announcements have significant effects on oil prices and volatility (Ye and Karali, 2016). The API and the EIA provide similar information, and both are considered highly reliable. Furthermore, both EIA and API collect data from almost the same respondents and cover around $90 \%$ of the U.S. oil and gas industry. According to API, "API collects an exact copy of the data submitted to EIA. Respondents send data to API using the same weekly survey forms that EIA uses.”

Our sample period spans from January 2011 to August $2019 .{ }^{18}$ This sample period provides sufficient data to conduct our analysis and ensure that our results are not driven by a particular market regime. Due to holidays, EIA announcements occasionally take place on Thursdays instead of Wednesdays. In such cases, the time interval between the API and the EIA announcements may exceed 18 hours. In our main analysis, we exclude those EIA announcements that took place on

\footnotetext{
16 The EIA information is provided on the EIA's website at https://www.eia.gov/.

17 The API information is available on the API's website at https://www.api.org/.

18 The sample period is chosen based on availability of the API actual data.
} 
Thursdays. ${ }^{19}$ The resulting sample contains 385 EIA oil inventory announcements.

We use data for the nearby WTI oil futures contracts, since they are very liquid (Chiang and Hughen, 2017). These futures are considered to be very efficient in incorporating public information. We use intraday data, which allows us to analyze trading activity and price behavior around the EIA and API inventory announcements. We use the oil futures data to construct the illiquidity measure following Amihud (2002). This illiquidity measure is defined as follows:

$$
I L L I Q=\left(\frac{\left|r_{d, s}\right|}{v o l_{d, s}}\right)
$$

where $r_{d, s}$ is the absolute return and $d v o l_{d, s}$ is the volume on day $d$ in period $s$. This measure is widely used in the literature (Goyenko, Holden, and Trzcinka, 2009). ${ }^{20}$

Da, Engelberg, and Gao (2011) use the Google Search Volume Index (SVI) and find that an increase in SVI can predict stock returns up to two weeks in advance. Oil attention has been shown to have significant predictive power for oil prices at both daily and weekly frequencies (Han, Lv, and Yin, 2017). We measure attention to oil prices using daily Google SVI data. We use the search activity for "oil" as our measure of attention to oil prices. We select the following search categories to capture attention to the oil market (1) Business \& Industrial, (2) Energy \& Utilities, (3) Oil \& Gas. ${ }^{21}$ Moreover, we download the consensus forecasts for the EIA announcements from Bloomberg. We also download the U.S. oil inventory level from the EIA website.

We construct the combination forecast according to the weights estimated by the relative importance analysis. This method is proposed by Lindeman, Merenda, and Gold (1981), henceforth LMG. Figure 1 shows the annual weights allocated to the API actuals computed based

\footnotetext{
${ }^{19}$ Our results remain significant and very similar if these announcements are included in the sample.

${ }^{20}$ The Amihud measure has been shown to have the largest correlation with liquidity benchmarks in commodity markets (Marshall, Nguyen, and Visaltanachoti, 2012).

${ }^{21}$ We have used several variations of search categories to ensure the robustness of our attention measure.
} 
on relative importance regression using data for the previous year. We can see that the API actual receives weights of more than $50 \%$ throughout our sample period. Table 1 provides summary statistics for the main variables used in the analysis. The table shows that the means of both API actual and Bloomberg consensus are below the mean of the EIA actual. In addition, the mean of the surprises that are computed based on the combination forecast falls between the means of the surprises computed based on Bloomberg consensus and API actual.

$$
\text { [Insert Table } 1 \text { Here] }
$$

\subsection{Results and Discussion}

As mentioned above, we use the sequence of two very similar U.S. oil inventory announcements to examine the informational efficiency of energy markets. In this section, we discuss our results and relate them to the existing literature. Rousse and Sévi (2019) find a significant drift in the "correct" direction before the EIA oil inventory announcements. They attribute this drift potentially to leaked news. Gu and Kurov (2018) ascribe a similar drift before the EIA natural gas inventory announcements to superior forecasting. Consistent with these studies, Figure 2 shows a price drift in the oil futures before the EIA oil inventory announcements. Below, we provide evidence that processing mere public information explains much of this preannouncement drift. Figure 3 shows no evidence of statistically significant drift prior to the API oil inventory announcements, which is consistent with the API oil inventory surprises being less predictable compared to the EIA inventory news. ${ }^{22}$

[Insert Figures 2 and 3 Here]

\footnotetext{
${ }^{22}$ We use the Thomson Reuters survey as a proxy for market expectations for the API announcements because the results of this survey are usually released at about 2 pm ET on the announcement days (Ye and Karali, 2016). The cumulative average returns are very similar when we use the Bloomberg consensus as a proxy for market expectations.
} 


\subsubsection{Predicting Returns Before the EIA Inventory Announcements}

We begin by testing whether the information contained in the API inventory announcements is efficiently incorporated in oil futures prices. The efficient market hypothesis posits that prices reflect all public information. Therefore, earlier returns should not predict subsequent returns. Panel A of Table 2 shows that the 30-minute return of oil futures post-API release predicts the 60minute return of oil futures prior to the EIA oil inventory announcements. ${ }^{23}$ We find almost the same significant predictability of the oil futures returns in other time intervals before the EIA oil inventory announcements such as 30 and 90 minutes before the announcement. ${ }^{24}$ Figure 4 uses Welch and Goyal (2008) methodology to show significant out-of-sample predictive power of the post-API oil futures returns over the pre-EIA returns. ${ }^{25}$ These findings present an apparent violation of weak-form market efficiency. ${ }^{26}$ The information in the API announcements is not fully incorporated in the price immediately, perhaps because some traders delay trading on this information until right before the EIA announcement. ${ }^{27}$

A plausible explanation for the delayed incorporation of information released by the API could be attributed to the unique setting of our study. API oil inventory announcements are known to provide reliable estimates of the U.S. oil inventory level. However, the EIA announcements are more widely recognized and followed compared to the API announcements. Furthermore, WTI crude oil futures have a one-hour trading break starting at 5:00 pm ET, and when trading resumes at 6:00 pm the market liquidity is relatively low. These factors may contribute to delayed

\footnotetext{
${ }^{23}$ We choose 30-minute return of oil futures after the API announcement because these announcements are released at 4:30 pm ET and WTI oil futures do not trade from 5:00 pm to 6:00 pm ET.

${ }^{24}$ We use the 60-minutes interval before the EIA announcements to conduct our main analysis because it represents a midpoint between the other alternatives.

${ }^{25}$ An explanation of the Welch and Goyal (2008) method is provided in the Appendix.

${ }^{26}$ In a weak-form efficient market, past market data cannot be used to forecast future returns.

${ }^{27}$ We find no evidence of significant asymmetry in the predictability of the pre-EIA oil futures return. Specifically, the difference between positive post-API oil futures return and negative post-API oil futures return in predicting preEIA oil futures return is not statistically significant.
} 
incorporation of information in the API oil inventory announcements.

The Bloomberg consensus forecast of oil inventory changes is publicly available before the inventory announcements. However, this forecast is almost never updated after the API announcements. Since this forecast does not reflect the API oil inventory news, it is not an up-todate measure of market expectations at the time of the EIA oil inventory announcements. Hence, we construct a simple predictor computed as the difference between the API actual and the Bloomberg median consensus. The predictor represents a forecast of the surprise of the EIA oil inventory announcements, if one uses the widely followed Bloomberg consensus as a proxy for market expectations. Panel B of Table 2 and Figure 5 show that the predictor can predict the oil futures returns before the EIA announcements both in-sample and out-of-sample. These results provide further evidence of market inefficiencies as the predictor is based on public information. ${ }^{28}$

[Insert Table 2 and Figures 4 and 5 Here]

\subsubsection{Predictability of Inventory Surprises}

We further analyze whether the EIA inventory surprises can be predicted using the post-API oil futures return and our predictor. Following previous studies (e.g., Halova, Kurov, and Kucher, 2014), we compute the oil inventory surprises as the difference between the EIA actual and the Bloomberg median consensus divided by the level of inventory. Table 3 shows that both the postAPI oil future return and the predictor can predict the oil inventory surprises. Hence, the EIA oil inventory surprises are highly predictable by using public information, probably due to the fact that the Bloomberg forecasts of the EIA oil inventory changes are rarely updated after the API inventory releases. To address the potential autocorrelation in the EIA inventory surprises, we have

\footnotetext{
${ }^{28}$ As part of our robustness checks, we split the sample in two equal sub-samples and repeated the entire analysis of Table 2. The results in both subsamples are similar to those reported in the paper.
} 
included the lags of the surprises. ${ }^{29}$ Table 3 shows that this leaves our results essentially unchanged.

[Insert Table 3 Here]

\subsubsection{Market Conditions and Return Predictability}

Elaborating on our primary findings under different market conditions, Table 4 provides the results of our analysis during times with different levels of liquidity and oil attention. Liquidity plays a vital role in market efficiency. Green (2004) shows that price discovery surrounding the release of public announcements occurs through trading. Therefore, information will be incorporated into prices faster when the market is more liquid. Several recent studies show that sophisticated trading, such as high-frequency and algorithmic trading, enhances price discovery and liquidity (Brogaard et al., 2014; Hasbrouck and Saar, 2013). Accordingly, we expect that as liquidity increases in the market, predictability driven by market inefficiencies decreases. Consistent with this view, in Table 4, our results indicate that the predictive power of the post-API oil futures return for the preEIA oil return is significant only when the liquidity in the oil futures market is low.

Investor attention influences the efficiency of processing public information. Barber and Odean (2008) find that investors are more likely to purchase stocks that catch their attention. Vozlyublennaia (2014) and Dimpfl and Jank (2016), show a significant relation between investor attention measured by Google SVI and volatility in financial markets. Fink and Johann (2014) relate investor attention to different aspects of markets microstructure. They find that trading by all types of traders increases during high-attention days. Regression estimates in Table 4 show that return predictability before the EIA announcements is statistically significant only during periods of low attention. This indicates that the market processes the API inventory news faster when

\footnotetext{
${ }^{29}$ The optimal numbers of lags were determined using the Akaike information criterion.
} 
traders pay attention to oil. ${ }^{30}$

[Insert Table 4 Here]

\subsubsection{Return Predictability for Energy Stocks}

We also examine if a similar market inefficiency is present in energy stocks. Oil is a primary production input for energy firms. Therefore, changes in oil prices represent important fundamental information for energy companies. The regression estimates in Table 5 show that the 30-minute post-API crude oil futures return can be used to predict the returns of oil companies from the CRSP database on the day of the EIA oil inventory announcements. ${ }^{31}$ This suggests that opening prices of energy stocks do not fully incorporate information about oil inventory released after the previous stock market close.

We also use intraday data for the NYSE ARCA Oil and Gas Index to examine how long it takes for energy stocks to incorporate information contained in the API oil inventory announcements. Table 5 shows that energy stocks incorporate this information within the first ten minutes of the stock market opening. This predictability is no longer significant after the first ten minutes of trading. Our findings support the view that oil has predictive ability for stock returns. In addition, the 30-minute post-EIA oil futures return has no significant predictive power over the NYSE ARCA Oil and Gas Index return during the time interval from 11:00 am until the stock market close. ${ }^{32}$ Therefore, energy stocks seem to be efficiently incorporating oil-related fundamental information during the trading hours.

\section{[Insert Table 5 Here]}

\footnotetext{
${ }^{30}$ The correlation between the liquidity and oil attention measures in our sample is approximately 0.10 . This low correlation indicates that these two market conditions are different from each other.

${ }^{31}$ We identify oil companies using the following SIC codes: 1300, 1310-1319, 1320-1329, 1330-1339, 1370-1379, 1380-1382, 1389, 2900-2912, 2990-2999, 3533, 4612-4613, 5171-5172, 6792.

${ }^{32}$ These results are not tabulated for brevity but are available upon request.
} 


\subsubsection{Combination Forecast}

We want to explore how the choice of a proxy for market expectations influences the estimated impact of the EIA oil inventory surprises on the oil futures returns. Table 6 shows that when using the Bloomberg consensus forecast as the market expectations proxy yields an estimated OLS response coefficient of -0.24 and an $R^{2}$ of $9 \%$. In contrast, computing the EIA oil inventory surprises as the difference between the EIA and API actual announced values produces an estimated market response coefficient of -0.42 and an $R^{2}$ of $18 \% .{ }^{33}$ This validates the importance of using the information released by the API in measuring market expectations prior to the EIA announcements.

As mentioned above, the Bloomberg consensus forecast does not capture changes in market expectations after the API inventory announcements. However, this does not rule out the possibility that the Bloomberg consensus forecast contains information not captured by the API actual. Regression estimates in Table 7 show that both the Bloomberg median forecast and the API actual are useful predictors of the weekly EIA inventory change. Therefore, we employ a relative importance method to construct a combination forecast of the EIA oil inventory announcements by objectively allocating weights to the Bloomberg consensus forecast and the API actual. Grömping (2006) provides a discussion of this approach. The LMG method decomposes the $R^{2}$ of a multivariate regression into non-negative contributions of each independent variable. Furthermore, the LMG technique overcomes the potential problem that the contribution of each regressor depends on the order in which the regressors are added to the model. The LMG method achieves this by using simple averaging over all the possible orderings of the regressors. To describe the LMG approach, we use the same notations and steps as in Grömping (2006). For a set

\footnotetext{
${ }^{33}$ To compute the surprises, we scale the unexpected inventory changes by the level of inventory as in Halova, Kurov and Kucher (2014).
} 
$S$ that consist of all regressors in the model, the $R^{2}$ can be expressed as:

$$
R^{2}(S)=\frac{\text { Model } S S(\text { model } \text { with regressors in } S)}{\text { Total } S S}
$$

Once we add an additional regressor that is in set $M$ to the previous set $S$, the additional $R^{2}$ can be computed as follows:

$$
\operatorname{seq}^{2}(M \mid S)=R^{2}(M \cup S)-R^{2}(S)
$$

The number of possible orderings is the permutation of the chosen regressors $x_{1}, \ldots, x_{p}$ which are denoted by the tuple of indices $r=\left(r_{1}, \ldots, r_{p}\right)$. The model is assumed to include multiple regressors, $S_{k}(r)$, before the regressor $x_{k}$. The part of the $R^{2}$ allocated to the regressor $x_{k}$ can be formulated as:

$$
\operatorname{seqR}^{2}\left(\left\{x_{k}\right\} \mid S_{k}(r)\right)=R^{2}\left(\left\{x_{k}\right\} \cup S_{k}(r)\right)-R^{2}\left(S_{k}(r)\right)
$$

Finally, from equation (3) we can get the LMG metric as follows:

$$
\operatorname{LMG}\left(x_{k}\right)=\frac{1}{p !} \sum_{r \text { permutation }} \operatorname{seq}^{2}\left(\left\{x_{k}\right\} \mid r\right)
$$

Table 6 shows that using the combination forecast as a proxy for market expectations increases the $R^{2}$ of the energy announcement impact on oil futures return by approximately $130 \%$ compared to the Bloomberg median consensus, and by approximately $17 \%$ compared to the API actual. Hence, using the combination forecast to compute the oil inventory surprises reduces measurement errors that could stem from the use of a single proxy for market expectations. ${ }^{34}$ To analyze the effect of such measurement errors of the estimated market response coefficients, we conduct an analysis using the Identification Through Censoring (ITC) technique proposed by Rigobon and Sack (2008). ${ }^{35}$ Regressors are often measured with error. It is well known that this

\footnotetext{
${ }^{34}$ We have explored other proxies for market expectations including the Bloomberg top-ranked analyst forecast. We used the Bloomberg consensus in weeks with missing top-ranked analyst forecast. The results are almost the same as those obtained using the Bloomberg consensus to measure market expectations before the EIA announcements.

${ }^{35}$ A more detailed description of the identification-through-censoring (ITC) technique is provided in the Appendix.
} 
measurement error induces a downward bias in the regression coefficients estimated with common techniques. The ITC methodology adjusts for such attenuation bias. Measurement errors in oil inventory surprises are driven by two factors. First, any proxy for expectations that does not incorporate all available information. Second, the EIA surveys do not cover the entire population of oil companies.

The ITC estimates of the market response coefficients are reported in Table 6. For all three measures of market expectations, the ITC estimates are close to -2. These estimates are much larger in absolute value than the corresponding OLS and robust regression estimates reported in the same table. These estimates are also about twice as large as the ITC estimate of the oil futures market response to crude oil inventory news reported in Halova, Kurov, and Kucher (2014). The larger ITC coefficient estimates in our study could reflect the rising importance of the U.S. in the energy markets. Due to the increased production of shale oil, the U.S. has become one of the largest oil producers in the world. Table 6 also shows that when we use the combination forecast as a measure of market expectations, the OLS estimate of the market response coefficient is closer to the estimates produced by the ITC technique compared to the OLS estimates based on either the Bloomberg median consensus or the API actual. Although the estimated proportion of the measured inventory surprise due to noise is quite large for all three measures of market expectations, it is smaller for the surprise based on the combination forecast compared to the surprises based on the other two expectation proxies. These results provide evidence that using the combination forecast to compute oil inventory surprises reduces measurement errors that stem from the use of a single stale proxy for market expectations.

[Insert Tables 6 and 7 Here] 


\subsubsection{Economic Significance}

To examine if oil futures return predictability before the EIA oil inventory announcements can be used for profitable trading, we propose a simple trading strategy based on our predictor, computed as the difference between the API actual announced value of inventory change and the Bloomberg consensus forecast. The strategy involves selling (buying) oil futures contracts 60 minutes before the EIA announcements and closing the position 1 minute before the EIA announcement if the predictor is positive (negative). Table 8 shows that this trading strategy generates an approximate annualized Sharpe ratio of 0.67 in the full sample, and an annualized Sharpe ratio of 2.1 when the predictor has large values. ${ }^{36} \mathrm{We}$ assume traders would open a futures position 60 minutes before the EIA announcements to be consistent with the other analyses in our study. Table 8 shows that this trading strategy generates substantial Sharpe ratios if it involves establishing a position 90 or 120 minutes before the EIA announcements.

\section{[Insert Table 8 Here]}

\subsection{Conclusion}

This paper uses sequential energy announcements to examine how futures and equity markets process information. We find that the oil futures return after the weekly inventory releases by the American Petroleum Institute (API) predicts the oil futures return before the U.S. Energy Information Administration (EIA) announcements on the following day. This predictability is statistically significant during periods of low liquidity and low attention to oil. Additionally, we find that the API actual and Bloomberg consensus forecasts are both useful in forecasting the change in oil inventory released by the EIA. We construct a predictor computed as the difference between the API actual and the Bloomberg median consensus. The predictor has significant

\footnotetext{
${ }^{36}$ The large values of the predictor are those in the top and bottom deciles.
} 
explanatory power for oil futures returns before the EIA announcements both in-sample and outof-sample. A simple trading strategy using large values of the predictor to generate trading signals would generate an annualized Sharpe ratio of 2.1 .

We develop a combination forecast based on the API actual and the Bloomberg median consensus to forecast the EIA oil announcements. The combination forecast increases the $R^{2}$ of the regression of oil futures returns on energy surprises by approximately $130 \%$ compared to the Bloomberg median consensus used in prior studies. Overall, our results show that asset prices do not instantaneously reflect new public information even in the case of widely anticipated scheduled announcements. Our results are useful for traders. Policymakers tasked with facilitating efficient price discovery in energy futures markets may also benefit from our study. For example, our results suggest that public announcements are more likely to be incorporated immediately into asset prices if they are released during regular trading hours. Furthermore, more media coverage of these releases would increase investor attention, which would facilitate quicker incorporation of new information into the prices. 


\section{Table 1: Summary Statistics}

This table reports summary statistics for the main variables used in the analysis. The EIA actual, API actual, combination forecast, and Bloomberg median consensus are in thousands of barrels. The predictor is computed as the difference between the API Actual and the Bloomberg median consensus divided by the level of inventory. The combination forecast is computed as the weighted average of the Bloomberg median consensus and the API actual, with the weights computed using the relative importance methodology described in Section 4. Post-API Return is the oil futures return in the 30 minutes after the API announcement. Surprise ${ }^{\text {Bloomberg }}$ is the oil inventory surprise computed based on the Bloomberg consensus, Surprise ${ }^{\mathrm{API}}$ is the oil inventory surprise computed

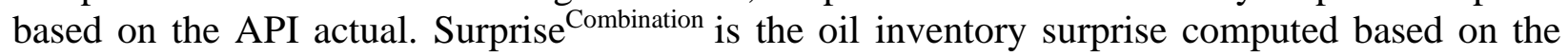
combination forecast. The inventory surprises are expressed in percentage and computed as the difference between the EIA actual and the corresponding market expectations proxy divided by the inventory level. The sample period is from January 2011 to August 2019 and contains 385 announcements.

\begin{tabular}{cccccc}
\hline Variable & $\mathrm{N}$ & Mean & St. Deviation & Minimum & Maximum \\
\hline EIA Actual & 385 & 307.81 & 4588.46 & -12788 & 14400 \\
API Actual & 385 & 191.11 & 4614.72 & -12400 & 14200 \\
Predictor & 385 & -0.01 & 1.02 & -3.34 & 2.86 \\
Combination Forecast & 385 & 199.38 & 3703.36 & -9560.56 & 13116.67 \\
Post-API Return & 385 & 0.003 & 0.51 & -2.36 & 2.01 \\
Bloomberg Median Consensus & 385 & 178.74 & 2256.5 & -4261 & 2240 \\
Surprise & 385 & 0.025 & 0.98 & -2.80 & 2.75 \\
Surprise $^{\text {API }}$ & 385 & 0.031 & 0.76 & -1.99 & 2.06 \\
Surprise $^{\text {Combination }}$ & 385 & 0.026 & 0.70 & -2.31 & 1.88 \\
\hline
\end{tabular}




\section{Table 2: In-sample Predictability of Pre-EIA Oil Futures Returns}

Panel A reports estimates for the following model: $R_{t}^{E I A}=\alpha+\beta_{1} R_{t-1}^{A P I}+\varepsilon_{t}$, where $R_{t}^{E I A}$ is the oil futures return from $60 \mathrm{~min}$ before to $1 \mathrm{~min}$ before the EIA announcement and $R_{t-1}^{A P I}$ is the oil futures return in the 30 minutes after the API announcement. Panel B reports estimates for the following model: $R_{t}^{E I A}=\alpha+\beta_{1} P_{t}+\varepsilon_{t}$, where $P_{t}$ is computed as the difference between the API Actual and the Bloomberg median consensus divided by the level of inventory. Panel $\mathrm{C}$ reports the estimates for the following model: $R_{t}^{E I A}=\alpha+\beta_{1} R_{t-1}^{A P I}+\beta_{2} P_{t}+\varepsilon_{t}$. The sample period is from January 2011 to August 2019 and contains 385 announcements. The regressions are estimated using (1) OLS with the White (1980) heteroskedasticity consistent covariance matrix and (2) Yohai (1987) MM weighted least squares procedure robust to outliers. Standard errors are shown in parentheses. $*, * *$, and $* * *$ indicate statistical significance at $10 \%, 5 \%$, and $1 \%$ levels, respectively.

\begin{tabular}{|c|c|c|}
\hline Panel A & \multicolumn{2}{|c|}{ Post-API Return } \\
\hline \multirow[b]{2}{*}{ Slope } & OLS & Robust Regression \\
\hline & $\begin{array}{c}0.17^{* * *} \\
(0.04)\end{array}$ & $\begin{array}{c}0.14^{* * *} \\
(0.05)\end{array}$ \\
\hline \multirow[t]{2}{*}{ Intercept } & 0.002 & -0.01 \\
\hline & $(0.02)$ & $(0.02)$ \\
\hline $\mathrm{R}^{2}$ & 0.04 & 0.02 \\
\hline \multirow[t]{2}{*}{ Panel B } & \multicolumn{2}{|c|}{ Predictor } \\
\hline & OLS & Robust Regression \\
\hline \multirow[t]{2}{*}{ Slope } & $-0.06^{* * *}$ & $-0.05^{* *}$ \\
\hline & $(0.023)$ & $(0.02)$ \\
\hline \multirow[t]{2}{*}{ Intercept } & -0.0002 & -0.01 \\
\hline & $(0.02)$ & $(0.02)$ \\
\hline $\mathrm{R}^{2}$ & 0.02 & 0.01 \\
\hline \multirow[t]{2}{*}{ Panel C } & \multicolumn{2}{|c|}{ Post-API Return and Predictor } \\
\hline & OLS & Robust Regression \\
\hline \multirow[t]{2}{*}{ Post-API Return } & $0.16^{* * *}$ & $0.13^{* *}$ \\
\hline & $(0.06)$ & $(0.05)$ \\
\hline \multirow[t]{2}{*}{ Predictor } & -0.02 & -0.01 \\
\hline & $(0.03)$ & $(0.03)$ \\
\hline \multirow[t]{2}{*}{ Intercept } & 0.0001 & -0.01 \\
\hline & $(0.02)$ & $(0.02)$ \\
\hline $\mathrm{R}^{2}$ & 0.04 & 0.02 \\
\hline
\end{tabular}




\section{Table 3: Predictability of Oil Inventory Surprises}

Panel A reports the estimates for the following model: $S_{t}=\alpha+\beta_{1} R_{t-1}^{A P I}+\sum_{n=1}^{L} \beta_{n} S_{t-n}+\varepsilon_{t}$, where $S_{t}$ is the EIA oil inventory surprise for day $t$ and $R_{t-1}^{A P I}$ is the return of the oil future contracts in the 30 minutes after the API announcement. Panel B reports the estimates for the following model: $S_{t}=\alpha+\beta_{1} P_{t}+\sum_{n=1}^{L} \beta_{n} S_{t-n}+\varepsilon_{t}$, where $P_{t}$ is computed as the difference between the API Actual and the Bloomberg median consensus divided by the level of inventory. $S_{t}$ is computed as the difference between the EIA oil inventory change and Bloomberg median consensus divided by the level of inventory. The optimal number of lags was determined using the Akaike information criterion. The sample period is from January 2011 to August 2019 and contains 385 announcements. The regressions are estimated using OLS with the White (1980) heteroskedasticity consistent covariance matrix. Standard errors are shown in parentheses. *, **, and $* * *$ indicate statistical significance at $10 \%, 5 \%$, and $1 \%$ levels, respectively.

\begin{tabular}{ccc}
\hline Panel A & Without Lags of Surprise & $\mathrm{L}=1$ \\
\hline Intercept & 0.03 & 0.02 \\
Post-API Return & $(0.04)$ & $(0.04)$ \\
& $-0.92^{* * *}$ & $-0.95^{* * *}$ \\
$\mathrm{R}^{2}$ & $(0.09)$ & $(0.09)$ \\
Panel B & 0.23 & 0.24 \\
\hline Intercept & Without Lags of Surprise & $\mathrm{L}=2$ \\
\hline \multirow{2}{*}{ Predictor } & 0.03 & 0.03 \\
& $(0.035)$ & $(0.035)$ \\
$\mathrm{R}^{2}$ & $0.68^{* * *}$ & $0.69^{* * *}$ \\
& $(0.03)$ & $(0.035)$ \\
\end{tabular}




\section{Table 4: Predictability of Pre-EIA Oil Futures Return under Different Market Conditions}

This table reports estimates for the following model: $R_{t}^{E I A}=\alpha+\beta_{1} R_{t-1}^{A P I}+\varepsilon_{t}$ where $R_{t}^{E I A}$ is the oil futures return from $60 \mathrm{~min}$ before to $1 \mathrm{~min}$ before the EIA announcement, $R_{t-1}^{A P I}$ is the oil futures return in the 30 minutes after the API announcement. We split the sample into high and low for each of the following market conditions: liquidity and SVI oil attention. High is defined as above the median and low is defined as below the median. The sample period is from January 2011 to August 2019 and contains 385 announcements. The regressions are estimated using OLS with the White (1980) heteroskedasticity consistent covariance matrix. Standard errors are shown in parentheses. *, **, and $* * *$ indicate statistical significance at $10 \%, 5 \%$, and $1 \%$ levels, respectively.

\begin{tabular}{ccccc}
\hline & \multicolumn{2}{c}{ Liquidity } & \multicolumn{2}{c}{ Oil Attention } \\
\hline \multirow{3}{*}{ Post-API Return } & Low & High & Low & High \\
\cline { 2 - 5 } & $0.20^{* * *}$ & 0.10 & $0.22^{* * *}$ & 0.10 \\
Intercept & $(0.07)$ & $(0.07)$ & $(0.05)$ & $(0.086)$ \\
& 0.01 & -0.01 & -0.01 & 0.03 \\
$\mathrm{R}^{2}$ & $(0.04)$ & $(0.03)$ & $(0.02)$ & $(0.05)$ \\
& 0.05 & 0.01 & 0.06 & 0.01 \\
\hline
\end{tabular}




\section{Table 5: Predicting Returns of Energy Stocks}

The first column reports estimates for the following model: $R_{t}^{C R S P}=\alpha+\beta_{1} R_{t-1}^{A P I}+\varepsilon_{t}$, where $R_{t}^{C R S P}$ is the full day return of all oil companies in the CRSP database on the days of the EIA announcements and $R_{t-1}^{A P I}$ is the oil futures return in the 30 minutes after the API announcement. The second and third columns report estimates for the following model: $R_{t}^{N Y S E}=\alpha+\beta_{1} R_{t-1}^{A P I}+\varepsilon_{t}$, where $R_{t}^{N Y S E}$ is the return of the NYSE ARCA Oil and Gas Index on the days of the EIA announcements in the specified time window. The sample period for the estimation in the first column is from January 2011 to December 2018 and contains 354 announcements. The sample period for the estimations in columns 2 and 3 is from January 2011 to August 2019 and contains 385 announcements. The regressions are estimated using OLS with the White (1980) heteroskedasticity consistent covariance matrix. Standard errors are shown in parentheses. *, **, and $* * *$ indicate statistical significance at $10 \%, 5 \%$, and $1 \%$ levels, respectively.

\begin{tabular}{cc|cc}
\hline & CRSP Oil Companies & \multicolumn{2}{c}{ NYSE ARCA Oil and Gas Index } \\
\cline { 2 - 4 } Time Interval & Open - Close & $9: 30 \mathrm{am}-9: 40 \mathrm{am}$ & $9: 40 \mathrm{am}-$ Close \\
\cline { 2 - 4 } Slope & $0.28^{* * *}$ & $0.13^{* * *}$ & 0.13 \\
& $(0.01)$ & $(0.04)$ & $(0.11)$ \\
Intercept & $-0.09^{* * *}$ & -0.01 & -0.03 \\
& $(0.01)$ & $(0.02)$ & $(0.056)$ \\
$\mathrm{R}^{2}$ & 0.01 & 0.026 & 0.003 \\
\hline
\end{tabular}




\section{Table 6: Response of Oil Futures Prices to Oil Inventory Announcements}

This table reports estimates for the following model: $R_{t}=\alpha+\beta_{1} S_{t}+\varepsilon_{t}$, where $R_{t}$ is the oil futures return from 5 minutes before to 10 minutes after the EIA announcement and $S_{t}$ is the oil inventory surprise. The inventory surprise is computed as the difference between the EIA actual and a market expectation proxy, divided by the inventory level. The Bloomberg consensus forecast, the API actual, and the combination forecast are used to proxy for market expectations in columns (1), (2), and (3), respectively. The combination forecast is computed using the relative importance method proposed by Lindeman, Merenda, and Gold (1981). The inventory surprises are expressed in percentage terms. The regressions are estimated using (1) OLS with the White (1980) heteroskedasticity consistent covariance matrix and (2) Yohai (1987) MM weighted least squares procedure robust to outliers and (3) the identification-through-censoring (ITC) technique proposed by Rigobon and Sack (2008). The sample period is from January 2011 to August 2019 and contains 385 announcements. Standard errors are shown in parentheses. *, **, and *** indicate statistical significance at $10 \%, 5 \%$, and $1 \%$ levels, respectively.

\begin{tabular}{cccc}
\hline & $(1)$ & $(2)$ & $(3)$ \\
& Bloomberg & API & Combination Forecast \\
\cline { 2 - 4 } Slope & $-0.24^{* * *}$ & $-0.42^{* * * *}$ & $-0.49^{* * * *}$ \\
& $(0.04)$ & $(0.05)$ & $(0.05)$ \\
$R^{2}$ & 0.09 & 0.18 & 0.21 \\
\hline \multirow{2}{*}{ Slope } & $-0.16^{* * *}$ & Robust Regression \\
& $(0.03)$ & $-0.25^{* * *}$ & $-0.31^{* * * *}$ \\
$R^{2}$ & 0.06 & $(0.03)$ & $(0.03)$ \\
Slope & \multicolumn{3}{c}{ Identification-Through-Censoring (ITC) } \\
\cline { 2 - 4 } & $-2.03^{* * *}$ & $-1.89^{* * *}$ & $-1.89^{* * *}$ \\
Pseudo- $R^{2}$ & $(0.43)$ & $(0.24)$ & $0.26)$ \\
Proportion of measured & 0.97 & 0.95 & 0.94 \\
surprise due to noise & $88 \%$ & $78 \%$ & $74 \%$ \\
\hline
\end{tabular}




\section{Table 7: Predicting the EIA Announcements using the Bloomberg Consensus and API Actual}

This table reports estimates for the following model EIA Actual $=\alpha+\beta_{1} B C+\beta_{2} A P+\varepsilon_{t}$, where EIA actual is the weekly released EIA oil inventory change, BC is the Bloomberg median consensus, and AP is the API actual. The regressions are estimated using (1) OLS with the White (1980) heteroskedasticity consistent covariance matrix and (2) Yohai (1987) MM weighted least squares procedure robust to outliers. The sample period is from January 2011 to August 2019 and contains 385 announcements. Standard errors are shown in parentheses. *, **, and *** indicate statistical significance at $10 \%, 5 \%$, and $1 \%$ levels, respectively.

\begin{tabular}{ccc}
\hline & OLS & Robust Regression \\
\cline { 2 - 3 } Intercept $(\alpha)$ & 0.11 & -0.037 \\
& $(0.13)$ & $(0.14)$ \\
$\mathrm{BC}\left(\beta_{1}\right)$ & $0.38^{* * *}$ & $0.43^{* * *}$ \\
& $(0.07)$ & $(0.07)$ \\
$\mathrm{AP}\left(\beta_{2}\right)$ & $0.69^{* * *}$ & $0.69^{* * *}$ \\
& $(0.03)$ & $(0.04)$ \\
$R^{2}$ & 0.65 & 0.50 \\
\hline
\end{tabular}




\section{Table 8: Performance of Trading Strategy based on Predictor}

This table reports the annualized Sharpe ratio of the following trading strategy: selling (buying) oil futures contracts 60 or 90 or 120 minutes before the EIA announcements and closing the position 1 minute before the EIA announcement if the predictor is positive (negative). The predictor is computed as the API Actual minus the Bloomberg median consensus divided by the level of inventory. The large values of the predictor are defined as the upper and lower deciles. The Sharpe ratio is computed by dividing the sample mean return by the sample standard deviation. The annualized Sharpe ratio is computed based on per-event Sharpe ratio times the square root of the average number of events per year. The sample period is from January 2011 to August 2019 and contains 385 announcements.

\begin{tabular}{ccc}
\hline Window & Full Sample $(\mathrm{N}=385)$ & Large Values $(\mathrm{N}=77)$ \\
\hline$(-60 \mathrm{~min},-1 \mathrm{~min})$ & 0.67 & 2.1 \\
$(-90 \mathrm{~min},-1 \mathrm{~min})$ & 0.62 & 1.05 \\
$(-120 \mathrm{~min},-1 \mathrm{~min})$ & 0.54 & 1.19 \\
\hline
\end{tabular}




\section{Figure 1: Weights Allocated to the API Actual in the Combination Forecast}

This figure shows the weights allocated to API actuals in constructing the combination forecast based on the relative importance method proposed by Lindeman, Merenda, and Gold (1981) and estimated separately for each year. The remaining weight in the combination forecast is allocated to the Bloomberg consensus forecast. The period is from January 2011 to August 2019 and contains 385 announcements.

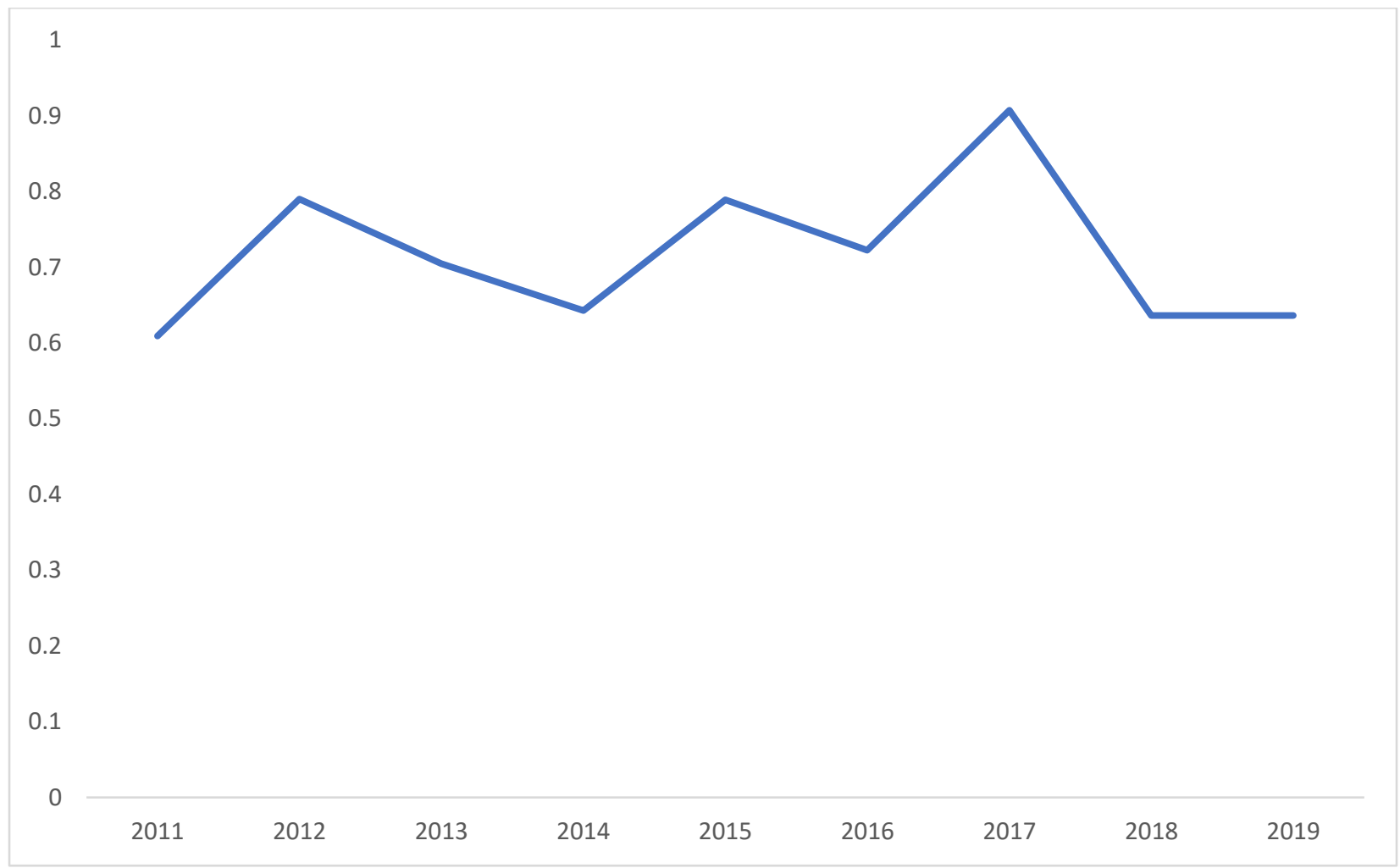




\section{Figure 2: Cumulative Average Return of Oil Futures before EIA Oil Announcements}

This figure shows the cumulative average return (CAR) of the nearby oil futures contract around the releases of the weekly Oil Storage Report. In order to aggregate CARs for positive and negative surprises, we invert the sign of returns for positive surprises as in Bernile, Hu, and Tang (2016). The inventory surprise is computed as the difference between the EIA actual and the Bloomberg median consensus, divided by the inventory level. Only observations with inventory surprises in the top and bottom deciles are used. The sample period is from January 2011 to August 2019 and contains 77 announcements.

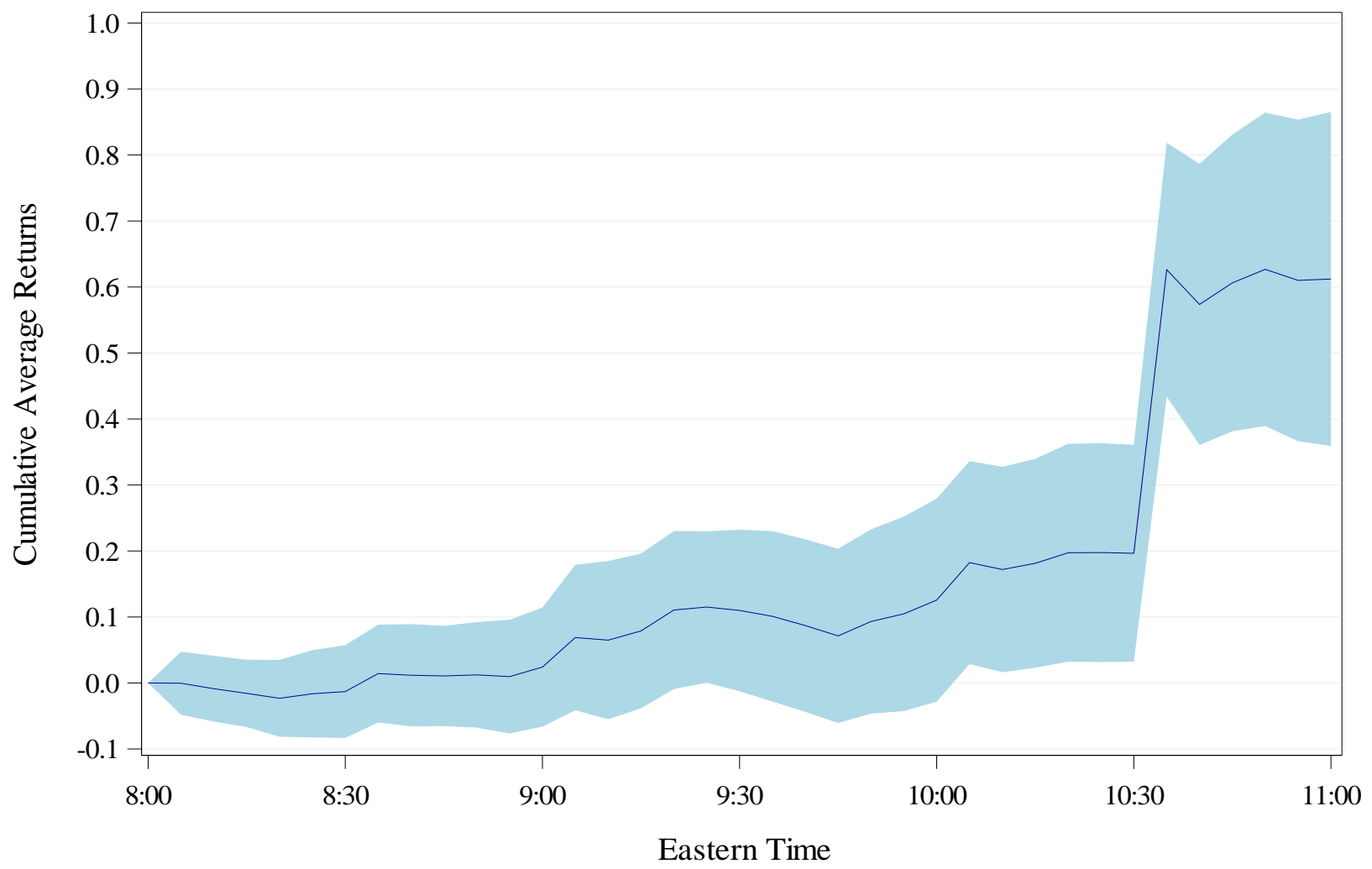




\section{Figure 3: Cumulative Average Return of Oil Futures before API Oil Announcements}

This figure shows the cumulative average return (CAR) of the nearby oil futures contract around the releases of the weekly American Petroleum Institute (API). In order to aggregate CARs for positive and negative surprises, we invert the sign of returns for positive surprises as in Bernile, $\mathrm{Hu}$, and Tang (2016). The inventory surprise is computed as the difference between the API actual and the Thomson Reuters survey, divided by the inventory level. Only observations with inventory surprises in the top and bottom deciles are used. The sample period is from January 2011 to August 2019 and contains 77 announcements.

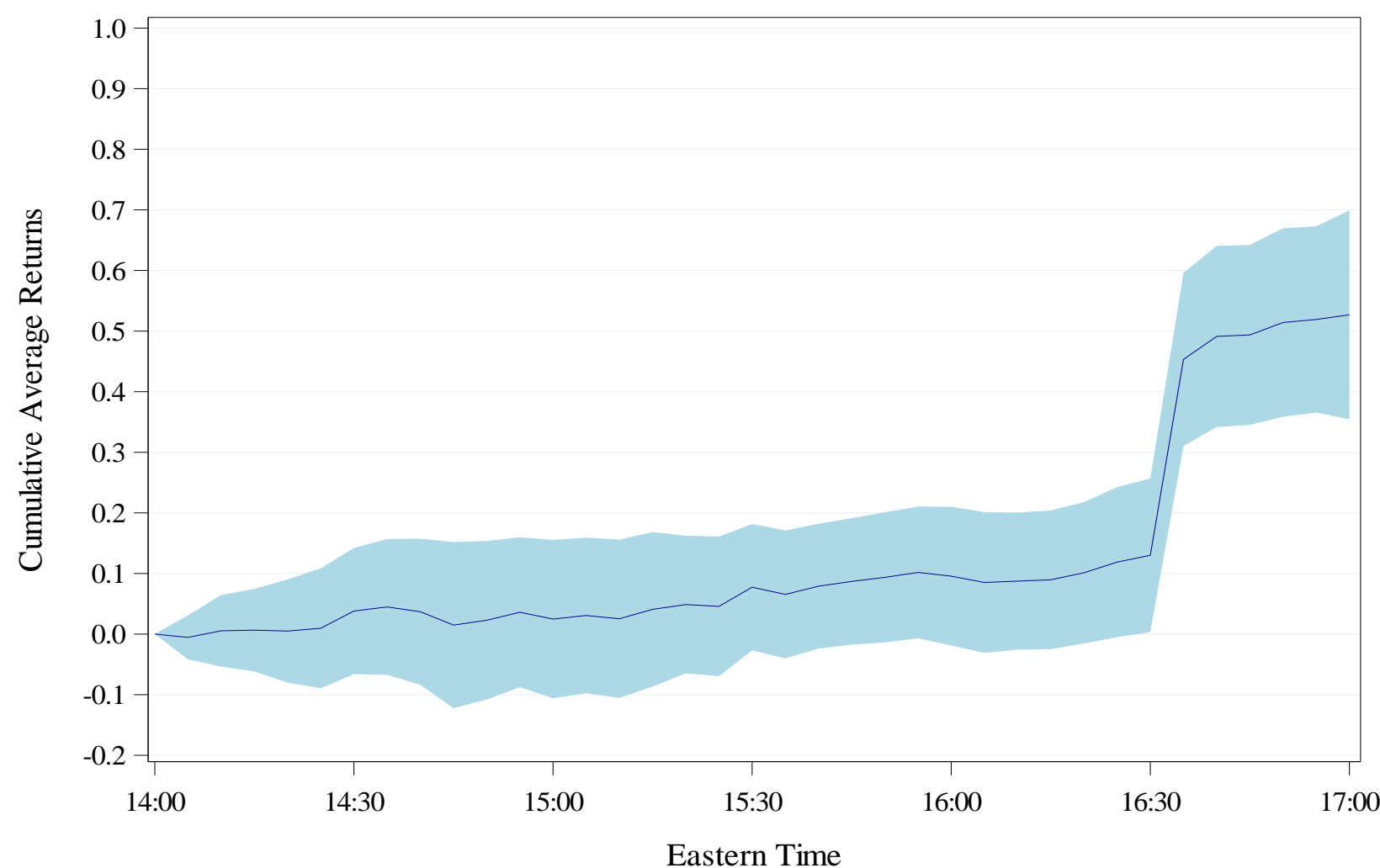


Figure 4: Out-of-Sample Predictability of Pre-EIA Oil Futures Returns using Post-API Oil Futures Returns

This figure plots out-of-sample (OOS) performance of a weekly predictive regression using the methodology proposed by (Welch and Goyal 2008b). Particularly, these are the cumulative squared predictions errors of the NULL minus the cumulative squared prediction errors of the alternative. The alternative model is $R_{t}^{E I A}=\alpha_{t}+\beta_{1} R_{t-1}^{A P I}+\varepsilon_{t}$, where $R_{t}^{E I A}$ is the oil futures return from 60 minutes before to 1 minute before the EIA announcement, $R_{t-1}^{A P I}$ is the oil futures return in the 30 minutes after the API announcement. The sample period is from January 2010 to August 2019 and contains 385 announcements. The NULL uses the recursively estimated mean of the preEIA oil futures return. An increasing line indicates better performance of the alternative model. A decreasing line indicates better performance of the NULL. The blue band represents the equivalent of a 95\% confidence interval and is constructed according to the MSE-T critical values from McCracken (2007).

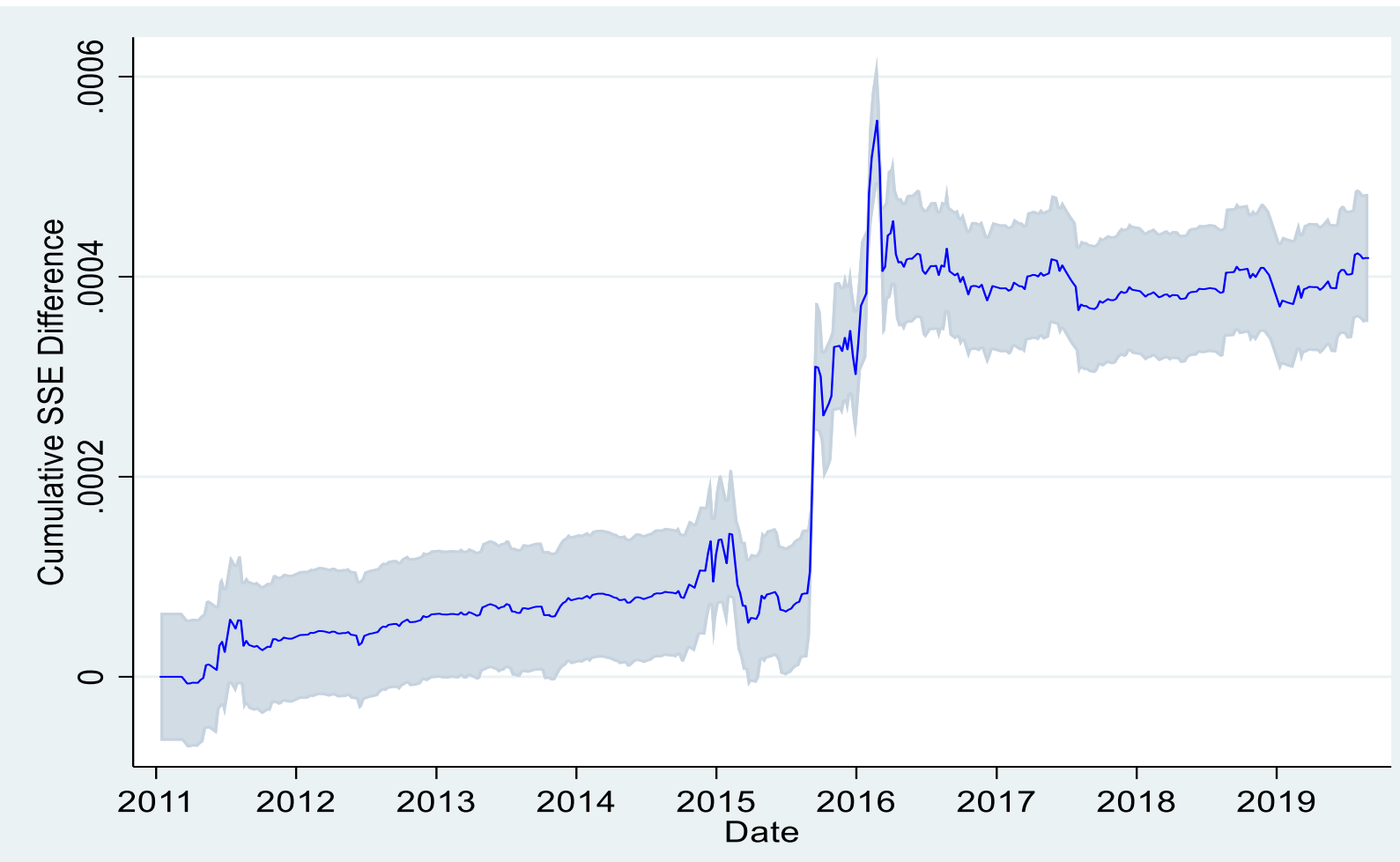


Figure 5: Out-of-Sample Predictability of Pre-EIA Oil Futures Returns using the Predictor

This figure plots out-of-sample (OOS) performance of a weekly predictive regression using the methodology proposed by (Welch and Goyal 2008b). Particularly, these are the cumulative squared predictions errors of the NULL minus the cumulative squared prediction errors of the alternative. The alternative model is $R_{t}^{E I A}=\alpha_{t}+\beta_{1} P_{t}+\varepsilon_{t}$, where $R_{t}^{E I A}$ is the oil futures return from 60 minutes before to 1 minute before the EIA announcement, and $P_{t}$ is computed as the difference between the API Actual and the Bloomberg median consensus divided by the level of inventory. The sample period is from January 2010 to August 2019 and contains 385 announcements. The NULL uses the recursively estimated mean of the pre-EIA oil futures return. An increasing line indicates better performance of the alternative model. A decreasing line indicates better performance of the NULL. The blue band represents the equivalent of a $95 \%$ confidence interval and is constructed according to the MSE-T critical values from McCracken (2007).

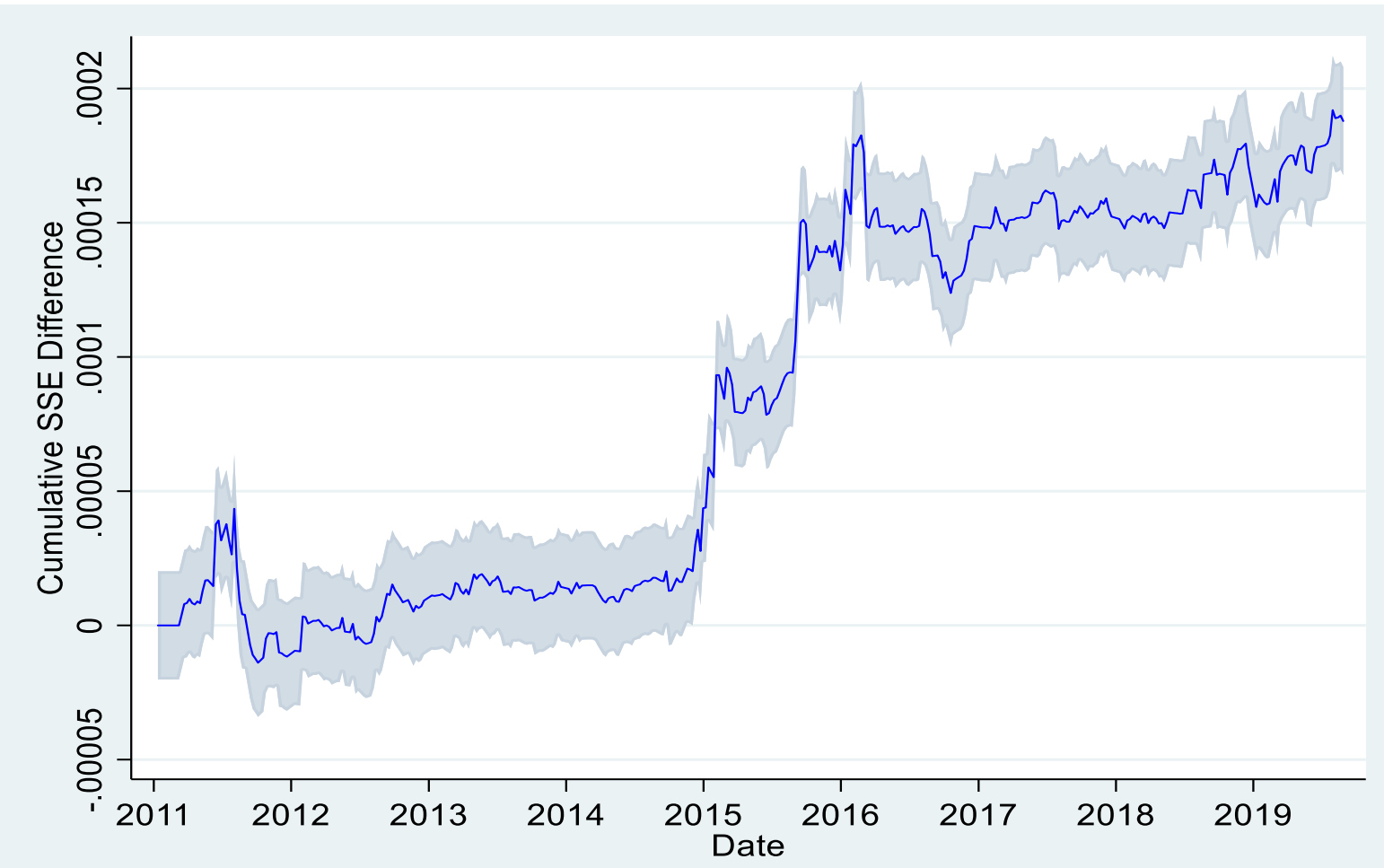




\section{Appendix A: Essay 2}

\section{Identification-Through-Censoring}

In a part of our analysis, we use the identification-through-censoring (ITC) technique proposed by Rigobon and Sack (2008). The ITC technique is employed to adjust for the bias that stems from measurement error in the inventory surprises. The measurement error could be due to two reasons. First, our measures of market expectations are imperfect, as they do not incorporate all relevant information available at the time of the announcement. Second, the actual released value of the inventory change is not precise, since it does not cover the entire population of oil companies. ${ }^{37}$ We use several proxies for market expectations, which helps to shed some light on the sources of measurement error in the inventory surprises. The effect of inventory news on oil futures can be estimated using the following simple regression model: ${ }^{38}$

$$
\begin{aligned}
& R_{t}=\gamma z_{t}+\varepsilon_{t} \\
& z_{t}=\Delta I_{t}-E_{t-\tau}\left[\Delta I_{t}\right]
\end{aligned}
$$

where $R_{t}$ is the oil futures return computed in the specific intraday window around the announcement, $z_{t}$ is the inventory surprise calculated as the difference between the actual change of inventory level, $\Delta I_{t}$, and the proxy for the market expectations of that inventory change, $E_{t-\tau}\left[\Delta I_{t}\right]$. As mentioned above, $z_{t}$ is measured with error. Therefore, it can be represented as:

$$
z_{t}=z_{t}^{*}+\delta_{t}
$$

where $\delta_{t}$ is the measurement error and $z_{t}^{*}$ is the "true" inventory surprise. In a regular OLS estimation, the impact of inventory surprises on returns is represented as follows:

\footnotetext{
${ }^{37}$ The EIA oil inventory survey usually covers about $90 \%$ of the population of oil companies, which leaves about $10 \%$ not surveyed. This may cause some noise in the estimates of the change in oil inventory. This issue is discussed at https://www.api.org/products-and-services/statistics/api-weekly-statistical-bulletin.

${ }^{38}$ For a more detailed discussion of the ITC technique in the context of energy inventory announcements, see Halova et al. (2014).
} 


$$
\begin{aligned}
& R_{t}=\gamma z_{t}+v_{t}, \\
& v_{t}=\varepsilon_{t}-\gamma \delta_{t} .
\end{aligned}
$$

However, the coefficient $\gamma$ is biased since the regressor is correlated with error term. We can express the OLS estimate of the response coefficient as:

$$
\hat{\gamma}_{O L S}=\gamma\left(1-\frac{\sigma_{\delta}^{2}}{\sigma_{z^{*}}^{2}+\sigma_{\delta}^{2}}\right)
$$

This means that the OLS estimator is biased downwards. Rigobon and Sack (2008) argue that dealing with the measurement error bias presents an identification problem. They suggest this problem can be solved by noting that the measurement error is "censored" in periods with no announcements. In such periods both the "true" inventory surprise $z_{t}^{*}$ and the measurement error $\delta_{t}$ are zero. Using returns in the same intraday interval on the day before the announcement, $R_{t-1}$, the model parameters can be estimated using the generalized method of moments (GMM) based on the following set of moment conditions:

$$
\begin{gathered}
\operatorname{var}\left(R_{t-1}\right)=\sigma_{\varepsilon}^{2}, \\
\operatorname{var}\left(R_{t}\right)=\gamma^{2} \sigma_{z^{*}}^{2}+\sigma_{\varepsilon}^{2}, \\
\operatorname{var}\left(z_{t}\right)=\sigma_{z^{*}}^{2}+\sigma_{\delta}^{2} \\
\operatorname{cov}\left(R_{t}, z_{t}\right)=\gamma^{2} \sigma_{z^{*}}^{2}
\end{gathered}
$$

Solving these equations produces the following estimator of the market response coefficient:

$$
\gamma=\frac{\operatorname{var}\left(R_{t}\right)-\operatorname{var}\left(R_{t-1}\right)}{\operatorname{cov}\left(R_{t}, z_{t}\right)}
$$

For returns on non-announcement days, we use the same intraday interval (from 10:25 am to $10: 40 \mathrm{am}$ ) as the interval used to measure the returns around the announcement.

We compute the following pseudo- $R^{2}$ statistic to compare the explanatory power of the 
ITC estimation with that of the OLS:

$$
\text { pseudo- } R^{2}=1-\frac{\sigma_{\varepsilon}^{2}}{\operatorname{var}\left(R_{t}\right)}
$$

Intuitively, the pseudo- $R^{2}$ captures the fraction of return variance described by the model. We estimate the variance of the structural shocks $\varepsilon_{t}$ using non-announcement returns. Therefore, equation (A.7) assumes that inventory surprises fully explain the post-announcement increase in the variance of returns.

\section{Out-of-Sample Forecasting}

Several studies show that the predictors that seem to perform well in-sample may lose their predictive power out-of-sample (e.g., Welch and Goyal 2008). Hence, we conduct an out-ofsample predictability analysis for our main empirical findings. We use the same methodology as in Welch and Goyal (2008). The benchmark model (Null) is the recursively estimated mean of the pre-EIA oil futures return. Subsequently, we compare the benchmark model with the following alternative predictive regression:

$$
Y_{t}=\alpha_{0}+\alpha_{1} X_{t-1}+\varepsilon_{t}
$$

where $X_{t-1}$ is either the post-API oil futures return or the predictor, which is computed as the difference between the API actual and the Bloomberg consensus forecast divided by the level of inventory. The performance of the predictive regression is evaluated by computing the difference between the cumulative squared predictions errors of the Null and the cumulative squared prediction errors of the Alternative. If this difference is positive, it means the Alternative performs better than the Null, and if it is negative it means the Null has better predictive ability than the Alternative. 


\section{Essay 3. The Impact of Oil Shocks on Sovereign Default Risk*}

\subsection{Introduction}

The significant influence of oil on the performance of domestic and global markets is well documented in the literature (see, for e.g., Nandha and Faff, 2008; Ready, 2018; Sim and Zhou, 2015; You, Guo, Zhu and Tang, 2017). Hamilton (2008) finds that the price of oil is one of the essential factors that triggered each recession since World War II. In a similar vein, Kilian and Park (2009); Kilian (2008, 2009); and Ready (2018), show the substantial impact of both oil supply and demand shocks on several economies and financial markets. Governments usually try to offset the influence of oil shocks using multiple channels, such as monetary policy, fiscal policy, trading policies, among others (Hamilton and Herrera, 2004; Kilian and Lewis, 2011). However, the solvency of these governments could be adversely affected, which raises concerns about their debt default risk (Chuffart and Hooper, 2019; Shahzad, Naifar, Hammoudeh, and Roubaud, 2017). In this paper, we investigate the impact of daily oil shocks on changes in the spreads of sovereign credit default swaps (CDS).

There are several ways in which the price of oil can affect economies, and in particular the solvency of governments. For oil-importing and oil-exporting countries, the solvency of governments could be mainly influenced through changes in their current and future potential tax revenue, and through changes in the perception of their solvency risk. In the case of oil-importing

\footnotetext{
* This essay is based on a paper coauthored with Ann Marie Hibbert.
} 
countries, oil shocks affect governments' tax revenue through several channels. Volatility and changes in the price of oil have pronounced effects on the cost of production and inflation, which in turn, influences governments' tax revenue as taxable income for both firms and individuals is affected (Cologni and Manera, 2008; Thoresen, 1982). Moreover, an increase in oil price can adversely impact the productivity of firms, and the potential output at any given level of capital for countries (Cunado and Perez De Gracia, 2005). Additionally, fluctuation in oil prices may increase economic uncertainty, leading to a decrease in irreversible corporate investments and foreign direct investments, which will potentially impact governments' tax revenue (Clark, 1996). In the case of oil-exporting countries, changes in oil prices will have a substantial impact on export revenues, fiscal balances, and government expenditure (Chuffart and Hooper, 2019). Hence, the sustainability of public finances and the financial soundness of oil exporters would change with oil shocks, which in turn affect the cost of insuring against default on sovereign debt. Finally, one would expect the perception of solvency risk to be altered for both oil-importing and oil-exporting countries since oil shocks have a significant impact on economies and financial markets (Kilian and Park, 2009; Kilian, 2009; Ready, 2018).

Our main objective is to comprehensively analyze the impact of oil shocks on the perceived default risk of major oil-exporting and importing countries. Ready (2018) proposes a model to classify oil shocks. One benefit of this classification system is that it allows us to disentangle the oil supply and demand shocks at a higher frequency (daily) than was previously possible. We employ this classification and investigate the respective impact of supply and demand shocks on sovereign default risk, as proxied by changes in their CDS spreads. We hypothesize that how each type of shock affects a country's default risk will depend on whether the country is a major oil importer or exporter. For example, a demand shock would most likely have a direct impact on the 
economies of oil exporters but an indirect impact, (i.e via prices) on the economies of major oil importers. Conversely, a supply shock would more likely have an immediate (delayed) impact on net oil exporters (importers).

In line with our main hypothesis, we first investigate the impact of oil supply and demand shocks on changes in the sovereign CDS spreads of (i) major oil-importing countries as proxied by a sample of G10 countries, and (ii) a sample of major oil-exporting countries. Since prior studies find that the determinants of sovereign CDS spreads vary across the conditional distribution of spread changes (Hibbert and Pavlova, 2017; Shahzad, Naifar, Hammoudeh, and Roubaud, 2017), we also investigate whether the impact of oil shocks varies across the quantiles of spread changes.

A number of prior studies have documented nonlinear impacts of oil prices on stock markets and economies (Kilian and Vigfusson, 2011; Zhu, Su, You and Ren, 2017; Uddin, Rahman, Shahzad and Rehman, 2018). Our second goal is to investigate whether the impact of oil supply and demand shocks varies with the state of the economy. We first use a two-state Markov regime switching modeling to test whether there are non-linearities in the relation between oil shocks and changes in sovereign CDS spreads. We also investigate whether global economic conditions or a country's dependence on oil influences the relation between oil shocks and changes in sovereign CDS spreads.

We make at least four important contributions to the literature that investigates the factors that affect changes in sovereign CDS spreads. First, we provide robust evidence that oil supply and demand shocks have a significant impact on changes in the CDS spread of both the G10 countries as well as major oil-exporting countries. Our second contribution is to show how demand and supply shocks affect changes in spreads across the entire distribution of CDS changes using a quantile regression model. For both the G10 and oil-exporting countries, we find that demand 
shocks affect spreads across all quantiles of the CDS changes. However, supply shocks affect spreads in only some quantiles. In the case of the G10 countries, the impact of supply shocks is more important in the extreme quantiles only while in the case of the oil-exporting countries, supply shocks are important in both the middle and upper quantiles. These findings are consistent with prior studies that report significant variation in the impact of some global factors across the distribution of sovereign CDS spreads.

Our findings present a different picture than previous literature as we focus on the underlying causes of oil movements; oil supply and demand shocks (Da Fonseca, Ignatieva and Ziveyi, 2016; Wegener, Basse, Kunze, and Mettenheim, 2016). The differential impact of these shocks on each of our samples underlines the importance of identifying the source of changes in the price of oil, as well as the need to acknowledge the heterogeneity in the response of net oil-importers viz-a-viz oil-exporters.

Results of our bi-variate Markov regime switching modeling show that demand shocks have a significant impact in both high and low volatility states for the G10 countries and oilexporting countries. However, the magnitude of the impact of demand shocks is almost ten times higher during the more volatile state. On the other hand, supply shocks have a significant impact only in the high volatility state for the G10 countries and oil-exporting countries. We also find that the cumulative impact of oil shocks, as well as the standard deviations are statistically different across the two states for both the G10 and oil-exporting countries. These results support the importance of considering the nonlinearity assumption when examining the effect of oil shocks on sovereign CDS. We also show that the impact of oil shocks on CDS spreads varies with the level of global economic activity as proxied by an index of world industrial production (see Hamilton, 2019). We find that both supply and demand shocks significantly affect CDS spread changes for 
the G10 countries in low levels of global economic activity, but neither shock has an impact during periods of high global economic activity. For oil-exporting countries, supply shocks only significantly lower CDS spreads during high levels of global economic activity, whereas demand shocks only affect spreads during low levels of global economic activity.

Finally, we show that the impact of oil shocks on spread changes depends on how reliant the country is on oil. Specifically, we find that the magnitude of the impact of oil shocks on changes in CDS spreads is stronger for the G10 countries that are more reliant on imported oil. Similarly, we find that supply shocks only significantly impact spreads for oil-exporting countries that are heavily reliant on oil revenue.

The rest of this paper is organized as follows: Section 3.2 provides a brief review of related literature and outlines our main research questions, Section 3.3 discusses the data, variable construction and provides univariate statistics, Section 3.4 describes our methodology, Section 3.5 provides the empirical results and discussions, and Section 3.6 presents our conclusions.

\subsection{Related Literature and Research Questions}

There are two main strands of literature that are relevant to our study; first, there are those studies that investigate the relative importance of global versus domestic factors in explaining changes in sovereign CDS spreads, and the second are those studies that investigate the role of oil prices in explaining CDS spreads. We provide a brief review of each of these strands.

\subsubsection{Sovereign CDS Spreads: Global vs. Domestic Factors}

Longstaff, Pan, Pedersen, and Singleton (2011), one of the most widely cited papers in this area; study sovereign CDS for 26 different countries. They find that compared to country-specific factors, global market factors are more important in determining sovereign credit risk. In addition, 
by decomposing the spreads for each country into risk-premium and default-risk components, they show that global factors have a more significant influence on default-risk components relative to the risk-premium component. In a similar vein, Pan and Singleton (2008) use CDS data for Mexico, Turkey and Korea and find a significant correlation between risk premiums and economic measures of global risk.

Several other studies support the significant influence of global factors on CDS spreads based on different regions, time periods, and empirical methodologies. For example, Augustin and T'edongap (2016) find that global macroeconomic factors significantly impact the full term structure of a geographically dispersed panel of 38 countries. Similarly, Dooley and Hutchison (2009) show that several financial and real economic news originating from the U.S. during the 2007 financial crisis significantly affect sovereign CDS spreads in a sample of 14 emerging markets, and Oliveira, Curto and Nunes (2012) find that domestic factors greatly influence Eurodenominated government bonds before the financial crisis, but global factors dominate during and after the crisis period. Furthermore, Wang and Moore (2012) employ a dynamic conditional correlation from a multivariate GARCH model to show that the correlation between sovereign CDS spreads in 38 developed and emerging countries are greatly driven by U.S. economic conditions. Fender, Hayo and Neuenkirch (2012) also find that emerging markets' sovereign CDS are primarily driven by global and regional risk premia, and not by country-specific risk factors. These influences, by global and regional risk premia, are more pronounced during periods of economic stress than under ordinary periods.

There are other studies, however, that indicate the importance of domestic factors in determining sovereign CDS spreads. Ang and Longstaff (2013) find that local financial market factors influence the systematic risk of sovereign CDS for both the U.S. and Eurozone countries. 
In addition, Beirne and Fratzscher (2013) analyze sovereign CDS spreads of 31 advanced and emerging economies during the European sovereign debt crisis. Their results show that, compared to global factors, country-specific and regional factors have more significant explanatory power. Afonso, Furceri, and Gomes (2012) conduct an event study to show that European Union sovereign bond yield and CDS spreads significantly respond to negative rating changes and outlook. Recently, Eichler (2014) shed light on the role of political factors in determining sovereign bond yield in 27 emerging markets during the period between 1996 and 2009. Their findings show that elections and the degree of democracy have limited influence on sovereign bond yield, whereas governance quality and parliamentary systems substantially affect sovereign bond yield.

\subsubsection{Oil as a Global Factor}

There is a body of literature that analyzes the interaction between oil and CDS. More closely related to our study are those that investigate the impact of oil on sovereign CDS spreads. An example is that of Chuffart and Hooper (2019), who use a Time-Varying Transition Probabilities Markov Switching model to analyze the impact of oil price and volatility on the CDS of Russia and Venezuela. They find that oil return has a significant impact on the CDS spread of Venezuela only during turbulent economic periods. In addition, they show that oil return significantly influences the CDS of Russia in all regimes (but) only before adding global factors.

A few studies have made the distinction between oil-exporters versus oil-importers. For example, Naifar, Shahzad, and Hammoudeh (2017) show that oil price volatility more significantly affects sovereign CDS spreads of oil-rich countries than other major global regions such as the G7, BRICS, Council of Europe (CE), Asia, and North America (NA). Pavlova, Boyrie, and Parhizgari (2018) investigate the dynamic spillover of crude oil prices and volatilities on sovereign CDS spreads for oil-exporting countries. Their findings suggest that the spillover effects of the oil 
market to sovereign CDS spreads, changes over time and is only significant for some countries. Similarly, Wegener, Basse, Kunze, and von Mettenheim (2016) use a VAR-GARCH model and find that positive oil price shocks lower the CDS spreads of Brazil, Malaysia, Norway, Qatar, Russia, Saudi Arabia, the United Kingdom, the United States of America and Venezuela. In terms of predictability, the empirical findings of Shahzad, Naifar, Hammoudeh and Roubaud (2017) posit that oil volatility predicts sovereign CDS in different quantiles for the GCC and the other oilexporting countries. ${ }^{39}$

Unlike prior studies, we are the first to conduct a robust analysis of the impact of daily oil supply and demand shocks on the sovereign CDS spreads of major oil-exporting and oil-importing countries. Specifically, our four main hypotheses are:

H1: Oil supply and demand shocks affect daily changes in the sovereign CDS spreads of oilimporting and oil-exporting countries.

H2: The impact of oil supply and demand shocks varies across the conditional distribution of sovereign spread changes.

H3: The relation between oil supply and demand shocks and sovereign spread changes is statedependent.

H4: The relation between oil supply and demand shocks and sovereign spread changes varies with the country's dependence on oil.

\footnotetext{
${ }^{39}$ Some studies also investigate the impact of oil on corporate CDS spreads. See for example, Guo, Chen, and Huang (2011); Lahiani, Hammoudeh, and Gupta (2016); and Dai and Serletis (2018).
} 


\subsection{Data, Variable Construction and Univariate Statistics}

\subsubsection{Sovereign CDS}

Sovereign credit default swaps (CDS) are financial contracts providing insurance for investors whendebt issuers default on their outstanding debts. Buyers of these contracts pay a premium in order to receive a contingent payment, which becomes due if the contractually stated event materializes (Longstaff, Pan, Pedersen, and Singleton, 2011). These premiums are usually quoted in basis points per notional value of the contracts. Each CDS has five main contractual features: (1) the debt issuer (e.g., sovereign entities in our study), (2) the outlined obligations, (3) the term of the contract, (4) a specified value for the notional principal, and (5) the potential events that prompt contingent payments. To investigate the impact of oil supply and demand shocks on sovereign default risk, we use the CDS of a sample of G10 countries and four major oil-exporting countries. The G10 countries included in our sample are the United States, the United Kingdom, France, Germany, Italy, Japan, Belgium, Netherlands, Sweden, and Switzerland. ${ }^{40}$ The oilexporting countries included in our sample are Russia, Iraq, United Arab Emirates (UAE), and Kazakhstan. These countries are selected based on two criteria: (1) they are among the largest oilexporting countries, ${ }^{41}$ and (2) Bloomberg provides data on their five-year CDS spreads.

Appendix A provides the level of government debt for each of the countries in our sample, for the period from 2009 to 2018. In Panel A, we report the summary statistics of the level of government debt in billions of U.S. dollars. The U.S. and Japan have the highest mean sovereign debt of approximately 1.76 and 1.1 trillion dollars, respectively. In order to put the level of

\footnotetext{
${ }^{40}$ We do not include Canada as its CDS data is available only from the end of 2017.

${ }^{41}$ More information on the size of the oil exports for these countries is at https://www.cia.gov/library/publications/theworld-factbook/rankorder/2242rank.html.
} 
government debt into perspective, we report the percentage of debt to GDP in Panel B. Japan has the highest mean percentage of debt to GDP of $226.86 \%$, followed by $125.52 \%$ for Italy.

\section{[Insert Panels A and B of Appendix A Here]}

We use the 5-year CDS for each of the countries in our sample as they are among the most liquid sovereign CDS. The sample period is from July 2009 to December 2018 for the G10 countries, and from February 2011 to December 2018 for the oil-exporting countries. The start of the sample period is based on the availability of the data in Bloomberg. The sovereign CDS spreads are highly sensitive to changes in the solvency of countries. For instance, Greece faced substantial financial difficulty, which resulted in Greece missing its scheduled 1.55 billion euro payment on June 30, 2015. The 5-year sovereign CDS spread of Greece skyrocketed approximately five-fold from 1443.51 basis points on June 29, to 6739.21 basis points on June 30 (See Figure 1).

\section{[Insert Figure 1 Here]}

Figure 2 plots the evolution in spreads for each country in our sample. There is a spike in the CDS of most of the European countries between 2011 and 2012. This is approximately the time of the European debt crisis. In addition, there is a spike for both Russia and Iraq around the year 2015, which is just after the plunge of oil prices.

\section{[Insert Figure 2 Here]}

\subsubsection{Oil Shocks Data and Variable Construction}

We follow Ready (2018) in constructing the oil shocks and so we use the same data. In order to construct the oil shocks, we need three variables: (1) daily prices of the one-month NYMEX Light Sweet Crude Oil contract from the EIA website, (2) the World Integrated Oil and Gas Producer Index from Thomson Reuters Database, and (3) the CBOE volatility index (VIX) from 
the CBOE website. The simple intuition behind this approach is that oil-producing firms are affected by demand shocks but have a natural hedge against supply shocks. A supply disruption that causes an oil price increase would offset the negative impact of the decrease of oil supply. According to this setup, demand shocks are defined as "the portion of contemporaneous returns of a global index of oil-producing firms which is orthogonal to unexpected changes in the log of the VIX index" (Ready, 2018). In addition, supply shocks are defined as "the portion of contemporaneous oil price changes which is orthogonal to demand shocks as well as to innovations in the VIX" (Ready, 2018).

We use similar notation as in Ready (2018) to explain the method to construct the shocks. As mentioned before, this approach classifies oil shocks into supply, demand, and risk shocks by

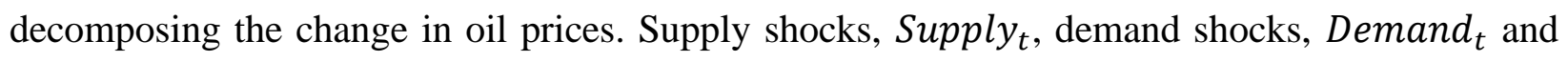
risk shocks $v_{t}$ are assumed to be orthogonal and defined as follows:

$$
X_{t}=\left[\begin{array}{c}
\Delta p_{t} \\
R_{t}^{\text {Prod }} \\
\zeta \text { VIX }
\end{array}\right], Z_{t}=\left[\begin{array}{c}
\text { Supply }_{t} \\
\text { Demand }_{t} \\
v_{t}
\end{array}\right], A \equiv\left[\begin{array}{ccc}
1 & 1 & 1 \\
0 & a_{22} & a_{23} \\
0 & 0 & a_{33}
\end{array}\right]
$$

The identified shocks in matrix $A$ are mapped into observable variables as follows:

$$
X_{t}=A Z_{t}
$$

To achieve the objective of imposing orthogonality, we satisfy:

$$
A^{-1} \sum_{X}\left(A^{-1}\right)^{T}=\left[\begin{array}{ccc}
\sigma_{\text {supply }}^{2} & 0 & 0 \\
0 & \sigma_{\text {demand }}^{2} & 0 \\
0 & 0 & \sigma_{v}^{2}
\end{array}\right]
$$

$\Sigma_{X}$ represents the covariance matrix of the observable $X_{t}$, and $\sigma_{\text {Supply }}, \sigma_{\text {Demand }}, \sigma_{v}$ are the volatilities of the identified shocks. This procedure can be considered a simple renormalization of 
the standard orthogonalization that is employed to define the structural shocks in a SVAR framework. In addition, we aggregate the shocks to sum up to the total change in the oil price.

\subsubsection{Other Variables}

Our choice of control variables is motivated by prior studies, discussed in Section 2 (Chuffart and Hooper 2019; Hibbert and Pavlova 2017; Longstaff, Pan, Pedersen, and Singleton, 2011). The control variables can be categorized into two groups. The first group includes two domestic variables: (1) St. Return is the daily return for each country's stock market, and (2) FX Rate is the change in the exchange rate for each country's currency against the U.S. dollar. Appendix B list the respective index that we use for each country's stock market. In the case of the U.S., we use the Trade Weighted U.S. Dollar index, which is "a weighted average of the foreign exchange value of the U.S. dollar against a subset of the broad index currencies" ${ }^{\prime 2}$. The second group consists of variables intended to capture global factors. These include: the change in the TED spread ( $\triangle$ TedRate) the change in the CBOE volatility index $(\triangle V I X)$, the S\&P 500 index return $(S \& P 500)$, the change in the Euro Stoxx 50 Volatility index $(\triangle V 2 X)$, the change in the German 10-year Bond yield ( $\triangle$ German Bond), the change in the effective Federal Fund rate ( $\Delta F e d F u n d)$, the change in the European Repo rate ( $\triangle$ Euro Repo), and the change in the 10-year U.S. Treasury yield (4Treasury). ${ }^{43}$ The data for all control variables is from Bloomberg.

To measure global economic activity, we use the monthly industrial production index for the OECD and six other major countries (Brazil, China, India, Indonesia, the Russian Federation, and South Africa). ${ }^{44}$ Hamilton (2019) highlights the superiority of this index compared to other

\footnotetext{
${ }^{42}$ More information on the index is at the Federal Reserve Bank of St. Louis website.

${ }^{43}$ We take first differences for all the variables other than the returns variables as they have a unit root based on the Augmented Dickey-Fuller test.

44 The data is from Professor James Hamilton's website: https://econweb.ucsd.edu/ jhamilton/\#publications. Baumeister and Hamilton (2019) extend the original index to the present.
} 
alternative indexes of real economic activity. To measure each country's oil dependency, for the G10 countries, we use the ratio of energy imports to total domestic energy; a higher ratio indicates a higher dependency. We use the ratio of oil rents to GDP to differentiate between high and low oil revenue dependency for the oil-exporting countries. The data for the two proxies of the country's oil dependency is from the World Bank database.

\subsubsection{Univariate Statistics}

In Panels A and B of Table 1, we report summary statistics for the daily sovereign CDS spread changes over our sample period. We provide results for the G10 countries in Panel A, and in Panel B, we provide similar analysis for the oil-exporting countries. For the G10 countries, we see that Italy experiences the highest average spread change, while Sweden has the lowest. Among the oilexporting countries, Iraq has the highest mean change in spreads, whereas UAE has the lowest. Comparing the results in Panel A to those in Panel B shows that the spread change of the oilexporting countries are largely more volatile than those of the G10 countries. In Panel C of Table 1 , we report summary statistics for the control variables used in our multivariate analyses discussed in Section 4. All of our data series are well behaved, with values similar to those reported in prior studies.

\section{[Insert Table 1 Here]}

We report the correlation between all the countries' CDS spread changes in Panel A of Table 2. The correlation between spread changes for countries in the same region is relatively high. For instance, the correlation between the CDS of Germany and France is 0.79, and that between the Netherlands and Belgium is 0.69 , with both being highly statistically significant. In Panel B we report the correlation between all our control variables. The correlation between almost all the 
control variables is moderately low. Furthermore, the correlation between the oil shocks and all the control variables is very low.

[Insert Table 2 Here]

\subsection{Methodology}

\subsubsection{Main Regression Model}

We start our baseline analysis by using the following regression model to test our first hypothesis

$$
\begin{gathered}
\Delta C D S_{i, t}=\beta_{0, i}+\beta_{1} \Delta \operatorname{CDS}_{i, t-1}+\sum_{j=1}^{n} \beta_{2, j} \text { DOMESTIC }_{j, i, t}+\sum_{j=1}^{m} \beta_{3, j} \text { GLOBAL }_{j, t}+ \\
\gamma \text { Demand }_{t-1}+\text { SSupply }_{t-1}+\varepsilon_{i, t}
\end{gathered}
$$

where $\triangle C D S_{i, t}$ is the daily change in spreads of countries denoted by $i$ over days denoted by $t$, $\triangle C D S_{i, t-1}$ is the one-day lagged change in spreads, included to allow for any autocorrelation in spread changes, DOMESTIC $C_{j, i, t}$ is the set of domestic control variables denoted by $j$ for each country denoted by $i$, and $G L O B A L_{j, t}$ is the set of global control variables denoted by $j$, described in Section 3.3. Our main variables of interest are Demand $_{t-1}$, the one-day lagged shock to the demand side of oil, and Supply $y_{t-1}$, the one-day lagged shock to the supply side of oil, both constructed based on Ready's (2018) method described briefly in Section 3.2. We estimate the model in (4) using both pooled ordinary least squares as well as a panel regression model separately for the sample of G10 countries and for the oil-exporting countries. We report standard errors that are robust to heteroscedasticity and clustered at the country level to account for serial dependency for the panel regression model with country and year fixed effects to control for heterogeneity across countries and years, respectively. 


\subsubsection{Quantile Regressions}

To test our second hypothesis, we follow Koenker (2004) who develops the panel data model for quantile regression. Koenker (2004) starts the model with a classical linear random-effects model:

$$
y_{i t}=x_{i t} \beta+\alpha_{i}+u_{i t}
$$

In our context, $y_{i t}$ is the daily change in the CDS spread, $t$ is the daily observation for each country $i$, and $\alpha_{i}$ is intended to represent unobserved heterogeneity across countries that is not captured by the control variables in the model. The conditional quantile functions of the response of the $i^{\text {th }}$ country in day $t$ is given by:

$$
Q_{y_{i t}}\left(q \mid x_{i t}\right)=\alpha_{i}+x_{i t} \beta(q)
$$

According to this formula, the conditional quantiles for the dependent variable are affected by the pure location shift $\alpha_{i}$. The effects of $\alpha_{i}$ are not allowed to depend on the quantile of interest, $q$, however the covariates $x_{i t}$ are allowed to. The model in expression (6) can be estimated simultaneously for several quantiles by solving the following model:

$$
\underset{(\alpha, \beta)}{\min } \sum_{k=1}^{p} \sum_{i=1}^{n} \sum_{t=1}^{T} w_{k} \rho_{q k}\left(y_{i t}-\alpha_{i}-x_{i j} \beta\left(q_{k}\right)\right)
$$

where $\rho_{q}(u)=u(k-I(u<0))$ represents the piecewise linear quantile loss function of Koenker and Bassett (1978). According to Koenker (2004), equation (7) can be iteratively solved by a sequence of diagonally weighted least squares steps using Cholesky factorization. Expression (7) can be rearranged to present the panelized version as:

$$
\min _{(\alpha, \beta)} \sum_{k=1}^{p} \sum_{i=1}^{n} \sum_{t=1}^{T} w_{k} \rho_{q k}\left(y_{i t}-\alpha_{i}-x_{i j} \beta\left(q_{k}\right)\right)+\lambda \sum_{i=1}^{n}\left\lfloor\alpha_{i}\right\rfloor
$$


Based on Koenker (2004), we get an estimate of the model purged of the fixed effects as $\lambda \rightarrow$ $\infty$ the $\widehat{\alpha}_{l} \rightarrow 0$.

\subsubsection{Markov Switching}

To test our third hypothesis, whether the impact of supply and demand shocks on sovereign CDS is state-dependent, we develop a Markov-switching panel model. Asea and Blomberg (1998) is one of the first papers that employ the Markov-switching panel model. Their approach was later extended by several other papers such as Cermeño (2002), Chen (2007), and Zhu et al. (2017). We follow Zhu et al. (2017) since they conduct a very similar analysis to ours. Starting with the model in expression (4), we construct the bivariate Markov-switching panel model as:

$$
\begin{gathered}
\Delta C D S_{i, t}=\beta_{0, i, s_{t}}+\beta_{1} \Delta C D S_{i, t-1}+\sum_{j=1}^{n} \beta_{2, j} \text { DOMESTIC }_{j, i, t}+\sum_{j=1}^{m} \beta_{3, j} G L O B A L_{j, t}+ \\
\gamma_{s_{t}} \text { Demand }_{t-1}+\delta_{s t} \text { Supply }_{t-1}+\varepsilon_{i, t}
\end{gathered}
$$

Specifically, our aim is to allow the impact of Demand $_{t-1}$, and Supply $y_{t-1}$ to be dependent on the regime $S_{t}$ at time $t$. This state-dependent impact is captured by the coefficients, $\gamma_{\mathrm{s}_{\mathrm{t}}}$ and $\delta_{\mathrm{s}_{\mathrm{t}}}$.

The transition probability matrix for $S_{t}$, which is an unobservable two-regime Markov process, is given by:

$$
P=\left(\begin{array}{ll}
p_{11} & p_{21} \\
p_{12} & p_{22}
\end{array}\right)
$$

where $p_{i j}=p\left(S_{t}=j \mid S_{t-1}=i\right)$, with $\sum_{j=1}^{2} p_{i j}=1$ for regime $i(i=1,2)$. We also assume that the regime switching process follows a first-order Markov chain. We estimate the model with two states, state-dependent regression oil shocks' coefficients, and state-dependent volatility for the 
error process. Specifically, the Markov-switching model is estimated using student $\mathrm{t}$ distribution as it improves the stability of the regimes.

To measure the accuracy and fit of the Markov-switching model, we follow Ang and Bekaert (2002) and compute the regime classification measure (RCM):

$$
R C M=100 S^{2} \frac{1}{T} \sum_{t=1}^{T} \prod_{j=1}^{S} \widetilde{P_{J}, t}
$$

$R C M$ is the average of the product smooth probabilities $p$, and $S$ is the number of states. The RCM ranges between 0 and 100, where 0 indicates that the Markov-Switching model perfectly classifies regimes and 100 indicates the model's failure to classify regimes. Hence, low RCM values are better than high RCM values.

\subsection{Results and Discussion}

\subsubsection{The Impact of Oil Shocks on Sovereign CDS Spreads}

In this section, we discuss the results of our empirical tests of hypotheses 1 and 2 . We start with a discussion of the results for the model in Equation (4). Table 3 provides results separately for the G10 countries and the major oil-exporting countries. We find consistent results between the pooled OLS regression model and the panel model with fixed effects for both groups of countries. ${ }^{45}$ For the G10 countries, demand shocks significantly lower the spreads of the sovereign CDS. A positive demand shock leads to a decrease in spreads of about 0.12 basis points. These results are consistent with the view that positive demand shocks are indicators of healthy economies (Kilian, 2009; Ready, 2018). Thus, we find generally that demand-driven movements of oil prices lower the sovereign default credit risk of oil-importing countries. Conversely, supply shocks increase the

\footnotetext{
${ }^{45}$ In unreported results, we estimate a panel regression model without fixed effects. Also, we estimate a panel regression model without control variables other than the oil supply and demand shocks. The results, available upon request, are consistent with those reported.
} 
spreads of the G10 CDS. A one unit positive supply shock results in a significant 0.04 basis points increase in spreads. Supply shocks cause an almost immediate increase in uncertainty regarding oil supply, which increases spreads of G10 countries. ${ }^{46}$

The results for the major oil-exporting countries show that both oil supply and demand shocks lower the spreads of the sovereign CDS for the oil-exporting countries. The finding that a demand shock causes a decrease in spreads for oil exporters is intuitive since an increase in demand for oil is good news for oil exporters. Similarly, a supply shock, consistent with a decrease would likely lead to an increase in prices and would have a favorable impact on the economies of oil exporters, resulting in lower spreads. Thus, both shocks mainly convey good news for those

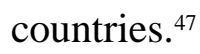

\section{[Insert Table 3 Here]}

Table 4 reports estimates of the quantile regression model for the G10 countries and the major oil-exporting countries. The low quantile indicates low default risk, whereas the upper quantile indicates a high default risk. In Panel A of Table 4, we find that demand shocks affect spreads across all the quantiles for the G10 countries. However, supply shocks have a relatively limited influence in the middle quantile of the spreads. Hence, the supply-driven oil movements mostly affect spreads at the tails of default risk. These findings are consistent with the literature that shows a significant impact of oil during turbulent periods of sovereign debt (Chuffart and Hooper, 2019). The results for the oil-exporting countries, reported in Panel B of Table 4 show

\footnotetext{
${ }^{46}$ In unreported results, we estimate a panel regression without Italy, in the case of G10 countries, as the standard deviation of its CDS spread is large compared to that for other countries (see Table 1). We also estimate a panel regression without the U.S. as its dependence on imported oil has been changing. The results, available upon request, are consistent with those reported.

${ }^{47}$ In unreported results, we estimate a panel regression without Iraq, in the case of oil-exporting countries, as the standard deviation of its CDS spread is quite large compared to that for other countries (see Table 1). The results, available upon request, are consistent with those reported.
} 
that demand shocks have a significant effect across the entire conditional distribution of spread changes, but the supply shocks mostly impact the upper quantiles. These results indicate that supply shocks mainly impact spreads when the default risk is high. However, supply shocks seem to have a limited effect on the left tail of the distribution of spread changes, i.e. when there is low default risk.

\section{[Insert Table 4 Here]}

Together the results so far provide evidence in support of Hypotheses 1 and 2. Specifically, both oil supply and demand shocks affect changes in spreads of the G10 countries and major oilexporting countries. CDS spreads decrease due to oil demand shocks for both the G10 countries and oil-exporting countries. In contrast, oil supply shocks increase the spreads of the G10 countries, but reduce the spreads of oil-exporting countries. Furthermore, the effect varies across the conditional distribution of spread changes for these countries.

\subsubsection{Regime Switching Model and Other Tests}

The nonlinearity of oil prices and shocks have been the subject of extensive discussions in the energy literature (Kilian and Vigfusson, 2011; Zhu, Su, You and Ren, 2017; Uddin, Rahman, Shahzad and Rehman, 2018). In this section, we first investigate whether the impact of oil shocks that we report in the previous sub-section is state-dependent, i.e. we test our third hypothesis. State 1 is the low volatility state and State 2 is the high volatility state, as measured by the variance in each respective state. We confirm (in unreported results) that the cumulative impact of oil shocks and the states' standard deviations (sigmas) are different between the two states. In addition, the RCM values for both the G10 countries and oil-exporting countries, reported in Table 5, confirm that the model fits the data very well. Figure 3 graphs the smoothed probabilities of the high volatility state for each group of countries. For most of our sample period, the probability of 
spreads being in the high volatility state is largely consistent with major world events. Furthermore, the probability of spreads being in high or low volatility states for each group of countries is very similar. An exception is the period from around 2015-2016 when only the spreads of the oil-exporting countries were largely in a high volatility state.

[Insert Table 5 and Figure 3 Here]

Table 6 provides results for the bivariate Markov-Switching model given in equation 9. For both the G10 countries and oil-exporting countries, demand shocks have a significant influence on spreads in both high and low volatility states, while supply shocks impact spreads only in the more volatile state. Furthermore, both demand and supply shocks have a larger impact on spreads in the more volatile state. For instance, a positive demand shock leads to a significant 0.07 basis

point decrease in spreads of the G10 countries in the low volatility state whereas it leads to a significant 0.66 basis point decrease in spreads in the highly volatile state. The results in Table 6 also show that within each state, the magnitude of the impact of both supply and demand shocks is significantly greater for the oil-exporting countries compared to the G10 countries. Together these results are in support of our third hypothesis that the impact of oil shocks on sovereign spread changes is state-dependent.

\section{[Insert Table 6 Here]}

We also examine the influence of economic conditions and the countries' oil dependence on the relation between oil shocks and changes in spreads. In Table 7, we show that oil shocks have a significant influence on spreads only during low economic activity periods. These results indicate that the G10 countries are more prone to the effect of oil shocks during times of economic downturns. On the other hand, we find that supply shocks lower the spreads of oil-exporting 
countries only during high economic activity. The demand for oil would be elevated during periods of high global economic activity, thus, a disruption in oil supply would likely result in a significant increase in oil price which potentially has positive consequences for oil exporters. We find that demand shocks lower the spreads of oil-exporting countries only during periods of low economic activity. When the global economy slows down, oil exporters most likely will be negatively affected. Hence, an increase in the oil price due to demand shocks during these adverse periods would deliver good news for oil exporters as they likely need additional revenue.

\section{[Insert Table 7 Here]}

Finally, we analyze the influence of the countries' oil dependency on the relation between oil shocks and changes in sovereign spreads. We use the ratio of energy imports to total domestic energy use to differentiate between high and low oil imports dependency for the G10 countries. The results in Panel A of Table 8 show that the magnitude of the influence of oil shocks on spreads is greater for countries that are highly dependent on imported oil. These results are of great importance for policymakers, institutions and portfolio managers in the G10 countries. The debate regarding the reliance on imported and conventional oil may benefit from the results of this study. For oil-exporting countries, we use the ratio of oil rents to GDP, to differentiate between high and low oil revenue dependency. The results for the oil-exporting countries in Panel B of Table 8 show that supply shocks affect only countries that are heavily reliant on oil revenue.

\section{[Insert Table 8 Here]}

\subsection{Conclusion}

In this paper, we examine the effect of oil shocks on sovereign CDS spreads. Our sample of countries consists of the G10 countries and major oil-exporting countries. Using the recently developed classification of oil shocks by Ready (2018), we provide robust evidence that oil 
demand shocks lower the spreads of the sovereign CDS for both the G10 countries and the oilexporting countries, with the effect of oil demand shocks being significant across all quantiles for both groups of countries. On the other hand, oil supply shocks increase the spreads of the G10 countries, but lower the spreads of oil-exporting countries, with the impact concentrating in the upper quantiles of spreads. We also test for nonlinearity by employing two-state Markov-switching modeling and find the significant influence of oil shocks mostly concentrates in a highly volatile state. In addition, the impact of oil shocks on the changes of CDS spreads is sensitive to the global economic conditions and to the country's dependence on oil.

Our results are beneficial for governments, corporations, and international organizations. The sensitivity of the sovereign CDS spreads to oil shocks underlines the importance of designing and structuring hedging strategies against this type of risk. Governments may benefit from the results in this study as they consider their reliance and exposure to oil shocks Moreover, our study underscores the importance of assessing the nonlinearity between sovereign CDS and global determinants such as oil shocks. 


\section{Appendix A: Essay 3}

\section{Summary Statistics of each Country's Sovereign Debt}

The level of each country's government debt is from the World Bank database and the percentage of debt to GDP is from the IMF database. The sample period is from $2009-2018$.

Panel A - Government Debt in Billion of USD

\begin{tabular}{lrrrrr}
\hline & $\mathrm{N}$ & Mean & Std. Dev. & Min & Max \\
\cline { 2 - 6 } Belgium & 10 & 518.2 & 31.6 & 482.1 & 570.6 \\
France & 10 & $2,479.4$ & 177.0 & $2,232.9$ & $2,733.1$ \\
Germany & 10 & $2,679.7$ & 254.5 & $2,408.0$ & $2,994.9$ \\
Italy & 10 & $2,587.2$ & 149.3 & $2,411.3$ & $2,836.0$ \\
Japan & 10 & $11,870.0$ & $1,242.9$ & $10,166.0$ & $14,205.4$ \\
Netherlands & 10 & 523.5 & 50.6 & 473.3 & 605.9 \\
Sweden & 10 & 213.2 & 22.9 & 175.9 & 258.5 \\
Switzerland & 10 & 282.7 & 21.8 & 238.8 & 304.9 \\
United Kingdom & 10 & $2,237.0$ & 333.7 & $1,525.5$ & $2,640.2$ \\
United States & 10 & $17,600.9$ & $2,862.0$ & $12,527.2$ & $21,375.4$ \\
Iraq & 10 & 91.1 & 17.0 & 74.1 & 113.8 \\
Kazakhstan & 10 & 27.1 & 9.1 & 11.8 & 40.4 \\
Russia & 10 & 232.9 & 60.8 & 121.0 & 331.7 \\
UAE & 10 & 66.8 & 6.7 & 61.0 & 79.1 \\
\hline
\end{tabular}

Panel B - Government Debt as a Percentage of GDP

\begin{tabular}{lrrrrr}
\hline & $\mathrm{N}$ & Mean & Std. Dev. & Min & Max \\
\hline Belgium & 10 & 103.7 & 2.8 & 99.5 & 107.5 \\
France & 10 & 92.5 & 5.6 & 83.0 & 98.4 \\
Germany & 10 & 73.8 & 6.9 & 61.7 & 82.3 \\
Italy & 10 & 125.5 & 7.9 & 112.5 & 132.2 \\
Japan & 10 & 226.9 & 12.7 & 201.0 & 237.1 \\
Netherlands & 10 & 61.5 & 5.3 & 52.4 & 68.0 \\
Sweden & 10 & 40.4 & 2.6 & 37.2 & 45.0 \\
Switzerland & 10 & 42.7 & 1.0 & 40.5 & 44.1 \\
United Kingdom & 10 & 82.6 & 7.7 & 63.7 & 87.9 \\
United States & 10 & 101.6 & 6.2 & 86.7 & 106.8 \\
Iraq & 10 & 51.1 & 17.2 & 32.0 & 87.4 \\
Kazakhstan & 10 & 15.3 & 4.9 & 10.2 & 21.9 \\
Russia & 10 & 13.6 & 2.5 & 9.9 & 16.4 \\
UAE & 10 & 19.0 & 2.7 & 15.5 & 24.1 \\
\hline
\end{tabular}




\section{Appendix B: Essay 3}

\section{Stock Exchanges}

This table reports the stock exchanges used to compute the domestic stock market return variable (St. Return) in our analyses.

\begin{tabular}{ll}
\hline Country & Stock Exchange \\
\hline USA & Dow Jones \\
UK & FTSE 100 \\
France & CAC 40 \\
Germany & DAX \\
Italy & FTSE MIB \\
Japan & Nikkei 225 \\
Belgium & BEL 20 \\
Netherlands & AEX \\
Sweden & OMX Stockholm 30 \\
Switzerland & Swiss Market Index \\
Russia & MXRU Russia stock \\
Iraq & Iraq Stock Exchange (ISX) \\
UAE & Abu Dhabi Securities Market General Index \\
Kazakhstan & Kazakhstan Stock Exchange Index KASE \\
\hline
\end{tabular}




\section{Table 1: Summary Statistics of CDS Spread Changes}

This table presents summary statistics of the variables used in the analyses. Panels A and B summarize the daily CDS spread change for the G10 countries and the major oil-exporting countries, respectively, and Panel C summarizes the control variables. Spreads are reported in basis points. St. Return is the daily return for each country's stock market, FX Rate is the exchange rate for each country against the U.S. dollar. TedRate is the TED spread, VIX is the CBOE volatility index, Oil Realized Volatility is the square root of the sum of squared five-minute returns of oil futures prices. V2X is the Euro Stoxx 50 Volatility index, Oil price is the one-month price of oil future contract, Demand is a shock to the demand side of oil, Supply is a shock to the supply side of oil, both shocks constructed based on Ready's (2018) method. $S \& P 500$ is the S\&P 500 index return, German Bond is the German 10-year Bond yield, FedFund is the effective Federal Fund rate, Euro. Repo is the daily rate of the European Repo, Treasury is the 10-year U.S. Treasury yield. A list of the countries' stock market is provided in Appendix A. The sample period is from July 2009 to December 2018 for the G10 countries and from February 2011 to December 2018 for the major oil-exporting countries. The oil-exporting countries are Russia, Iraq, UAE, and Kazakhstan.

Panel A - Daily Change of CDS Spread for G10 Countries

\begin{tabular}{lrrcrr} 
& $\mathrm{N}$ & Mean & Std. Dev. & Min & \multicolumn{1}{c}{ Max } \\
\cline { 2 - 6 } All & 24,754 & -0.004 & 3.68 & -72.50 & 109.00 \\
Belgium & 2,476 & -0.010 & 4.59 & -57.52 & 37.14 \\
France & 2,476 & 0.002 & 3.16 & -30.28 & 23.30 \\
Germany & 2,476 & -0.007 & 1.54 & -14.50 & 11.13 \\
Italy & 2,476 & 0.051 & 9.27 & -72.50 & 109.00 \\
Japan & 2,476 & -0.009 & 1.97 & -17.36 & 19.28 \\
Netherlands & 2,476 & -0.012 & 1.78 & -14.41 & 15.44 \\
Sweden & 2,476 & -0.018 & 1.22 & -7.76 & 8.69 \\
Switzerland & 2,470 & -0.020 & 1.75 & -17.06 & 43.73 \\
UK & 2,476 & -0.012 & 1.61 & -17.92 & 13.66 \\
USA & 2,476 & -0.005 & 1.26 & -10.47 & 12.47 \\
\hline
\end{tabular}

Panel B - Daily Change of CDS Spread for Oil-Exporting Countries

\begin{tabular}{lcrrrr}
\hline & $\mathrm{N}$ & \multicolumn{1}{c}{ Mean } & Std. Dev. & \multicolumn{1}{c}{ Min } & \multicolumn{1}{c}{ Max } \\
\cline { 2 - 6 } All & 8,180 & 0.017 & 10.02 & -105.09 & 304.78 \\
Iraq & 2,059 & 0.079 & 16.93 & -105.09 & 304.78 \\
Kazakhstan & 2,059 & -0.039 & 6.46 & -51.41 & 51.31 \\
Russia & 1,981 & 0.037 & 8.27 & -88.41 & 66.96 \\
UAE & 2,059 & -0.016 & 2.18 & -14.84 & 13.79 \\
\hline
\end{tabular}


Table 1: (Continued)

Panel C - Control Variables

\begin{tabular}{lrrrrr}
\hline & $\mathrm{N}$ & \multicolumn{1}{c}{ Mean } & \multicolumn{1}{c}{ Std. Dev. } & \multicolumn{1}{c}{ Min } & \multicolumn{1}{c}{ Max } \\
\cline { 2 - 6 } St. Return & 24,165 & 0.023 & 1.278 & -13.923 & 12.195 \\
$\Delta$ FX Rate & 24,747 & 0.001 & 0.188 & -3.940 & 3.300 \\
$\Delta$ TedRate & 24,330 & 0.000 & 0.015 & -0.080 & 0.090 \\
$\Delta$ VIX & 24,700 & 0.000 & 1.593 & -12.940 & 20.010 \\
$\Delta$ V2X & 24,299 & -0.015 & 1.640 & -10.937 & 12.783 \\
Demand & 24,700 & 0.000 & 0.972 & -5.764 & 3.949 \\
Supply & 24,700 & -0.001 & 1.575 & -7.742 & 8.236 \\
S\&P500 Return & 24,720 & 0.045 & 0.924 & -6.663 & 4.741 \\
$\Delta$ German Bond & 24,760 & -0.001 & 0.043 & -0.257 & 0.229 \\
$\Delta$ FedFund & 24,760 & 0.430 & 0.001 & 0.023 & -0.150 \\
$\Delta$ Euro. Repo & 24,660 & 0.460 & 0.000 & 0.013 & -0.250 \\
$\Delta$ Treasury & 24,760 & 2.490 & 0.000 & 0.049 & -0.200 \\
\hline
\end{tabular}




\section{Table 2: Correlation Between the Main Variables}

Panel A reports the correlation between changes in the 5-year sovereign CDS spread for each of the countries in our sample and Panel B reports the correlation between the explanatory variables used in the analyses. St. Return is the daily return for each country's stock market (described in Appendix A), FX Rate is the exchange rate for each country's currency against the U.S. dollar. TedRate is the TED spread, VIX is the CBOE volatility index, $S \& P 500$ is the S\&P 500 index return, V2X is the Euro Stoxx 50 Volatility index, German Bond is the German 10-year Bond yield, FedFund is the effective Federal Fund rate, Euro. Repo is the daily European Repo rate, Treasury is the 10-year U.S. Treasury yield. Demand is a shock to the demand side of oil, and Supply is a shock to the supply side of oil, both shocks constructed based on Ready's (2018) method. Correlations in bold are significant at the 5\% level or higher.The sample period is from July 2009 to December 2018 for the G10 countries and February 2011 to December 2018 for the oil-exporting countries.

Panel A - The Correlation Between Daily Changes in Sovereign CDS Spreads

\begin{tabular}{|c|c|c|c|c|c|c|c|c|c|c|c|c|c|}
\hline & USA & UK & France & Germany & Italy & Japan & Belgium & Netherlands & Sweden & Switzerland & Russia & Iraq & UAE \\
\hline UK & 0.23 & & & & & & & & & & & & \\
\hline France & 0.21 & 0.65 & & & & & & & & & & & \\
\hline Germany & 0.22 & 0.69 & 0.79 & & & & & & & & & & \\
\hline Italy & 0.17 & 0.55 & 0.70 & 0.59 & & & & & & & & & \\
\hline Japan & 0.13 & 0.34 & 0.33 & 0.37 & 0.31 & & & & & & & & \\
\hline Belgium & 0.22 & 0.64 & 0.80 & 0.74 & 0.70 & 0.31 & & & & & & & \\
\hline Netherlands & 0.21 & 0.6 & 0.71 & 0.72 & 0.58 & 0.34 & 0.69 & & & & & & \\
\hline Sweden & 0.23 & 0.52 & 0.56 & 0.57 & 0.45 & 0.28 & 0.56 & 0.57 & & & & & \\
\hline Switzerland & 0.08 & 0.40 & 0.35 & 0.39 & 0.25 & 0.26 & 0.36 & 0.38 & 0.31 & & & & \\
\hline Russia & 0.13 & 0.34 & 0.35 & 0.35 & 0.36 & 0.35 & 0.33 & 0.32 & 0.25 & 0.17 & & & \\
\hline Iraq & 0.02 & 0.08 & 0.09 & 0.07 & 0.09 & 0.11 & 0.07 & 0.05 & 0.06 & 0.03 & 0.13 & & \\
\hline UAE & 0.14 & 0.29 & 0.28 & 0.32 & 0.28 & 0.35 & 0.29 & 0.29 & 0.22 & 0.19 & 0.40 & 0.09 & \\
\hline Kazakhstan & 0.14 & 0.37 & 0.38 & 0.40 & 0.36 & 0.36 & 0.38 & 0.37 & 0.29 & 0.19 & 0.65 & 0.12 & 0.43 \\
\hline
\end{tabular}


Table 2: (Continued)

Panel B - The Correlation Between the Explanatory Variables Used in the Analyses

\begin{tabular}{|c|c|c|c|c|c|c|c|c|c|c|c|}
\hline & St. Return & FX Rate & TedRate & VIX & $\mathrm{V} 2 \mathrm{X}$ & $\begin{array}{c}S \& P \\
500\end{array}$ & $\begin{array}{c}\text { German } \\
\text { Bond }\end{array}$ & FedFund & $\begin{array}{l}\text { Euro. } \\
\text { Repo }\end{array}$ & Treasury & Demand \\
\hline$\Delta \mathrm{FX}$ Rate & -0.050 & & & & & & & & & & \\
\hline$\Delta$ TedRate & -0.030 & -0.024 & & & & & & & & & \\
\hline$\Delta \mathrm{VIX}$ & -0.460 & -0.080 & 0.004 & & & & & & & & \\
\hline$\Delta \mathrm{V} 2 \mathrm{X}$ & -0.620 & -0.075 & 0.001 & 0.570 & & & & & & & \\
\hline S\&P500 Return & 0.570 & 0.082 & -0.029 & -0.830 & -0.540 & & & & & & \\
\hline$\Delta$ German Bond & 0.390 & 0.072 & -0.040 & -0.280 & -0.380 & 0.350 & & & & & \\
\hline$\Delta$ FedFund & -0.024 & 0.004 & 0.049 & 0.014 & 0.004 & -0.020 & 0.010 & & & & \\
\hline$\Delta$ Euro. Repo & 0.010 & -0.001 & -0.008 & -0.010 & 0.010 & 0.020 & 0.030 & -0.001 & & & \\
\hline$\Delta$ Treasury & 0.310 & 0.145 & -0.070 & -0.360 & -0.340 & 0.440 & 0.630 & 0.020 & 0.020 & & \\
\hline Demand & 0.020 & 0.010 & 0.030 & -0.020 & 0.050 & 0.030 & 0.001 & -0.023 & -0.030 & 0.030 & \\
\hline Supply & 0.010 & -0.010 & -0.020 & 0.010 & -0.010 & 0.000 & 0.020 & 0.030 & 0.010 & 0.010 & 0.000 \\
\hline
\end{tabular}




\section{Table 3: Pooled and Panel Regressions}

This table reports the estimates for a pooled OLS regression model and a panel regression model with fixed effects of the following model:

$$
\begin{gathered}
\Delta C D S_{i, t}=\beta_{0, i}+\beta_{1} \Delta C D S_{i, t-1}+\sum_{j=1}^{n} \beta_{2, j} \text { DOMESTIC }_{j, i, t}+\sum_{j=1}^{m} \beta_{3, j} G_{L O B A L_{j, t}}+ \\
\gamma \text { Demand }_{t-1}+\text { SSupply }_{t-1}+\varepsilon_{i, t}
\end{gathered}
$$

$\triangle C D S_{i, t}$ is the daily change in sovereign CDS spread of countries denoted by $i$ over days denoted by $t$, and $\triangle C D S_{i, t-1}$ is the one day lagged change in spreads. DOMESTIC $C_{j, i, t}$ is the two control variables included for each country: the daily return on each country's stock market (St. Return), and the daily change in the exchange rate of each country's currency against the U.S. dollar ( $\triangle F X$ Rate). GLOBAL $L_{j, t}$ is the set of global control variables: the daily change in the CBOE volatility index ( $\triangle V I X)$, the daily S\&P 500 index return (S\&P500 Return), the daily change in the German 10-year Bond yield ( $\triangle$ German Bond), the daily change in the effective Federal Fund rate ( $\triangle F e d F u n d)$, the daily change in the European Repo rate (AEuro. Repo), the daily change in the 10-year U.S. Treasury yield

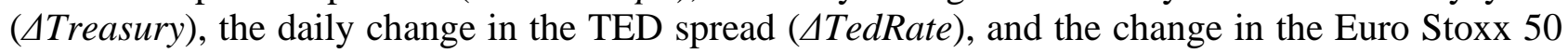
Volatility index $(\Delta V 2 X)$. Demand t $-1_{\text {is }}$ the one day lagged shock to the demand side of oil, and Supplyt$I$ is the one day lagged shock to the supply side of oil, both shocks constructed as in Ready (2018). We report results separately for the G10 countries (excluding Canada) and for a sample of major oilexporting countries. The major oil-exporting countries include Russia, Iraq, UAE, and Kazakhstan. (We exclude $\Delta T e d R a t e$ and $\Delta V 2 X$ from our oil-exporters model.) We report robust standard errors in parentheses below each estimate. ${ }^{* * *}, * *, *$ indicate significance at the $1 \%, 5 \%$, and $10 \%$, respectively. The sample period is from July 2009 to December 2018 for the G10 countries and from February 2011 to December 2018 for the oil-exporting countries. 
Table 3: (Continued)

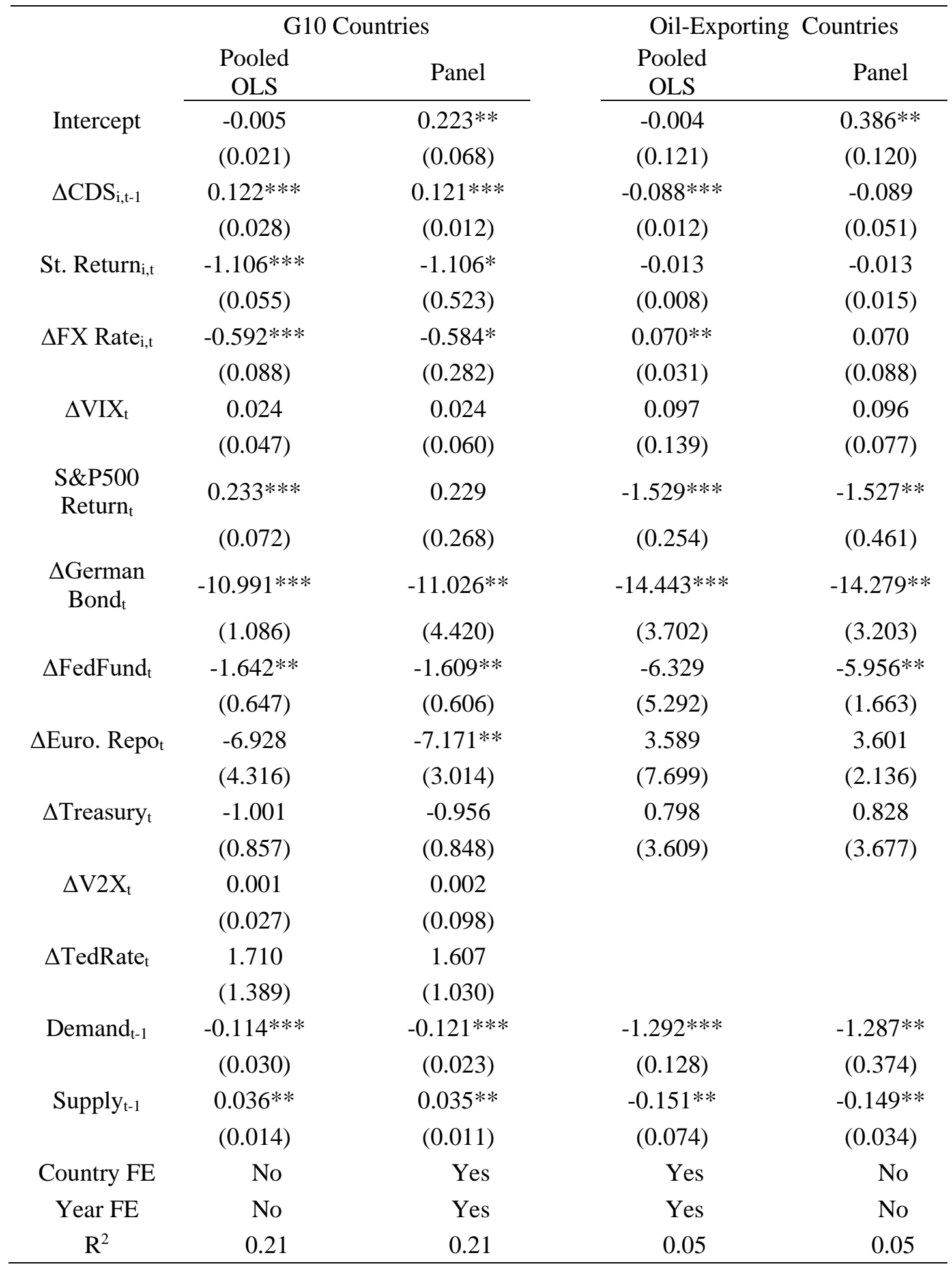




\section{Table 4: Quantile Regression Model of Daily Spread Changes}

This table reports estimates for a quantile regression daily changes in sovereign CDS spreads on oil demand and supply shocks. DOMESTIC $C_{j, i, t}$ and $G L O B A L_{j, t}$ are the set of control variables described in Table 3 and in the text. Demand $t-1$ is the one day lagged shock to the demand side of oil, and Supply $y_{t-1}$ is the one day lagged shock to the supply side of oil, both shocks constructed as in Ready (2018). Panel A includes all the G10 countries except for Canada, and Panel B includes Russia, Iraq, UAE, and Kazakhstan. We report robust standard errors in parentheses below each estimate. ${ }^{* * *}, * *, *$ indicate significance at the $1 \%, 5 \%$, and $10 \%$, respectively. The sample period is from July 2009 to December 2018 for the G10 countries and from February 2011 to December 2018 for the oilexporting countries.

Panel A: G10 Countries

\begin{tabular}{lccc}
\hline & \multicolumn{3}{c}{ Quantile } \\
\cline { 2 - 4 } Intercept & 0.25 & 0.50 & 0.75 \\
\cline { 2 - 4 }$\Delta$ CDS $_{\mathrm{i}, \mathrm{t}-1}$ & $-0.685^{* * *}$ & $-0.014 * *$ & $0.656^{* * *}$ \\
& $(0.017)$ & $(0.005)$ & $(0.016)$ \\
Demand $_{\mathrm{t}-1}$ & $0.066^{* * *}$ & $0.066^{* * *}$ & $0.092^{* * *}$ \\
& $(0.023)$ & $(0.017)$ & $(0.021)$ \\
Supply $_{\mathrm{t}-1}$ & $-0.097 * * *$ & $-0.059 * * *$ & $-0.080^{* * *}$ \\
& $(0.013)$ & $(0.006)$ & $(0.008)$ \\
& $0.013^{* *}$ & 0.003 & $0.017 * *$ \\
DOMESTIC $_{\mathrm{j}, \mathrm{i}, \mathrm{t}}$ & $(0.005)$ & $(0.004)$ & $(0.006)$ \\
GLOBAL $_{\mathrm{j}, \mathrm{t}}$ & & & \\
\hline
\end{tabular}

Panel B: Oil-Exporting Countries

\begin{tabular}{lccc}
\hline & Quantile & & \\
& 0.25 & 0.50 & 0.75 \\
\cline { 2 - 4 } Intercept & $-2.318^{* * *}$ & $-0.097^{*}$ & $2.801 * * *$ \\
& $(0.217)$ & $(0.057)$ & $(0.239)$ \\
\multirow{2}{*}{ CDS $_{\mathrm{i}, \mathrm{t}-\mathrm{t}}$} & 0.007 & $0.014^{*}$ & $0.029 * * *$ \\
& $(0.018)$ & $(0.008)$ & $(0.008)$ \\
Demand $_{\mathrm{t}-\mathrm{t}}$ & $-0.458^{* * *}$ & $-0.338^{* * *}$ & $-0.641^{* * *}$ \\
& $(0.104)$ & $(0.043)$ & $(0.116)$ \\
Supply $_{\mathrm{t}-1}$ & 0.002 & $-0.041^{* *}$ & $-0.082^{*}$ \\
& $(0.041)$ & $(0.016)$ & $(0.045)$ \\
DOMESTIC $_{\mathrm{j}, \mathrm{i}, \mathrm{t}}$ & YES & YES & YES \\
GLOBAL $_{\mathrm{j}, \mathrm{t}}$ & YES & YES & YES \\
\hline
\end{tabular}




\section{Table 5: Transition Probabilities, Expected Duration and other Indicators}

This table reports transition probabilities of a Markov Switching panel regression model of daily changes in CDS spreads on oil demand and supply shocks. The transition probabilities are reported as $P_{i J}$. The expected duration of being in state $i$ are reported as $D U_{i}$ i.e., DU1 for state 1 and DU2 for state 2. Sigma 1 and Sigma 2 are the standard deviation of state 1 and 2, respectively. The maximized $\log$-likelihood value is denoted as LL. The RCM is the regime classification measure. The G10 sample includes all the G10 countries except for Canada, and the Oil-exporting countries sample includes Russia, Iraq, UAE, and Kazakhstan. ${ }^{* * *},{ }^{* *},{ }^{*}$ indicate significance at the $1 \%, 5 \%$, and $10 \%$, respectively. The sample period is from July 2009 to December 2018 for the G10 countries and from February 2011 to December 2018 for the oil-exporting countries.

\begin{tabular}{lcccccccccc}
\hline & P11 & P12 & P21 & P22 & DU1 & DU2 & Sigma 1 & Sigma 2 & LL & RCM \\
\cline { 2 - 9 } G 10 & 0.97 & 0.03 & 0.10 & 0.90 & 32.15 & 9.98 & $0.82^{* * *}$ & $7.2^{* * *}$ & $-44,187.83$ & 0.002 \\
$\begin{array}{l}\text { Oil- } \\
\begin{array}{l}\text { Exporting } \\
\text { Countries }\end{array}\end{array}$ & 0.94 & 0.06 & 0.19 & 0.81 & 16.2 & 5.15 & $2.58^{* * *}$ & $20.11^{* * *}$ & $-20,505.46$ & 0.005 \\
\hline
\end{tabular}




\section{Table 6: Markov Switching Panel Model}

This table reports estimates of a Markov Switching panel regression model of daily changes in sovereign CDS spreads on oil demand and supply shocks. DOMESTIC $C_{j, i, t}$ and $G L O B A L_{j, t}$ are the set of control variables described in Table 3 and in the text. Demand $d_{t-1}$ is the one day lagged shock to the demand side of oil, and Supplyt-1 is the one day lagged shock to the supply side of oil, both shocks constructed as in Ready (2018). The G10 sample includes all countries except for Canada, and the major oil-exporting countries' column includes the following countries: Russia, Iraq, UAE, and Kazakhstan. ${ }^{* * *},{ }^{* *},{ }^{*}$ indicate significance at the $1 \%, 5 \%$, and $10 \%$, respectively. The sample period is from July 2009 to December 2018 for the G10 countries and from February 2011 to December 2018 for the oil-exporting countries.

\begin{tabular}{|c|c|c|}
\hline State 1 & G 10 & Exporting Countries \\
\hline \multirow[t]{2}{*}{ Demand $_{t-1}$} & $-0.072 * * *$ & $-0.259 * * *$ \\
\hline & $(0.007)$ & $(0.047)$ \\
\hline \multirow[t]{2}{*}{ Supply $_{\mathrm{t}-1}$} & 0.007 & -0.031 \\
\hline & $(0.004)$ & $(0.026)$ \\
\hline DOMESTIC $_{\mathrm{j}, \mathrm{i}, \mathrm{t}}$ & YES & YES \\
\hline GLOBAL $_{\mathrm{j}, \mathrm{t}}$ & YES & YES \\
\hline State 2 & G 10 & Exporting Countries \\
\hline \multirow[t]{2}{*}{ Demand $_{t-1}$} & $-0.658 * * *$ & $-2.484 * * *$ \\
\hline & $(0.092)$ & $(0.428)$ \\
\hline \multirow[t]{2}{*}{ Supplyt-1 } & $0.114^{*}$ & $-0.532 * *$ \\
\hline & $(0.063)$ & $(0.261)$ \\
\hline DOMESTIC $_{\mathrm{j}, \mathrm{i}, \mathrm{t}}$ & YES & YES \\
\hline GLOBAL $_{\mathrm{j}, \mathrm{t}}$ & YES & YES \\
\hline
\end{tabular}


Table 7: The Effect of Global Economic Conditions on the Relation Between Soverign CDS Spreads and Oil Shocks

This table reports estimates for a panel regression model of daily changes in sovereign CDS spreads on oil demand and supply shocks based on the level of global economic activity. DOMESTIC $C_{j, i, t}$ and $G L O B A L_{j, t}$ are the set of control variables described in Table 3 and in the text. Demand $d_{t-1}$ is the one day lagged shock to the demand side of oil, and Supplyt-1 is the one day lagged shock to the supply side of oil, both shocks constructed as in Ready (2018). We use the industrial production index to differentiate between high and low global economic activities (Hamilton, 2019). High and low global economic activities are defined as above and below the industrial economic index's median. Panel A provides results for above median global economic activity and Panel B provide similar analysis for below-median global economic activity. The G10 sample includes all countries except for Canada, and the major oil-exporting countries' column includes the following countries: Russia, Iraq, UAE, and Kazakhstan. ${ }^{* * *},{ }^{* *},{ }^{*}$ indicate significance at the $1 \%, 5 \%$, and $10 \%$, respectively. The sample period is from July 2009 to December 2018 for the G10 countries and from February 2011 to December 2018 for the oil-exporting countries.

Panel A: Above-Median Global Economic Activity

\begin{tabular}{lccc}
\hline & $\mathrm{G} 10$ & & Exporting Countries \\
\cline { 2 - 2 } Demand $_{\mathrm{t}-1}$ & -0.056 & -0.442 \\
& $(0.031)$ & $(0.199)$ \\
Supply & & & $-0.286^{* * *}$ \\
& 0.023 & & $(0.047)$ \\
DOMESTIC $_{\mathrm{j}, \mathrm{i}, \mathrm{t}}$ & $(0.020)$ & YES \\
GLOBAL $_{\mathrm{j}, \mathrm{t}}$ & YES & YES \\
\hline
\end{tabular}

Panel B: Below-Median Global Economic Activity

\begin{tabular}{lccc}
\hline & $\mathrm{G} 10$ & & Exporting Countries \\
\cline { 2 - 3 } Demand $_{\mathrm{t}-1}$ & & \\
& $-0.207^{* * *}$ & $-1.502^{* *}$ \\
Supply & & $(0.062)$ & $(0.316)$ \\
& $0.046^{* *}$ & 0.094 \\
DOMESTIC $_{\mathrm{j}, \mathrm{i}, \mathrm{t}}$ & $(0.019)$ & $(0.103)$ \\
GLOBAL $_{\mathrm{j}, \mathrm{t}}$ & YES & YES \\
\hline
\end{tabular}


Table 8: The Effect of Countries' Oil Dependency on the Relation Between Soverign CDS Spreads and Oil Shocks

This table reports estimates for a panel regression model of daily changes in sovereign CDS spreads on oil demand and supply shocks based on the country's reliance on oil imports/revenues. DOMESTIC $_{j, i, t}$ and GLOBAL $L_{j, t}$ are the set of control variables described in Table 3 and in the text. Demand $_{t-1}$ is the one day lagged shock to the demand side of oil, and Supply $y_{t-1}$ is the one day lagged shock to the supply side of oil, both shocks constructed as in Ready (2018). For the G10 countries (reported in Panel A), we use the ratio of energy imports to total energy domestic use to differentiate between high and low imported oil dependency. For the oil-exporting countries (in Panel B), we use the ratio of oil rents to GDP to differentiate between high and low oil revenue dependency. The G10 sample includes all countries except for Canada, and the major oil-exporting countries' column includes the following countries: Russia, Iraq, UAE, and Kazakhstan. ${ }^{* * *, * *, *}$ indicate significance at the $1 \%, 5 \%$, and $10 \%$, respectively. The sample period is from July 2009 to December 2018 for the G10 countries and from February 2011 to December 2018 for the oil-exporting countries.

Panel A: G10 Countries

\begin{tabular}{|c|c|c|}
\hline & \multicolumn{2}{|c|}{ Dependence on Oil Imports } \\
\hline & Above-Median & Below-Median \\
\hline \multirow[t]{2}{*}{ Demand $_{t-1}$} & $-0.188 * * *$ & $-0.150 * * *$ \\
\hline & $(0.030)$ & $(0.014)$ \\
\hline \multirow[t]{2}{*}{ Supply $\mathrm{t}_{\mathrm{t}-1}$} & $0.054 * *$ & $0.027 * *$ \\
\hline & $(0.022)$ & $(0.011)$ \\
\hline DOMESTIC $_{\mathrm{j}, \mathrm{i}, \mathrm{t}}$ & YES & YES \\
\hline GLOBAL $_{\mathrm{j}, \mathrm{t}}$ & YES & YES \\
\hline
\end{tabular}

Panel B: Oil-Exporting Countries

Dependence on Oil Revenues

Above-Median

Below-Median

\begin{tabular}{lcc} 
Demand $_{\mathrm{t}-1}$ & $-0.517^{*}$ & $-1.102 * * *$ \\
& $(0.292)$ & $(0.076)$ \\
Supply & $-0.142 * *$ & -0.140 \\
& $(0.068)$ & $(0.095)$ \\
DOMESTIC $_{\mathrm{j}, \mathrm{i}, \mathrm{t}}$ & YES & YES \\
GLOBAL $_{\mathrm{j}, \mathrm{t}}$ & YES & YES \\
\hline
\end{tabular}


Figure 1: Greece Sovereign CDS Spread Level from May 2013 to December 2017

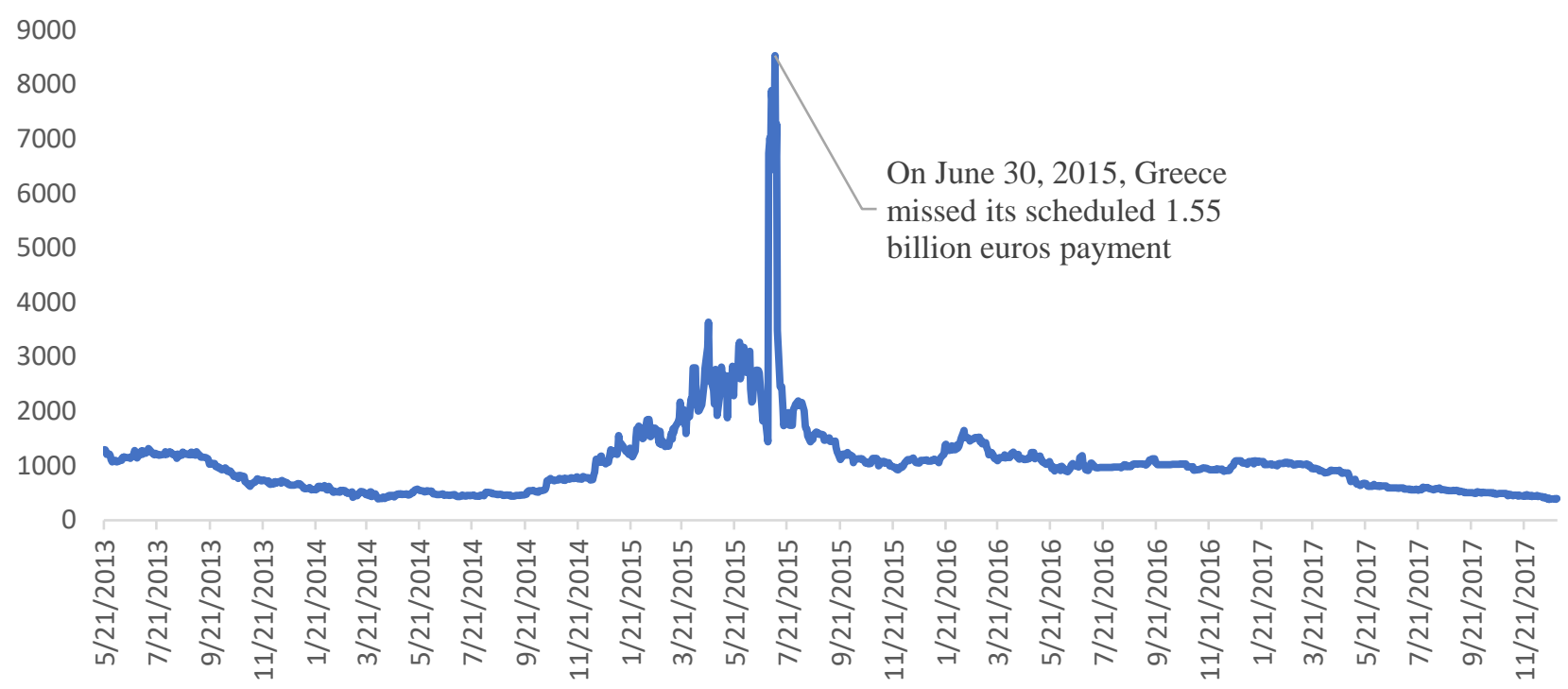




\section{Figure 2: Sovereign CDS Spread Levels}

This figure graphs the 5-year sovereign CDS spread for the G10 countries (excluding Canada) from July 2009 to December 2018 and the 5-year sovereign CDS spread for our sample of oilexporting countries (Russia, Iraq, UAE, and Kazakhstan) from February 2011 to December 2018.

Panel A - G10 Countries
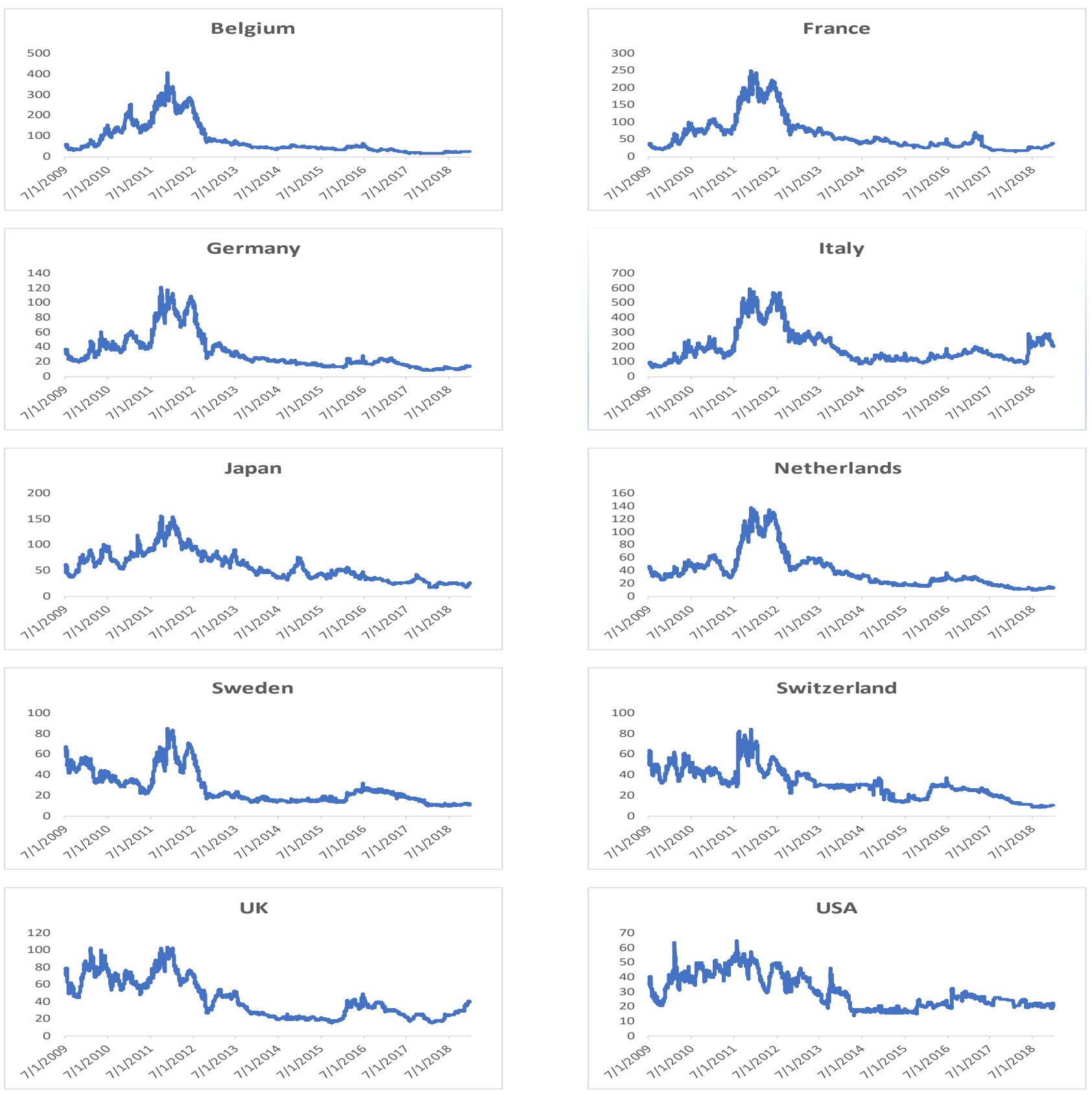
Figure 2 (Continued)

Panel B - Oil-Exporting Countries
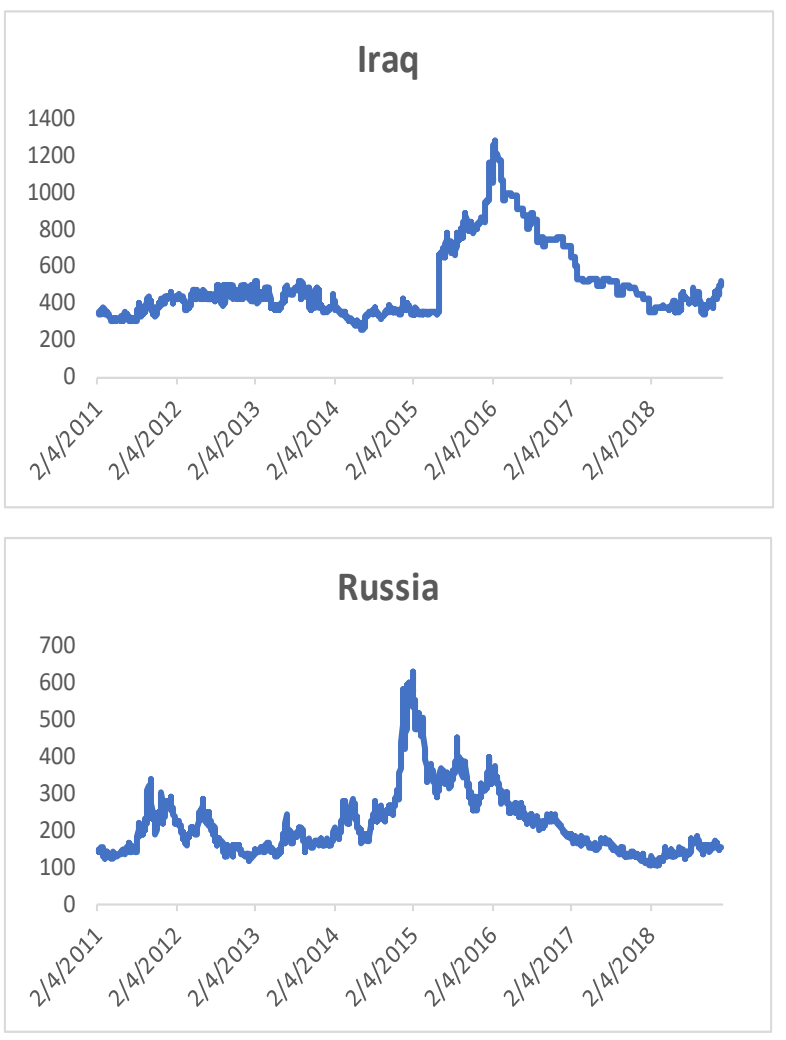
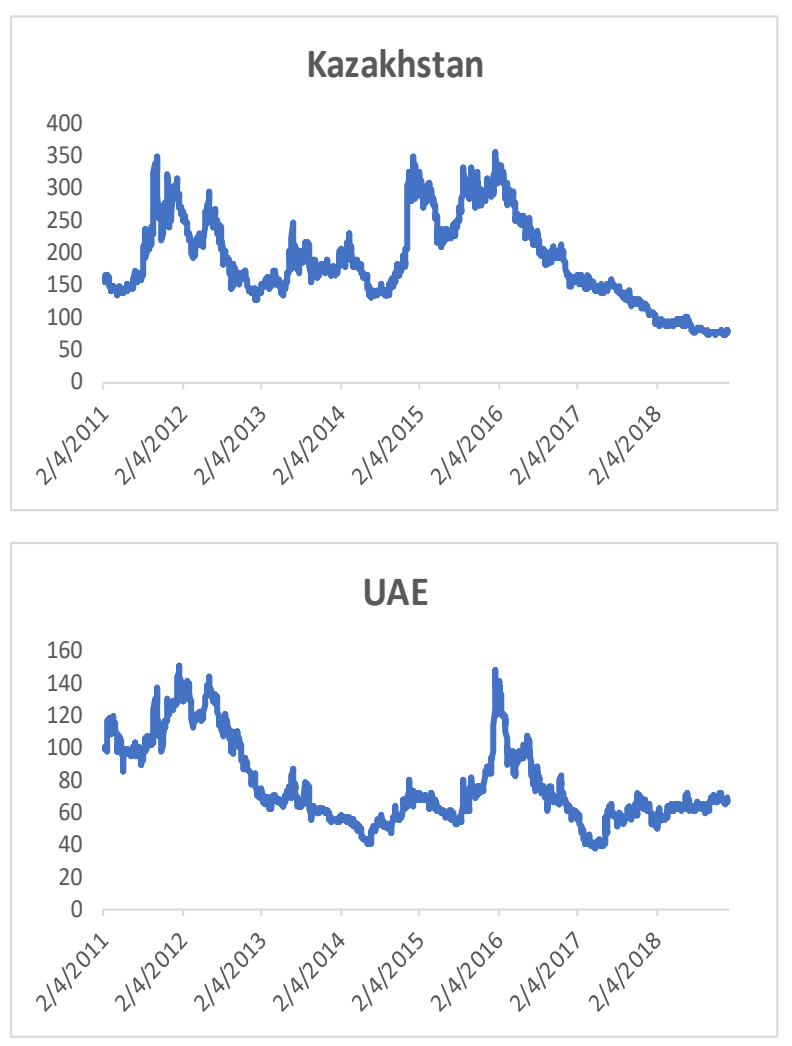
Figure 3: Smoothed Probabilities for the High Volatility State from the Bivariate MarkovSwitching Model

$$
\text { G10 }
$$

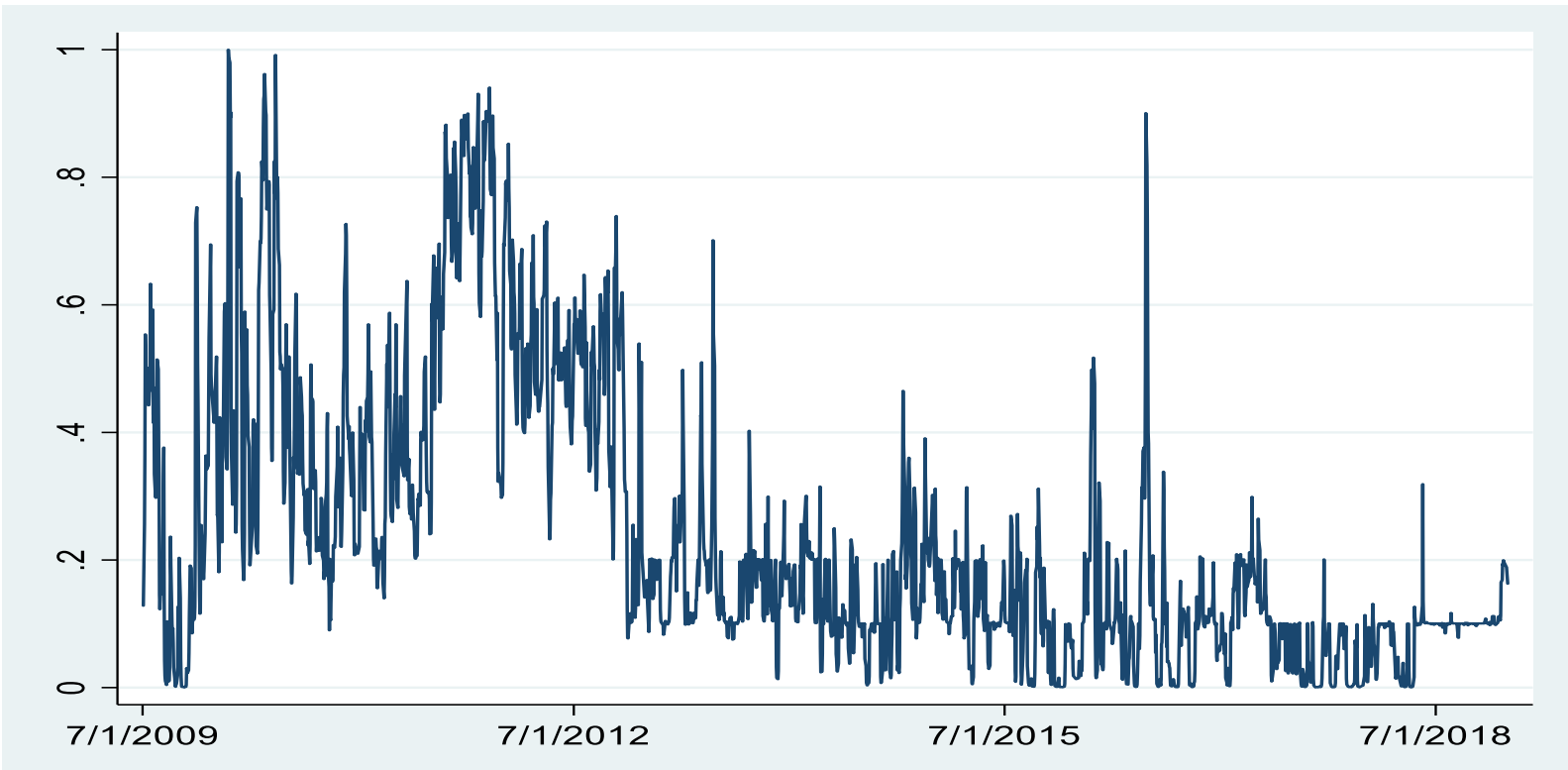

Oil Exporting Countries

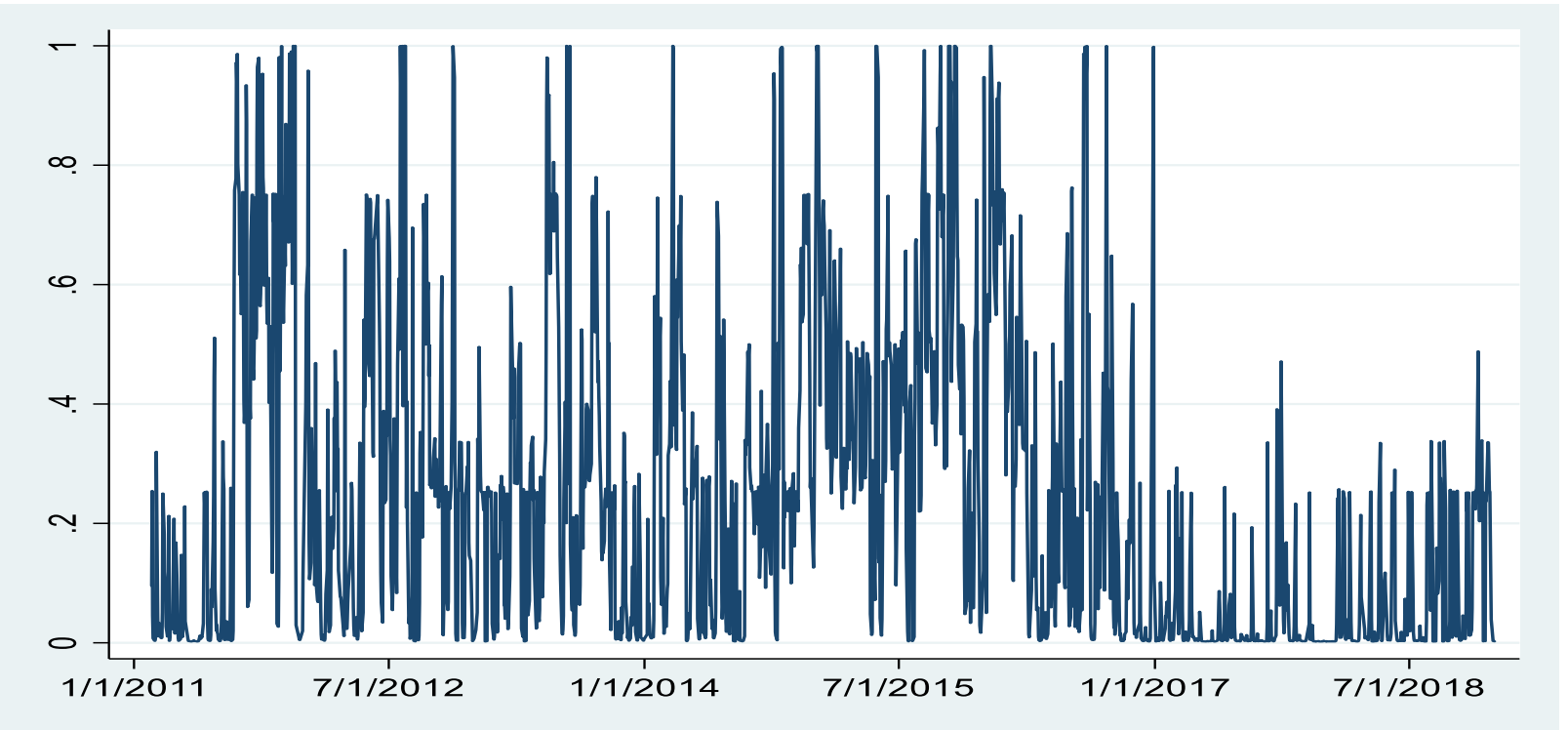




\section{REFERENCES}

Afonso, António, Davide Furceri, and Pedro Gomes. 2012. "Sovereign Credit Ratings and Financial Markets Linkages: Application to European Data.” Journal of International Money and Finance 31 (3): 606-638.

Akbas, Ferhat, Will J. Armstrong, Sorin M. Sorescu, and Avanidhar Subrahmanyam. 2016. “Capital Market Efficiency and Arbitrage Efficacy." Journal of Financial and Quantitative Analysis 51 (2): 387-413.

Akhtar, Shumi, Robert Faff, Barry Oliver, and Avanidhar Subrahmanyam. 2011. "The Power of Bad: The Negativity Bias in Australian Consumer Sentiment Announcements on Stock Returns.” Journal of Banking and Finance 35 (5): 1239-1249.

Alvarez-Ramirez, Jose, Jesus Alvarez, and Eduardo Rodriguez. 2008. "Short-Term Predictability of Crude Oil Markets : A Detrended Fluctuation Analysis Approach.” Energy Economics 30: $2645-2656$.

Alvarez-Ramirez, Jose, Jesus Alvarez, and Ricardo Solis. 2010. "Crude Oil Market Efficiency and Modeling: Insights from the Multiscaling Autocorrelation Pattern.” Energy Economics 32 (5): 993-1000.

Amihud, Yakov. 2002. "Illiquidity and Stock Returns: Cross-Section and Time-Series Effects." Journal of Financial Markets 5 (1): 31-56.

Anatolyev, Stanislav, Sergei Seleznev, and Veronika Selezneva. 2018. "Formation of Market Beliefs in the Oil Market.” Working Paper.

Ang, Andrew, and Geert Bekaert. 2002. "International Asset Allocation With Regime Shifts.” The Review of Financial Studies 15 (4): 1137-1187.

Ang, Andrew, and Francis A Longstaff. 2013. "Systemic Sovereign Credit Risk : Lessons from the U. S . and Europe.” Journal of Monetary Economics 60 (5): 493-510.

Apergis, Nicholas, and James Payne. 2013. "New Evidence on the Information and Predictive Content of the Baltic Dry Index.” International Journal of Financial Studies 1 (3): 62-80. 
Armstrong, Will J, Laura Cardella, and Nasim Sabah. 2017. "Information Shocks and Liquidity Innovations." Working Paper.

Asea, Patrick K., and Brock Blomberg. 1998. "Lending Cycles.” Journal of Econometrics 83 (12): 89-128.

Augustin, Patrick, and Rom'eo T'edongap. 2016. "Real Economic Shocks and Sovereign Credit Risk." Journal of Financial and Quantitative Analysis 51 (2): 541-587.

Baker, Malcolm, and Jeffrey Wurgler. 2006. "Investor Sentiment and the Cross-Section of Stock Returns." The Journal of Finance 61 (4): 1645-1680.

Bakshi, Gurdip, George Panayotov, and Georgios Skoulakis. 2011. "The Baltic Dry Index as a Predictor of Global Stock Returns, Commodity Returns, and Global Economic Activity.” Working Paper.

Barber, Brad M, and Terrance Odean. 2008. “All That Glitters : The Effect of Attention and News on the Buying Behavior of Individual and Institutional Investors." Review of Financial Studies 21 (2): 785-818.

Beechey, Meredith J, Benjamin K Johannsen, and Andrew T Levin. 2011. “American Economic Association Are Long-Run Inflation Expectations Anchored More Firmly in the Euro Area than in the United States?" American Economic Journal: Macroeconomics 3 (2): 104-129.

Beirne, John, and Marcel Fratzscher. 2013. "The Pricing of Sovereign Risk and Contagion during the European Sovereign Debt Crisis." Journal of International Money and Finance 34 (April): 60-82.

Ben-Rephael, Azi, Zhi Da, and Ryan D. Israelsen. 2017. "It Depends on Where You Search: Institutional Investor Attention and Underreaction to News.” Review of Financial Studies 30 (9): 3009-3047.

Ben-Rephael, Azi, Shmuel Kandel, and Avi Wohl. 2012. "Measuring Investor Sentiment with Mutual Fund Flows.” Journal of Financial Economics 104: 363-382.

Berger, David, and Harry J Turtle. 2015. "Sentiment Bubbles.” Journal of Financial Markets 23: $59-74$. 
Bernanke, Ben S. 1986. "Alternative Explanations of the Money-Income Correlation." CarnegieRochester Conference Series on Public Policy, no. 1842: 1-62.

Bernile, Gennaro, Jianfeng Hu, and Yuehua Tang. 2016. "Can Information Be Locked up? Informed Trading Ahead of Macro-News Announcements." Journal of Financial Economics 121: 496-520.

Bharath, Sreedhar T, Sudarshan Jayaraman, and Venky Nagar. 2013. "Exit as Governance: An Empirical Analysis." The Journal of Finance 68 (6): 2515-2547.

Bjørnland, Hilde C., and Kai Leitemo. 2009. "Identifying the Interdependence Between US Monetary Policy and the Stock Market." Journal of Monetary Economics 56 (2): 275-282.

Blanchard, Oliver J, and Mark W Watson. 1986. “Are Business Cycles All Alike?” National Bureau of Economic Research 0-226-3045: 123-180.

Blanchard, Olivier Jean, and Danny Quah. 1989. "The Dynamic Effects of Aggregate Demand and Supply Disturbances." National Bureau of Economic Research Working Paper Series, no. 2737.

Borovkova, Svetlana. 2011. "News Analytics for Energy Futures.” Working Paper.

Brandt, Patrick, and John Williams. 2006. Multiple Time Series Models. 1st ed. SAGE.

Brogaard, Jonathan, Terrence Hendershott, and Ryan Riordan. 2014. "High-Frequency Trading and Price Discovery." The Review of Financial Studies 27 (8): 2267-2306.

Brown, Gregory W, and Michael T Cliff. 2004. "Investor Sentiment and the Near-Term Stock Market." Journal of Empirical Finance, no. 11: 1-27.

Brown, Stephen P A, and Mine K Yücel. 2002. "Energy Prices and Aggregate Economic Activity: An Interpretative Survey." The Quarterly Review of Economics and Finance, no. 42: 193208.

Bu, Hui. 2014. "Effect of Inventory Announcements on Crude Oil Price Volatility." Energy Economics 46: 485-494.

Carroll, Christopher D., Jeffrey C. Fuhrer, and David W. Wilcox. 1994. "Does Consumer 112 
Sentiment Forecast Household Spending? If So, Why?” The American Economic Review 84 (5): 1397-1408.

Cavallo, Alberto, and Roberto Rigobon. 2016. "The Billion Prices Project: Using Online Prices for Measurement and Research." Journal of Economic Perspectives 30 (2): 151-178.

Cermeño, Rodolfo. 2002. "Growth Convergence Clubs: Evidence from Markov-Switching Models Using Panel Data." International Conferences on Panel Data.

Chang, Charles, Hazem Daouk, and Albert Wang. 2009. "Do Investors Learn about Analyst Accuracy?" Journal of Futures Markets, no. 29: 414-429.

Chen, Nai-Fu, Richard Roll, and Stephen A. Ross. 1986. "Economic Forces and the Stock Market." The Journal of Business 59: 383-403.

Chen, Shyh Wei. 2007. "Measuring Business Cycle Turning Points in Japan with the Markov Switching Panel Model." Mathematics and Computers in Simulation 76 (4): 263-270.

Chiang, I-hsuan Ethan, W Keener Hughen, and Jacob S Sagi. 2015. "Estimating Oil Risk Factors Using Information." Journal of Finance, no. 2: 769-804.

Chiang, I. Hsuan Ethan, and W. Keener Hughen. 2017. "Do Oil Futures Prices Predict Stock Returns?" Journal of Banking and Finance 79: 129-141.

Chordia, Tarun, Richard Roll, and Avanidhar Subrahmanyam. 2008. "Liquidity and Market Efficiency." Journal of Financial Economics, no. 2: 249-268.

Christensen, Jens H E, Jose A Lopez, and Glenn D Rudebusch. 2010. "Inflation Expectations and Risk Premiums in an Arbitrage-Free Model of Nominal and Real Bond Yields." Journal of Money, Credit and Banking 42: 143-178.

Chuffart, Thomas, and Emma Hooper. 2019. “An Investigation of Oil Prices Impact on Sovereign Credit Default Swaps in Russia and Venezuela." Energy Economics 80: 904-916.

Clark, U. 1996. "Oil Price Volatility and the Macroeconomy.” Journal of Macroeconomics 18 (1): $1-26$.

Cologni, Alessandro, and Matteo Manera. 2008. "Oil Prices, Inflation and Interest Rates in a 113 
Structural Cointegrated VAR Model for the G-7 Countries." Energy Economics 30 (3): 856888.

Corredor, Pilar, Elena Ferrer, and Rafael Santamaria. 2014. "Sentiment-Prone Investors and Volatility Dynamics between Spot and Futures Markets." International Review of Economics and Finance 35: 180-196.

Cunado, J, and F Perez De Gracia . 2005. "Oil Prices, Economic Activity and Inflation: Evidence for Some Asian Countries." The Quarterly Review of Economics and Finance 45: 65-83.

Da, Zhi, Joseph Engelberg, and Pengjie Gao. 2011. "In Search of Attention." The Journal of Finance, no. 5: 1461-1499.

Deeney, Peter, Mark Cummins, Michael Dowling, and Adam Bermingham. 2015. "Sentiment in Oil Markets." International Review of Financial Analysis 39: 179-185.

Dimpfl, Thomas, and Stephan Jank. 2016. "Can Internet Search Queries Help to Predict Stock Market Volatility?" European Financial Management 22 (2): 171-192.

Dooley, Michael, and Michael Hutchison. 2009. "Transmission of the U . S . Subprime Crisis to Emerging Markets: Evidence on the Decoupling - Recoupling Hypothesis.” Journal of International Money and Finance 28 (8): 1331-1349.

Dowling, Michael, Mark Cummins, and Brian M Lucey. 2016. "Psychological Barriers in Oil Futures Markets.” Energy Economics 53: 293-304.

Ederington, Louis H, Fang Lin, Scott C Linn, and Lisa Zongfei. 2019. "EIA Storage Announcements , Analyst Storage Forecasts, and Energy Prices.” Working Paper.

Eichler, Stefan. 2014. "The Political Determinants of Sovereign Bond Yield Spreads." Journal of International Money and Finance 46 (September): 82-103.

Fan, Qinbin, and Mohammad Jahan-Parvar. 2012. "US Industry-Level Returns and Oil Prices." International Review of Economics and Finance, no. 22: 112-128.

Fender, Ingo, Bernd Hayo, and Matthias Neuenkirch. 2012. "Daily Pricing of Emerging Market Sovereign CDS before and during the Global Financial Crisis." Journal of Banking and 
Finance 36 (10): 2786-2794.

Fink, Christopher, and Thomas Johann. 2014. "May I Have Your Attention, Please : The Market Microstructure Of Investor Attention.” Working Paper.

Fonseca, José Da, Katja Ignatieva, and Jonathan Ziveyi. 2016. "Explaining Credit Default Swap Spreads by Means of Realized Jumps and Volatilities in the Energy Market." Energy Economics 56: 215-228.

Garcia, Juan Angel, and Adrian Van Rixtel. 2007. "Inflation-Linked Bonds From A Central Bank Perspective." European Central Bank 62: 1-50.

Goyenko, Ruslan Y, Craig W Holden, and Charles A Trzcinka. 2009. "Do Liquidity Measures Measure Liquidity ?" Journal of Financial Economics 92 (2): 153-181.

Green, T Clifton. 2004. "Economic News and the Impact of Trading on Bond Prices." The Journal of Financ LIX (3): 1201-1234.

Grömping, Ulrike. 2006. "Relative Importance for Linear Regression in R: The Package Relaimpo." Journal Of Statistical Software 17 (1): 139-147.

Gu, Chen, and Alexander Kurov. 2018. "What Drives Informed Trading before Public Releases? Evidence from Natural Gas Inventory Announcements.” Journal of Futures Markets 15 (38): 1079-1096.

Halova, Marketa W., Alexander Kurov, and Oleg Kucher. 2014. "Noisy Inventory Announcements and Energy Prices." The Journal of Futures Markets 34 (10): 911-933.

Hamilton, James, and Christiane Baumeister. 2019. "Structural Interpretation of Vector Autoregressions with Incomplete Identification: Revisiting the Role of Oil Supply and Demand Shocks." American Economic Review 109 (1873-1910).

Hamilton, James D. 1983. "Oil and the Macroeconomy since World War II." Journal of Political Economy 91 (2): 228-248.

- 2009. Causes and Consequences of the Oil Shock of 2007-08. Brookings Papers on Economics Activity. 
—. 2019. "Measuring Global Economic Activity." Working Paper.

Hamilton, James, and Ana María Herrera. 2004. "Oil Shocks and Aggregate Macroeconomic Behavior: The Role of Monetary Policy: Comment." Journal of Money, Credit and Banking 36 (2): 265-286.

Han, Liyan, Qiuna Lv, and Libo Yin. 2017. “Can Investor Attention Predict Oil Prices ?” Energy Economics 66: 547-558.

Hasbrouck, Joel, and Gideon Saar. 2013. "Low-Latency Trading." Journal of Financial Markets 16 (4): 646-679.

He, Yanan, Shouyang Wang, and Kin Keung Lai. 2010. "Global Economic Activity and Crude Oil Prices: A Cointegration Analysis." Energy Economics 32 (4): 868-876.

Hibbert, Ann Marie, and Ivelina Pavlova. 2017. "The Drivers of Sovereign CDS Spread Changes: Local Versus Global Factors." The Financial Review 52: 435-457.

Hu, Conghui, and Wei Xiong. 2013. "Are Commodity Futures Prices Barometers of the Global Economy?" Working Paper.

Huang, Dashan, Fuwei Jiang, Jun Tu, and Guofu Zhou. 2014. "Investor Sentiment Aligned: A Powerful Predictor of Stock Returns." Review of Financial Studies 28 (3): 791-837.

Huang, Roger D., Ronald W Masulis, and Hans R Stoll. 1996. "Energy Shocks and Financial Markets." Journal of Futures Markets 16 (1): 1-27.

Huizinga, John. 1993. "Are the Macroeconomic Effects of Oil-Price Changes Symmetric?" Journal of Money, Credit and Banking 25 (2): 521-549.

Jiang, Haibo. 2018. “Oil Price, Bond Return, and Breakeven Inflation.” Working Paper.

Jo, Soojin. 2014. "The Effects of Oil Price Uncertainty on Global Real Economic Activity." Journal of Money, Credit and Banking 46 (6): 1113-1135.

Jochmann, Markus, Gary Koop, and Simon M Potter. 2010. "Modeling the Dynamics of Inflation Compensation." Journal of Empirical Finance 17 (1): 157-167.

Johnson, Jeff W, and James M Lebreton. 2004. "History and Use of Relative Importance Indices 116 
in Organizational Research.” Organizational Research Methods, no. 3.

Kahneman, Daniell. 1973. Attention and Effort. Englewood Cliffs, NJ: Prentice-Hall. Lee,.

Kajuth, Florian, and Sebastian Watzka. 2011. "Inflation Expectations from Index-Linked Bonds: Correcting for Liquidity and Inflation Risk Premia." Quarterly Review of Economics and Finance 51 (3): 225-235.

Karali, Berna, and Octavio A Ramirez. 2014. "Macro Determinants of Volatility and Volatility Spillover in Energy Markets." Energy Economics, no. 46: 413-421.

Kilian, L, and Cheolbeom Park. 2009. "The Impact of Oil Price Shocks on the US Stock Market." International Economic Review 50 (4): 1267-1287.

Kilian, Lutz. 2008. "A Comparison of the Effects of Exogenous Oil Supply Shocks on Output and Inflation in the G7 Countries." Journal of the European Economic Association 6 (1): 78-121.

—. 2009. "Not All Oil Price Shocks Are Alike: Disentangling Demand and Supply Shocks in the Crude Oil Market." American Economic Review 99 (3): 1053-1069.

Kilian, Lutz, and Logan T. Lewis. 2011. "Does the Fed Respond to Oil Price Shocks?" Economic Journal 121 (555): 1047-1072.

Kilian, Lutz, and Robert Vigfusson. 2011. "Nonlinearities in the Oil Price-Output Relationship." Macroeconomic Dynamics 15 (3): 337-363.

Kim, Soyoung, and Nouriel Roubini. 2000. "Exchange Rate Anomalies in the Industrial Countries: A Solution with a Structural VAR Approach.” Journal of Monetary Economics 45 (3): 561586.

Koenker, Roger. 2004. "Quantile Regression for Longitudinal Data." Journal of Multivariate Analysis 91: 74-89.

Koenker, Roger, and Gilbert Bassett. 1978. "Regression Quantiles.” Econometrica 46 (1): 33-50.

Kristoufek, Ladislav. 2018. "Are the Crude Oil Markets Really Becoming More Efficient over Time? Some New Evidence.” Energy Economics 82: 253-263.

Kristoufek, Ladislav, and Miloslav Vosvrda. 2014. "Commodity Futures and Market Efficiency.” 
Energy Economics 42: 50-57.

Kumar, Alok, and Charles M C Lee. 2006. "Retail Investor Sentiment and Return Comovements." The Journal of Finance 61 (5): 2451-2486.

Kutan, Ali M, and Riza Demirer. 2010. "The Behavior of Crude Oil Spot and Futures Prices around OPEC and SPR Announcements: An Event Study Perspective.” Energy Economics 32: 14671476.

Li, Jian, Zhenjing Xu, Lean Yu, and Ling Tang. 2016. "Forecasting Oil Price Trends with Sentiment of Online News Articles." Procedia Computer Science 91 (91): 1081-1087.

Lindeman, Richard, Peter Merenda, and Ruth Gold. 1981. "Introduction to Bivariate and Multivariate Analysis." Journal of the American Statistical Association 76 (375): 752.

Linn, Scott, and Zhen Zhu. 2004. "Natural Gas Prices and the Gas Storage Report: Public News and Volatility in Energy Futures Markets." The Journal of Futures Markets 24 (3): 283-313.

Longstaff, By Francis A, J U N Pan, Lasse H Pedersen, and Kenneth J Singleton. 2011. "How Sovereign Is Sovereign Credit Risk?” American Economic Journal 3 (2): 75-103.

Lumsdaine, Robin L. 2009. “The Relationship between Oil Prices and Breakeven Inflation Rates.” Working Paper.

Marshall, Ben R., Nhut H. Nguyen, and Nuttawat Visaltanachoti. 2012. "Commodity Liquidity Measurement and Transaction Costs." Review of Financial Studies 25 (2): 599-638.

Maslyuk-Escobedo, Svetlana, Kristian Rotaru, and Alexander Dokumentov. 2016. "News Sentiment and Jumps in Energy Spot and Futures Markets." Pacific-Basin Finance Journal 45: $186-210$.

McCracken, Michael W. 2007. "Asymptotics for out of Sample Tests of Granger Causality." Journal of Econometrics 140: 719-752.

Menkhoff, Lukas, Maik Schmeling, and Ulrich Schmidt. 2013. "Overconfidence, Experience, and Professionalism: An Experimental Study." Journal of Economic Behavior \& Organization 86: 92-101. 
Miao, Hong, Sanjay Ramchander, Tianyang Wang, and Jian Yang. 2018. "The Impact of Crude Oil Inventory Announcements on Prices: Evidence from Derivatives Markets." Journal of Futures Markets 38: 38-65.

Nader Naifar, Syed Jawad Hussain Shahzad and Shawkat Hammoudeh. 2017. "The Impact of Major Oil, Financial and Uncertainty Factors on Sovereign CDS Spreads: Evidence from GCC, Other Oil-Exporting Countries and Regional Markets - Economic Research Forum (ERF)."

Nandha, Mohan, and Robert Faff. 2008. "Does Oil Move Equity Prices? A Global View.” Energy Economics 30 (3): 986-997.

Neal, Robert, and Simon M Wheatley. 1998. "Do Measures of Investor Sentiment Predict Returns?" The Journal of Financial and Quantitative Analysis 33 (4): 523-547.

Oliveira, Luís, José Dias Curto, and João Pedro Nunes. 2012. "The Determinants of Sovereign Credit Spread Changes in the Euro-Zone." Journal of International Financial Markets, Institutions and Money 22 (2): 278-304.

Pavlova, Ivelina, Maria E De Boyrie, and Ali M Parhizgari. 2018. "A Dynamic Spillover Analysis of Crude Oil Effects on the Sovereign Credit Risk of Exporting Countries." Quarterly Review of Economics and Finance 68: 10-22.

Peersman, Gert, and Ine Van Robays. 2012. "Cross-Country Differences in the Effects of Oil Shocks." Energy Economics 34 (5): 1532-1547.

Ready, Robert C. 2018. “Oil Prices and the Stock Market.” Review of Finance, 155-176.

Rigobon, Roberto, and Brian Sack. 2008. "Noisy Macroeconomic Announcements, Monetary Policy, and Asset Prices." In J. Y. Campbell (Ed.), Asset Prices and Monetary Policy, 335370.

Roger, Edelen, Ozgur S Ince, and Gregory B Kadlec. 2016. "Institutional Investors and Stock Return Anomalies." Journal of Financial Economics 119 (3): 472-488.

Rousse, Olivier, and Benoit Sévi. 2019. "Informed Trading in the WTI Oil Futures Market." The Energy Journal 40 (2): 139-160. 
Sayim, Mustafa, Pamela D Morris, and Hamid Rahman. 2013. "The Effect of US Individual Investor Sentiment on Industry-Specific Stock Returns and Volatility." Review of Behavioral Finance 5 (1): 58-76.

Schmeling, Maik. 2007. "Institutional and Individual Sentiment: Smart Money and Noise Trader Risk?" International Journal of Forecasting 23 (1): 127-145.

Schmidbauer, Harald, and Angi Rösch. 2012. "OPEC News Announcements: Effects on Oil Price Expectation and Volatility." Energy Economics 34 (5): 1656-1663.

Schneider, Michael, Holger Kraft, Jan Pieter Krahnen, Lars Schweizer, and Erik Theissen. 2014. "Weather, Mood, and Stock Market Expectations: When Does Mood Affect Investor Sentiment?" Working Paper.

SENTIX. 2016. "Sentix Sentiment Database About Sentix.”

Shahzad, Syed Jawad Hussain, Nader Naifar, Shawkat Hammoudeh, and David Roubaud. 2017. "Directional Predictability from Oil Market Uncertainty to Sovereign Credit Spreads of OilExporting Countries: Evidence from Rolling Windows and Crossquantilogram Analysis." Energy Economics 68: 327-339.

Shambora, William E, and Rosemary Rossiter. 2007. "Are There Exploitable Inefficiencies in the Futures Market for Oil?" Energy Economics 29: 18-27.

Sias, Richard W. 2004. “Institutional Herding.” The Review of Financial Studies 17 (1): 165-206.

Sim, Nicholas, and Hongtao Zhou. 2015. "Oil Prices, US Stock Return, and the Dependence between Their Quantiles.” Journal of Banking and Finance 55: 1-8.

Sims, Christopher A. 1986. "Are Forecasting Models Usable for Policy Analysis?” Quarterly Review Federal Reserve Bank of Minneapolis Winter: 2-16.

Souleles, Nicholas S. 2004. "Expectations, Heterogeneous Forecast Errors, and Consumption: Micro Evidence from the Michigan Consumer Sentiment Surveys." Journal of Money, Credit, and Banking 36 (1): 39-72.

Spencer, Simon, and Don Bredin. 2019. "Agreement Matters: OPEC Announcement Effects on 
WTI Term Structure.” Energy Economics 80: 589-609.

Tabak, Benjamin M, and Daniel O Cajueiro. 2007. "Are the Crude Oil Markets Becoming Weakly Efficient over Time? A Test for Time-Varying Long-Range Dependence in Prices and Volatility." Energy Economics 29: 28-36.

Tetlock, Paul C. 2007. "Giving Content to Investor Sentiment: The Role of Media in the Stock Market.” Journal of Finance 62 (3): 1139-1168.

Thomas, D. Roland, PengCheng Zhu, Bruno D. Zumbo, and Shantanu Dutta. 2017. "On Measuring the Relative Importance of Explanatory Variables in a Logistic Regression." Journal of Modern Applied Statistical Methods 7 (1): 21-38.

Thoresen, Per E. 1982. “Oil Price and Inflation.” Energy Economics 4 (2): 121-126.

Uddin, Gazi Salah, Md Lutfur Rahman, Syed Jawad Hussain Shahzad, and Mobeen Ur Rehman. 2018. "Supply and Demand Driven Oil Price Changes and Their Non-Linear Impact on Precious Metal Returns: A Markov Regime Switching Approach.” Energy Economics 73: $108-121$.

UNCTAD. 2010. “Oil Prices and Maritime Freight Rates: An Empirical Investigation.” United Nations.

Vozlyublennaia, Nadia. 2014. "Investor Attention, Index Performance, and Return Predictability." Journal of Banking \& Finance 41: 17-35.

Wang, Ping, and Tomoe Moore. 2012. "The Integration of the Credit Default Swap Markets during the US Subprime Crisis : Dynamic Correlation Analysis.” Journal of International Financial Markets, Institutions \& Money 22 (1): 1-15.

Wang, Tao, and Jian Yang. 2010. "Nonlinearity and Intraday Efficiency Tests on Energy Futures Markets.” Energy Economics 32 (2): 496-503.

Wang, Yudong, and Li Liu. 2010. "Is WTI Crude Oil Market Becoming Weakly Efficient over Time? New Evidence from Multiscale Analysis Based on Detrended Fluctuation Analysis." Energy Economics 32 (5): 987-992. 
Wegener, Christoph, Tobias Basse, Frederik Kunze, and Hans-Jörg von Mettenheim. 2016. “Oil Prices and Sovereign Credit Risk of Oil Producing Countries: An Empirical Investigation.” Quantitative Finance 7688: 1469-1496.

Welch, Ivo, and Amit Goyal. 2008. "A Comprehensive Look at the Empirical Performance of Equity Premium Prediction.” Review of Financial Studies 21 (4): 1455-1508.

White, Halbert. 1980. "A Heteroskedasticity-Consistent Covariance Matrix Estimator and a Direct Test for Heteroskedasticity." Econometrica 48 (4): 817-838.

Wolfe, Marketa Halova, and Robert Rosenman. 2014. "Bidirectional Causality in Oil and Gas Markets.” Energy Economics 42: 325-331.

Ye, Shiyu, and Berna Karali. 2016. “The Informational Content of Inventory Announcements: Intraday Evidence from Crude Oil Futures Market.” Energy Economics 59: 349-364.

Yohai, V. J. 1987. "High Breakdown-point and High Efficiency Robust Estimates for Regression.” The Annals of Statistics 15 (20): 642-656.

You, Wanhai, Yawei Guo, Huiming Zhu, and Yong Tang. 2017. "Oil Price Shocks , Economic Policy Uncertainty and Industry Stock Returns in China: Asymmetric Effects with Quantile Regression.” Energy Economics 68: 1-18.

Zhu, Huiming, Xianfang Su, Wanhai You, and Yinghua Ren. 2017. “Asymmetric Effects of Oil Price Shocks on Stock Returns: Evidence from a Two-Stage Markov Regime-Switching Approach.” Applied Economics 49 (25): 2491-2507. 